\title{
Report on Assessment of Advanced Reactor Fuel Performance
}

Nuclear Fuel Cycle and Supply Chain

Prepared for U.S. Department of Energy Advanced Fuel Campaign Y. Miao, E. Hoffman, A. Karahan, A. Tentner, T. K. Kim Argonne National Laboratory September 30, 2019 ANL/NSE-19/37 


\section{DISCLAIMER}

This information was prepared as an account of work sponsored by an agency of the U.S. Government. Neither the U.S. Government nor any agency thereof, nor any of their employees, makes any warranty, expressed or implied, or assumes any legal liability or responsibility for the accuracy, completeness, or usefulness, of any information, apparatus, product, or process disclosed, or represents that its use would not infringe privately owned rights. References herein to any specific commercial product, process, or service by trade name, trade mark, manufacturer, or otherwise, does not necessarily constitute or imply its endorsement, recommendation, or favoring by the U.S. Government or any agency thereof. The views and opinions of authors expressed herein do not necessarily state or reflect those of the U.S. Government or any agency thereof. 


\section{Executive Summary}

Three activities have been performed in FY 2019 to support the Advanced Fuel Cycle Campaign, which include assessment of annular fuel performance in an ultra-high burnup sodium-cooled reactor (SFR), modeling of annular fuel behavior during a transient scenario, and feasibility of a sustainable closed fuel cycle utilizing melt-refining process.

Annular fuel performance parameters, including temperature profile, swelling strain, and cumulative damage fraction (CDF), in a 3000 MWt Sustainable Sodium-cooled Fast Reactor (SSFR) were assessed using the BISON fuel performance code. The SSFR is once-through ultralong-life core based on a 34-batch fuel management scheme with 1.5-year cycle length. The fuel residence time in the SSFR is 51 years and the average discharged burnup is about $30 \%$. Annular fuel has potential to irradiate for ultra-high burnup without major fuel-cladding mechanical interaction. This feature is achieved by using a low smeared density ( $\sim 55 \%)$. In the SSFR design, however, $75 \%$ smeared density and a thick fuel pin were preferred to maintain criticality for 51 years. Due to the high smeared density and thick fuel pin configuration, the annular fuel was predicted to suffer premature cladding failure before reaching the discharge burnup of the SSFR. The current fuel creep model predicts a prominent creep strain due to gravity over the halfcentury irradiation, which may significantly affect the evolution of CDF. Thus, in order to use the annular fuel in an ultra-high burnup core such as the SSFR, a low smeared density and thin annular fuel is strongly recommended.

Annular fuel behavior during transient scenarios prior to cladding failure has been simulated using the new metallic fuel models of SAS4A. Exploratory simulations of in-pin fuel relocation for an Unprotected Loss of Flow and Transient Over Power (ULOF-TOP) accident in the Advanced Burner Test Reactor (ABTRR) have been performed. During the simulations, fuel melting near the top of the annular fuel and molten fuel flow through central hole were observed when the central hole was not fully closed (i.e., at a low burnup - see figure). The downflow of molten fuel, which has not been observed in a solid fuel, adds a potential limited amount of positive reactivity to the reactor, which should be carefully considered in safety analysis of an SFR with annular fuels.

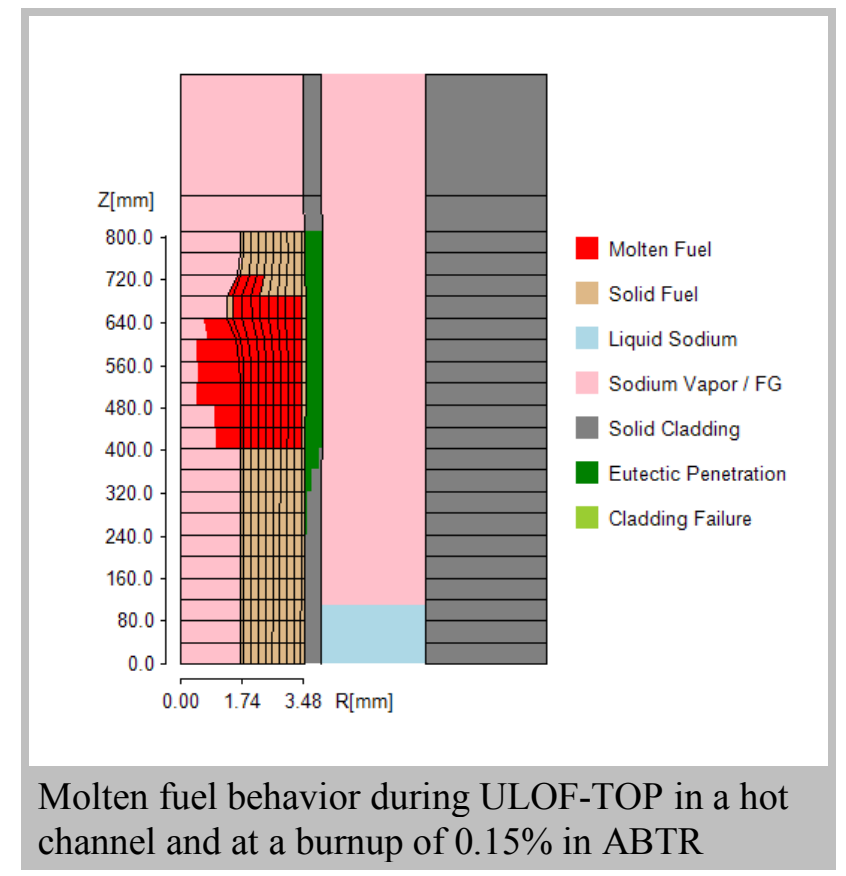

A sustainable closed fuel cycle in a fast reactor utilizing melt-refining process was studied. The melt-refining is an economically attractive with simple process, but as a trade-off, it loses actinides higher than $5 \%$ per process and cannot separate fission products completely from actinides. Thus, the motivation of this work is to ensure the feasibility of a closed fuel cycle utilizing the metal refining. From wide-range of core design studies, it was observed that a 
closed fuel cycle utilizing the melt-refining process is only possible in a breeder reactor because the core needs extra fissile materials per cycle in order to compensate neutron parasitic absorption by fission products and actinides loss. Compared to a high-performing reprocessing technology (for instance, electrochemical or aqueous reprocess), the melt-refining process makes fast reactor core design space narrow to achieve a closed fuel cycle (only high breeding ratio domain is allowed) and produces more high-level waste. 


\section{CONTENTS}

Executive Summary. i

Tables iv

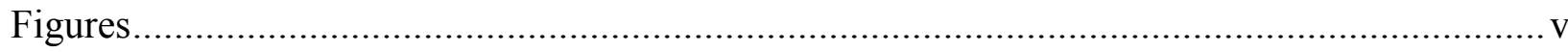

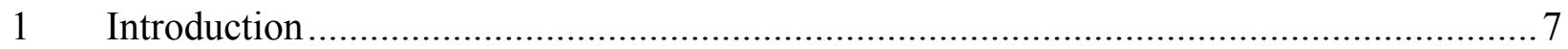

2 Assessment of Annular Fuel for SSFR ................................................................. 8

2.1 Description of the SSFR Concept ...................................................... 8

2.2 Methodology of Fuel Performance Evaluation................................................. 11

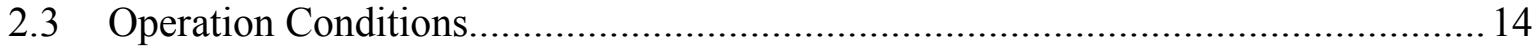

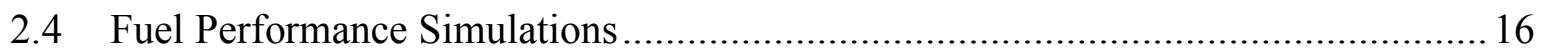

2.4.1 Annular Fuel Performance .................................................................... 19

2.4.2 Solid Fuel Performance........................................................................... 22

3 Annular Metal Fuel Behavior in Transient Scenario............................................... 27

3.1 Simulation of U-Pu-Zr annular fuel in ABTR reactor ...................................... 27

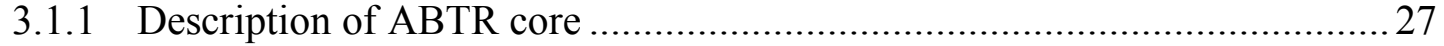

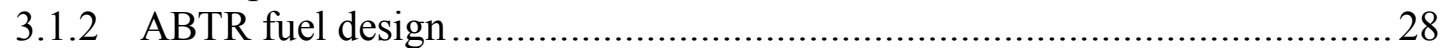

3.1.3 Pre-transient Simulation.................................................................. 29

3.1.4 Predicted Molten Fuel Cavity Patterns for postulated unprotected LOF and LOF-TOP Accidents .............................................................. 34

3.1.5 Initial Simulations of In-Pin Molten Fuel Relocation for low burnup annular fuel pins ....................................................................... 40

$4 \quad$ Feasibility of Closed Fuel Cycle using Melt-Refining .......................................... 45

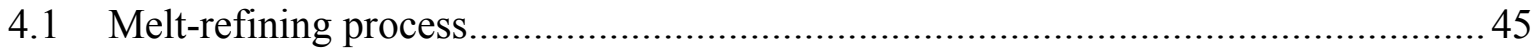

4.2 Closed Fuel Cycle Concept with Melt-Refining .......................................... 46

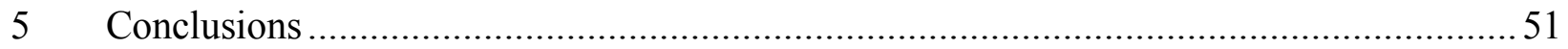

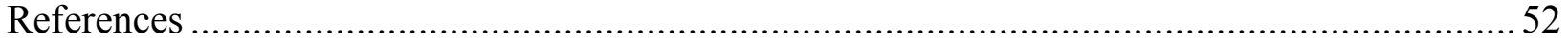




\section{Tables}

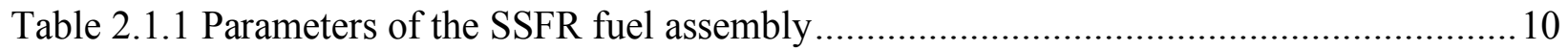

Table 2.2.1 Fuel pin parameters of two fuel configurations .......................................................11

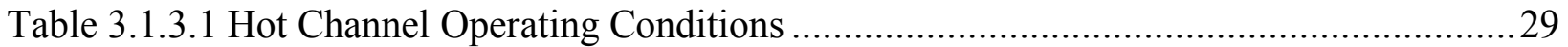

Table 4.2.1 Comparison of fuel cycle performance utilizing melt-refining and highperforming reprocessing.

Table 4.2.2 Mass flow data comparison for closed fuel cycles concepts based on highperforming reprocessing and melt-refining process. 50 


\section{Figures}

Figure 2.1.1 Radial core layout of the SSFR design.................................................... 9

Figure 2.1.2 Peak Linear Power Evolution of Fuel Management Paths A and B ..................... 10

Figure 2.2.1 BISON computed wastage compared with measured EBR-II X447 data.............. 13

Figure 2.3.1 Linear power profiles used in fuel performance simulations (Path A) .................. 14

Figure 2.3.2 Fast neutron flux profiles used in fuel performance simulations (Path A) ............ 15

Figure 2.3.3 Coolant fluxes used in fuel performance simulations (Path A) .......................... 16

Figure 2.4.1 Time evolution of average and peak fuel burnup of SSFR fuel pin (Path A) ......... 17

Figure 2.4.2 Coolant outlet, peak cladding, and peak fuel (solid fuel configuration)

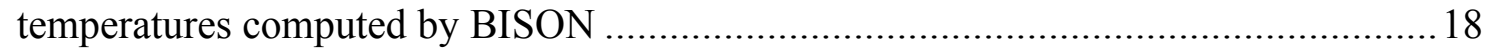

Figure 2.4.3 Time evolution of FCCI wastage thickness computed by BISON ...................... 18

Figure 2.4.1.1 Evolution of maximum CDF for SSFR annular fuels using different

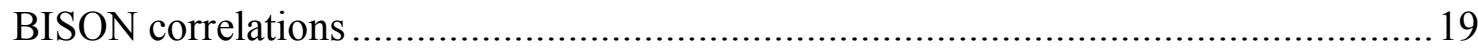

Figure 2.4.1.2 Average volumetric swelling strain evolution for the annular fuel

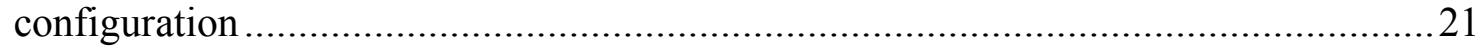

Figure 2.4.1.3 Time evolution of the hoop stress at the failure point..................................21

Figure 2.4.2.1 Time evolution of maximum CDF for SSFR solid fuels using different

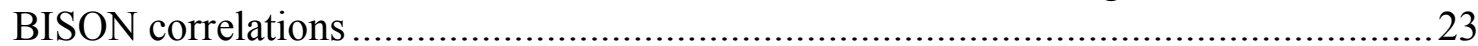

Figure 2.4.2.2 Time evolution of different components of volumetric swelling strain

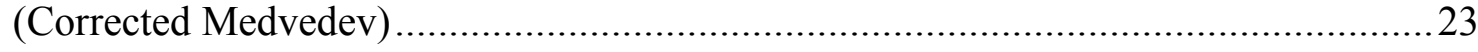

Figure 2.4.2.3 Time evolution of different components of volumetric swelling strain (LIFE-METAL).

Figure 2.4.2.4 Time evolution of axial fuel elongation strain versus average burnup of the pin predicted by different approaches to handle anisotropic swelling. .......................25

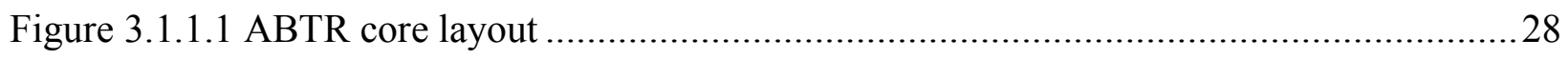

Figure 3.1.3.1 Fuel component distribution after 21 days of irradiation, burnup $\sim 0.15 \%$.........29

Figure 3.1.3.2 Fuel component distribution after 35 days of irradiation, burnup $\sim 0.25 \% \ldots \ldots \ldots . .30$

Figure 3.1.3.3 Fuel component distribution after 69 days of irradiation, burnup $\sim 0.50 \%$..........31

Figure 3.1.3.4 Fuel temperatures for ABTR fuel after 21 days of irradiation, burnup $0.15 \%$.

Figure 3.1.3.5 - Fuel temperatures for ABTR fuel after 35 days of irradiation, burnup $0.25 \%$ 33

Figure 3.1.3.6 Fuel temperatures for ABTR fuel after 69 days of irradiation, burnup $0.50 \%$. 
Figure 3.1.4.1 Fuel and Coolant Status in Channel $5(\mathrm{BU}=0.15 \%)$ at the time of cladding failure for the postulated ULOF accident

Figure 3.1.4.2 Fuel and Coolant Status in Channel $5(\mathrm{BU}=0.15 \%)$ at the time of cladding failure for the postulated ULOF-TOP accident with $2 \mathrm{c} / \mathrm{s}$ ramp. 36

Figure 3.1.4.3 Fuel and Coolant Status in Channel 5 (BU 0.25\%) at the time of cladding failure for the postulated ULOF accident 37

Figure 3.1.4.4 Fuel and Coolant Status in Channel 5 (BU 0.25\%) at the time of cladding failure for the postulated ULOF-TOP accident with $2 \mathrm{c} / \mathrm{s} \mathrm{ramp}$. .38

Figure 3.1.4.5 Fuel and Coolant Status in Channel $5(\mathrm{BU}=0.50 \%)$ at the time of cladding failure for the postulated ULOF accident

Figure 3.1.4.6 Fuel and Coolant Status in Channel $5(\mathrm{BU}=0.50 \%)$ at the time of cladding failure for the postulated ULOF-TOP accident with $2 \mathrm{c} / \mathrm{s}$ ramp. 40

Figure 3.1.4.7 Fuel and Coolant Status in Channel $5(\mathrm{BU}=0.15 \%)$ at $43 \mathrm{~ms}$ after the initiation of PINACLE-M for the postulated ULOF-TOP accident with $2 \mathrm{c} / \mathrm{s}$ ramp

Figure 3.1.4.8 Fuel and Coolant Status in Channel $5(\mathrm{BU}=0.15 \%)$ at $153 \mathrm{~ms}$ after the initiation of PINACLE-M for the postulated ULOF-TOP accident with $2 \mathrm{c} / \mathrm{s}$ ramp.

Figure 3.1.4.9 Fuel and Coolant Status in Channel $5(\mathrm{BU}=0.15 \%)$ at $203 \mathrm{~ms}$ after the initiation of PINACLE-M for the postulated ULOF-TOP accident with $2 \mathrm{c} / \mathrm{s}$ ramp.

Figure 3.1.4.10 Fuel and Coolant Status in Channel $5(\mathrm{BU}=0.15 \%)$ at $273 \mathrm{~ms}$ after the initiation of PINACLE-M for the postulated ULOF-TOP accident with $2 \mathrm{c} / \mathrm{s}$ ramp 44

Figure 4.1.1 Schematic Diagram of EBR-II Fuel Cycle based on Melt-Refining .......................45

Figure 4.1.2. Distribution of elements in the melt-refining process ...........................................46

Figure 4.2.1 Mass flow of used fuel recycling concept based on melt-refining process ..............47

Figure 4.2.2 Mass flow of used fuel recycling concept based on high-performing reprocessing technology 47

Figure 4.2.3 Breeder core configuration 48 


\section{ADVANCED FUEL CAMPAIGN REPORT ON ASSESSMENT OF ADVANCED FUEL PERFORMANCE}

\section{Introduction}

Three activities have been performed in FY 2019 to support the Advanced Fuel Cycle Campaign, which include application of annular metallic fuel concept to an ultra-high burnup sodium-cooled reactor, simulation of the annular fuel behavior in a transient scenario, and feasibility test of a sustainable closed fuel cycle utilizing metal refining.

The motivation of the first activity is to assess annular fuel performance in a long-life fast reactor because the annular fuel is under development as a high burnup fuel. For this purpose, the annular fuel performance in a 3000 MWt Sustainable Sodium-cooled Fast Reactor (SSFR) was simulated using the BISON code. The SSFR is a once-through long-life core based on 34-batch fuel management scheme with 1.5-year cycle length. The fuel residence time in the SSFR core is 51 years and the discharged burnup is about $30 \%$.

In the second activity, annular fuel behavior during a severe transient condition was modeled to understand molten fuel flow when central hole is not fully closed. If there is a downflow, the annular fuel may provide positive reactivity in a fuel melting transient condition. The transition modeling was developed using the Advanced Burner Test Reactor (ABTR) and simulated using the new metallic fuel version of the SAS4A code.

A simple reprocessing technology (such as melt-refining) with relaxed actinide loss rates during the process could result in an economically viable fuel cycle. However, as a trade-off, it may provide difficulty to achieve a sustainable closed fuel cycle with relatively large actinide loss rate per process and addition of fission products to fresh fuel. Thus, the motivation of the third activity is to ensure the feasibility of a sustainable closed fuel cycle utilizing melt-refining process, and to provide technical insights.

In Sections 2 and 3, the annular fuel performance in the ultra-high burnup SSFR and the molten fuel behavior during a severe transient scenario are described, respectively, and the feasibility of a sustainable closed fuel cycle utilizing the melt-refining process is explained in Section 4 . The conclusions are provided in Section 5. 


\section{Assessment of Annular Fuel for SSFR}

Advanced sodium-cooled fast reactors have unique advantages to breed fissile materials and therefore enable the extension of nuclear fuel resource. This exceptional feature allows to a sustainable mode operation in once-through systems without recycling used nuclear fuels. In such systems, the fertile materials, which are usually depleted or natural uranium fuels, are irradiated until sufficient fissile materials are bred by driver fuels and then are used to generate power in later stages of the fuel cycle. Based on this attractive "breed-burn" concept as well as several pioneering designs, the Sustainable Sodium-Cooled Reactor (SSFR) has been designed by Argonne National Laboratory [Kim 2010]. Unlike those once-through fuel cycle systems that eventually turns the bred blanket zone into power generation zone, such as TerraPower's Travelling Wave Reactor (TWR) [Gilleland 2010], the SSFR features fuel shuffling between cycles. The original depleted U-10Zr fuel is first bred in several positions of the outer core zone and then moved into the positions of the inner core zone to generate power. Each fuel assembly is irradiated in 34 different positions during 34 cycle with 1.5 -year cycle length and $90 \%$ capacity factor. Thus, the fuel residence time in the core is 51 years, which is equivalent to $\sim 46$ effective full power years with $90 \%$ capacity factor, and the resulting peak burnup is $\sim 37.0 \%$.

The 51-year irradiation time of each fuel assembly and extensive burnup have never been experimentally achieved for nuclear fuel, which may cause challenges in various aspects of fuel performance. Therefore, reliable fuel performance evaluation is required for further optimization and development of the SSFR design. In this project, the BISON advanced multi-physics fuel performance code [Hales 2016] was utilized to assess the fuel performance of the SSFR. Both conventional solid fuel configuration and novel annular fuel configuration were taken into consideration. The simulation results can be compared to help guide the further design of the SSFR and other once-through fuel cycle system. Also, as a 51-year irradiation time is an unprecedented task for both nuclear fuels and fuel performance code, the BISON simulation is also expected to provide insightful information to direct future fuel performance model development to better predict such irradiation conditions.

\subsection{Description of the SSFR Concept}

Sustainable Sodium-Cooled Fast Reactor (SSFR) concept has been designed and developed by Argonne National Laboratory as a once-through fuel cycle system. The SSFR is an advanced fast reactor design that adopts the breed-and-burn concept for enhanced fuel resource utilization. This class of reactors usually start with driver fuels with enriched uranium and breed fertile depleted uranium fuel in the early stage. Following the breeding of plutonium, the originally depleted uranium fuel can contribute to generate power and breeding plutonium in additional depleted uranium fuel. In some of these systems, fuel needs to be shuffled with incoming fuel made of depleted uranium. Examples of these system include the CANDLE concept, the travelling wave reactor concept by TerraPower, the ultra-long-life fast reactor (ULFR) by INIST/ANL [Tak 2013], and the fast-mixed spectrum reactor (FMSR) concept by BNL.

The SSFR concept was developed primarily as a sustainable sodium-cooled fast reactor that only uses depleted uranium feed. The core k-effective can be maintained at constant critical value for as long as required. The SSFR core is initially driven by fissile material but will become sustainable as enough bred plutonium is generated during the operation. 
The current SSFR design adopts the hexagonal-Z core configuration (see Figure 2.1.1). It consists 408 driver assemblies that are divided into four zones (inner, middle, outer core and depletion zones). The core height is $200 \mathrm{~cm}$ including upper and lower axial blankets. In each assembly, there are 127 fuel pins with a $20 \mathrm{~cm}$ assembly pitch. A more detailed list of the SSFR fuel assembly design parameters can be found in Table 2.1.1.

The SSFR core employs a 34-batch fuel management scheme as shown in Figure 2.1.1. Each cycle lasts for 1.5 years. Considering the hexagonal symmetry of the SSFR core, the 408 fuel assemblies can be divided into six identical sections of 68 fuel assembly. For each section, there are two fuel shuffling pathways (Paths A and B). The fresh depleted uranium fuel assemblies start the irradiation at the positions labelled by "1" and are moved to different positions after each cycle for 34 cycles. The peak linear power evolution is illustrated for both of the fuel management paths in Figure 2.1.2, which gives a final average burnup of $28.3 \%$ FIMA and a final peak burnup of $\sim 37.0 \%$ FIMA after 34 cycles.

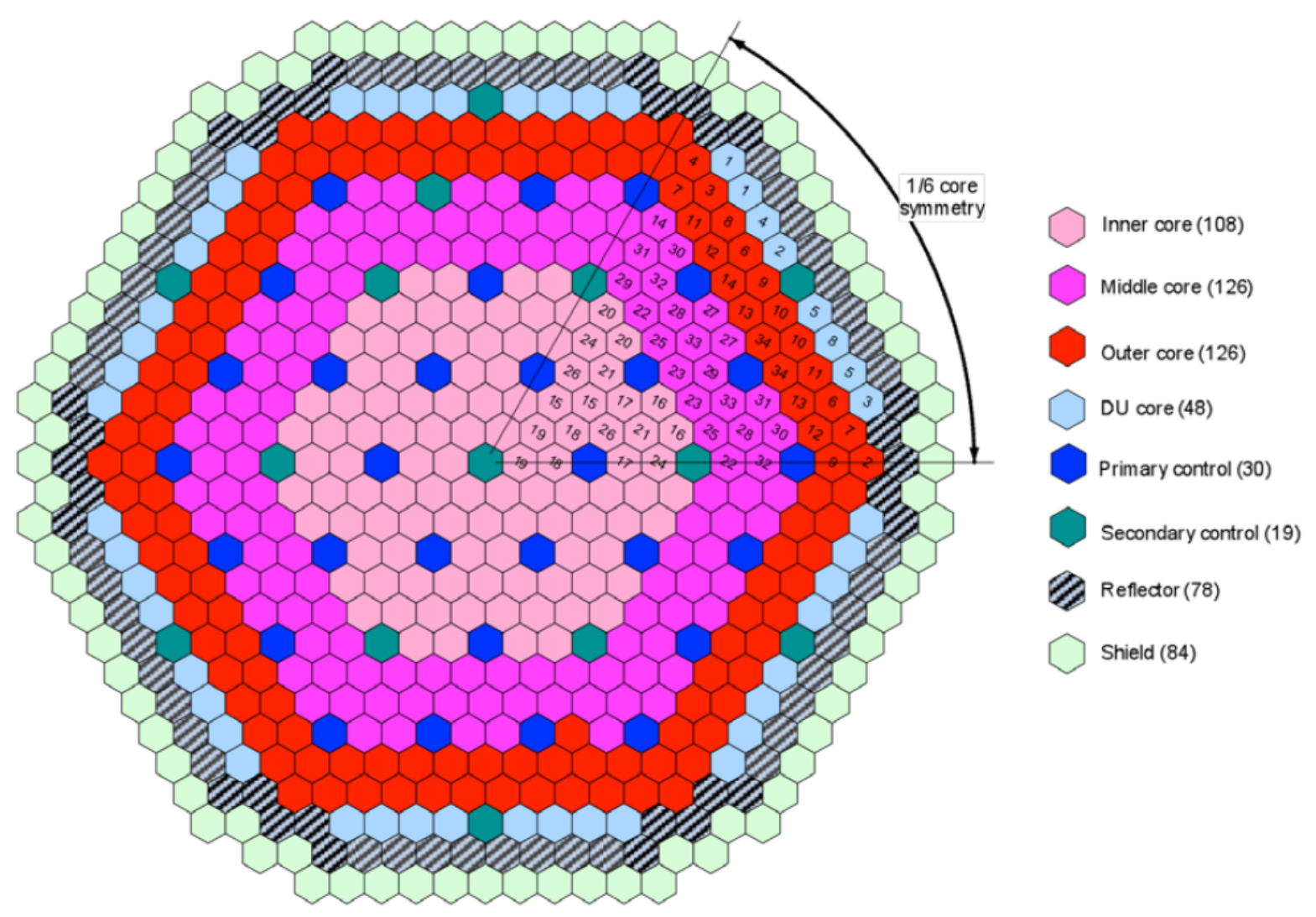

Figure 2.1.1 Radial core layout of the SSFR design 


\section{Table 2.1.1 Parameters of the SSFR fuel assembly}

\begin{tabular}{|l|c|}
\hline Parameters & Value \\
\hline Core height, cm & 200 \\
\hline Assembly outer flat-to-flat distance, cm & 19.60 \\
\hline Assembly inner flat-to-flat distance, cm & 19.00 \\
\hline Duct thickness, cm & 0.30 \\
\hline Inter-assembly gap, cm & 0.4 \\
\hline Assembly pitch, cm & 20.0 \\
\hline Number of pins/assemble & 127 \\
\hline Pin pitch, cm & 1.069 \\
\hline Fuel pin OD, cm & 1.55 \\
\hline Cladding material & $\mathrm{HT} 9$ \\
\hline Cladding thickness, cm & 0.056 \\
\hline Smeared density (SD) & $75 \%$ \\
\hline Fuel material & $\mathrm{U}-10 \mathrm{Zr}$ \\
\hline
\end{tabular}

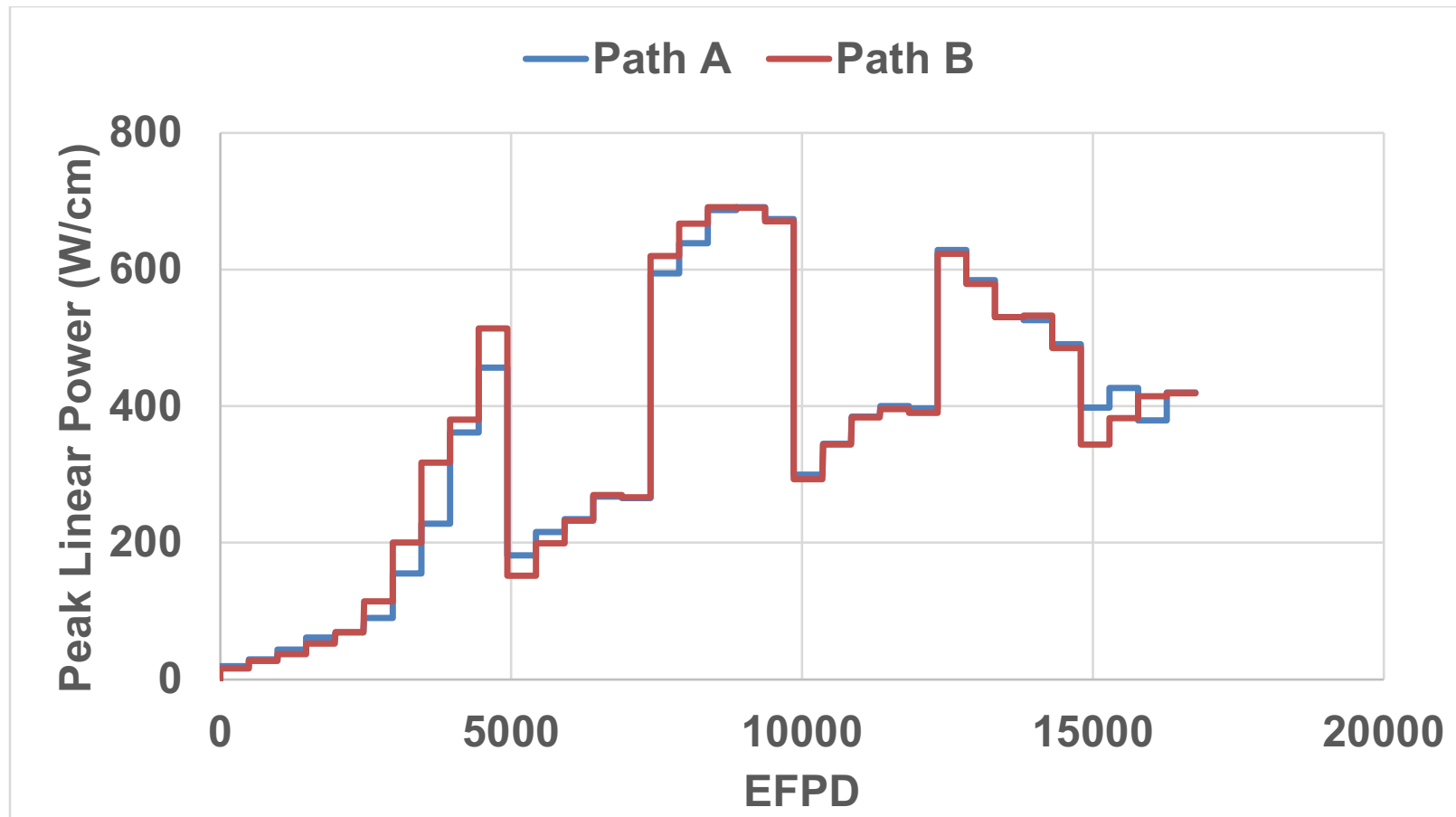

Figure 2.1.2 Peak Linear Power Evolution of Fuel Management Paths A and B

Because it takes 51 years for the SSFR to finish the entire 34 cycles, and the fuel pin will have a relatively high burnup at the end of its life, it is of great importance to evaluate the fuel performance of $\mathrm{U}-10 \mathrm{Zr}$ under such fast reactor conditions. This fuel performance evaluation is expected not only to demonstrate the feasibility of adopting the fuel management strategy used by the SSFR concept, but also provide insightful guidance for the further improvement of the 
SSFR design as well as other similar designs of once-through fuel cycle systems. Hence, the BISON fuel performance code was employed to perform the fuel performance simulation for SSFR fuels.

\subsection{Methodology of Fuel Performance Evaluation}

In conventional fast neutron reactors using metallic fuels (U-10Zr or U-xPu-10Zr), solid fuel slugs are usually used. In that case, extra room needs to be reserved with the fuel so as to accommodate the swollen fuel during irradiation, considering the extensive swelling strain of metallic fuels. A 75\% smeared density (SD) has been found appropriate for a solid fuel to reach considerable burnup (metallic fuel has been qualified for $10 \%$ FIMA burnup). In the solid fuel configuration, the SD is achieved by leaving an initial fuel-cladding gap. The entire fuel slug is immersed in liquid sodium so that the fuel and cladding can be thermally bonded. An alternative approach that is actively pursued by the Advanced Fuel Campaign is the annular fuel configuration [Miao 2019]. In the annular fuel configuration, the smeared density is achieved by preserving a cylindrical central void inside the fuel slug. The fuel outer surface directly contacts with the cladding inner surface. In previous in-pile irradiation [Harp 2018], sliding-in annular fuel showed defective fuel-cladding thermal contact. Hence, co-extrusion technique is proposed to be used to fabricate the fuel-cladding system to ensure perfect contact. In that case, the use of liquid sodium can be eliminated inside the fuel cladding enclosure. This will avert the handling of contaminated sodium during waste processing and thus help reduce the cost.

In a solid metallic fuel, the fuel slug swells both axially and radially. In spite of the reported anisotropic swelling, a U-10Zr fuel still swells approximately $8 \%$ in the axial direction before the closure of fuel-cladding gap [Hofman 1994]. On the other hand, in an annular fuel, the fuel slug is bonded to the cladding. As a result, the axial swelling of an annular fuel is marginal because of the constraints from cladding. That is, almost all of the volumetric swelling strain is contributed by radial swelling. Hence, the fuel swelling is a 3D phenomenon in the solid fuel configuration but an approximately 2D phenomenon in the annular fuel configuration. Namely, given the same $\mathrm{SD}$, the fuel-cladding gap in a solid fuel system is expected to accommodate a higher volumetric swelling strain compared to the central void in an annular fuel system. Consequently, annular fuel design usually adopts a lower SD (e.g. 65\% or 55\%). In this SSFR fuel performance evaluation, as $75 \% \mathrm{SD}$ is used in reactor design because a lower SD may compromise the neutronics performance of the core. Therefore, both solid and annular fuel configurations with $75 \% \mathrm{SD}$ were investigated in this fuel performance evaluation. The detailed fuel pin parameters can be found in Table 2.2.1.

Table 2.2.1 Fuel pin parameters of two fuel configurations

\begin{tabular}{|l|l|l|}
\hline & Annular Configuration & Solid Configuration \\
\hline Cladding OD, cm & 1.55 & 1.55 \\
\hline Cladding ID, cm & 1.438 & 1.438 \\
\hline Fuel Slug OD, cm & 1.438 & 1.245 \\
\hline Fuel Slug ID, cm & 0.719 & n/a \\
\hline Bonding Medium & n/a & Liquid sodium \\
\hline
\end{tabular}


The BISON code was used in this project to simulate the fuel performance of metallic fuel pins with both solid and annular fuel configurations in the SSFR. BISON is a finite element method (FEM) based advanced multi-physics fuel performance code developed at the Idaho National Laboratory [Hales 2016]. The code is developed on the MOOSE framework [Gaston 2009] and features a unique and comprehensive materials property database dedicated to nuclear materials. While the early-stage code development for BISON was focused on light water reactor (LWR) applications [Williamson 2016], capabilities of simulating metallic fuels in fast neutron reactors were established and have been continuously improved under the NEAMS-FPL program [Novascone 2018].

Full-size axisymmetric fuel pin model for the SSFR fuel was established and meshed. For the solid fuel configuration, BISON's intrinsic mesh module was used. For annular fuel, the CUBIT code developed at the Sandia National Laboratory [Blacker 1994] was adopted. The fuel and cladding dimension parameters were directly adopted from the new core design. A $5(\mathrm{R}) \times 700$ (Z) Quad8 meshing was used for the cladding, while a 10(R) $\times 700(\mathrm{Z})$ Quad8 meshing was used for the fuel slug.

As co-extrusion is expected to be used in future annular fuel fabrication to ensure perfect fuelcladding contact, the cladding and fuel are assumed to be bonded together in the annular fuel configuration simulations. For the solid fuel configuration simulations, the gap was filled by liquid sodium. Considering the long fuel life time in reactor and extensive target burnup, a vented plenum setup was assumed to maintain a constant 6 atm plenum gas pressure throughout the irradiation.

In this project, a series of material properties and correlations of U-10Zr fuel and HT-9 cladding were adopted for fuel behavior simulations. The $\mathrm{U}-10 \mathrm{Zr}$ was selected as the representative fuel despite that the original $\mathrm{U}-10 \mathrm{Zr}$ will be eventually bred into $\mathrm{U}-\mathrm{xPu}-10 \mathrm{Zr}$. As the difference in swelling behavior between $\mathrm{U}-10 \mathrm{Zr}$ and $\mathrm{U}-\mathrm{xPu}-10 \mathrm{Zr}$ mainly occurs at low burnup, the selection of U-10Zr is reasonable. The LANL thermal conductivity model [Matthews 2015] and the Savage heat capacity model [Savage 2006] with porosity correction available in the BISON code were used for thermophysical properties of the U-10Zr fuel. The thermomechanical properties of U-10Zr are also available in BISON. On the other hand, the HT-9 properties, including thermophysical properties, mechanical properties, thermal/irradiation creep behavior, and damage model, were assessed using the corresponding correlations available in the BISON code. Many of these properties and correlations were adopted from the Metallic Fuel Handbook developed in the IFR program [Hofman 2019].

One of the most important fuel behaviors of metallic fuels such as U-10Zr is irradiation swelling. In metallic fuels, the accumulation of fission gas leads to rapid fuel swelling to $\sim 36 \%$ in the first $1 \sim 2 \%$ FIMA burnup. Once the $\sim 36 \%$ gaseous swelling strain is reached, interconnection of fission gas bubbles releases fission gas and prevents further swelling due to gaseous fission products. On the other hand, solid fission products are calculated to contribute $\sim 1.5 \%$ volumetric swelling strain per 1\%FIMA burnup [Ogata 1999] $(\sim 1.2 \%$ in the presence of sodium bonding [Hofman 1994]), which becomes the dominant contributor to swelling once the gaseous swelling is "saturated". Additionally, the interconnection of fission gas bubbles transits the original close porosity into open porosity, which is subject to be compressed under pressure. This phenomenon, which is usually termed hot pressing, is especially important for metallic fuel at high burnup because this mechanism allows solid fission product to fill the open pores instead of pushing cladding [Ogata 2012]. 
As BISON's current fuel swelling correlation, which was developed by Medvedev in 2012 [Medvedev 203], underestimates the gaseous swelling rate at low burnup, a correction factor was developed to make the correlation more consistent with experimental observations (e.g. neutron radiography data of X423 experiment in EBR-II). The similar approach was used to assess the fuel performance of a low SD annular fuel design for ABR-1000. Meanwhile, as an ongoing effort supported by NEAMS-FPL, fuel swelling and fission gas release correlations of the LIFEMETAL fuel performance code [Yacout 2013], which has been validated based on the postirradiation examination (PIE) results of EBR-II experiments, are being implemented into the BISON code. The current LIFE-METAL fuel swelling and gas release correlations in BISON was also used to evaluated the fuel performance in this project.

Fuel-cladding chemical interaction (FCCI) is another important phenomenon for metallic fuel system as it reduced effective thickness of the cladding. As FCCI is a diffusion-controlled process, it is dependent on the irradiation time, temperature as well as available fission products (proportional to burnup). Hence, it is an important fuel performance component to investigate for SSFR due to its high burnup and extensive irradiation time. Three FCCI correlations developed by ANL have been implemented into the BISON code as a part of the NEAMS-FPL project. The burnup dependent correlation [Billone 2017] will be used in this project. As shown in Figure 2.2.1, the burnup dependent FCCI correlation computes wastage thickness that is most consistent with the metallography measurement of the X447/A subassembly pins irradiated in EBR-II.

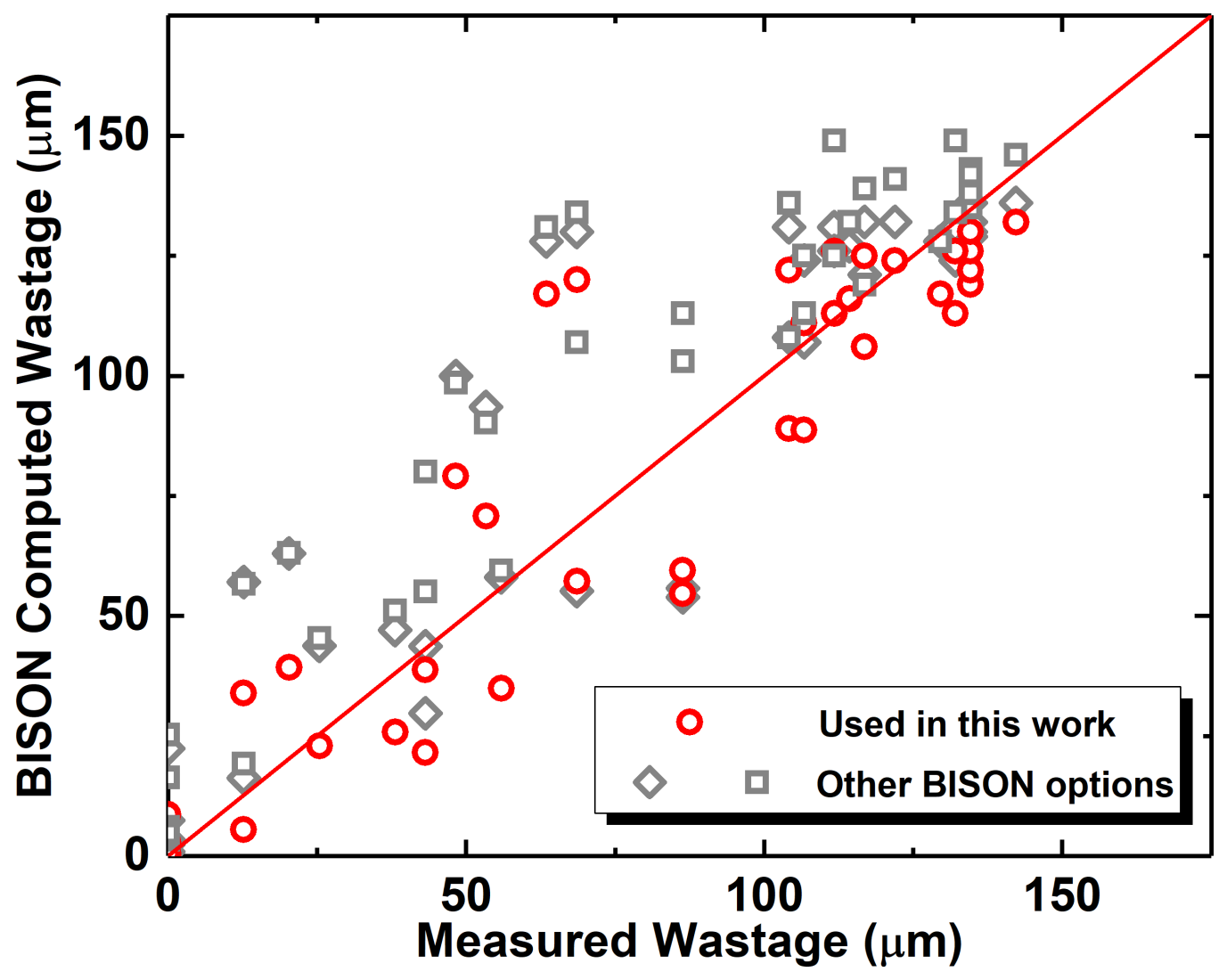

Figure 2.2.1 BISON computed wastage compared with measured EBR-II X447 data 
It is worth mentioning that the effect of the FCCI on cladding mechanical properties is a planned task for BISON metallic fuel development and was thus not included in this project. In this report, the FCCI model just helps provides an impression of the severity of wastage formation on the fuel-cladding interface. In those cases that BISON predicts formation of a thick wastage layer, the actually CDF is expected to be higher than the computed values.

For solid fuel configuration, the fuel-cladding contact model is important for the simulation of FCMI. In BISON, the available contact models include frictionless, friction (coulomb), and glue. The friction model is expected to provide the most realistic simulation but causes convergence issues that are hard to solve. The frictionless model leads to unrealistic axial elongation once FCMI is significant. Hence, the glue contact model was used in this report for conservative estimation. That is, the relative movement between fuel and cladding is forbidden once the fuelcladding gap is closed.

\subsection{Operation Conditions}

In the SSFR fuel management strategy, there are two paths as shown in Figure 2.1.1.

Considering the similarity between the two paths, only path A was used in this fuel performance evaluation work. The average linear powers and effective full power days (EFPDs) were used for the 34-cycle irradiation that lasts for 51 years with $90 \%$ capacity factor. For the 2-m long fuel, the linear power and neutron flux values are sampled at ten equally spaced axial positions from neutronics simulations. The axial linear power and fast neutron flux profiles over the 34 cycles are shown in Figures 2.3.1 and 2.3.2.

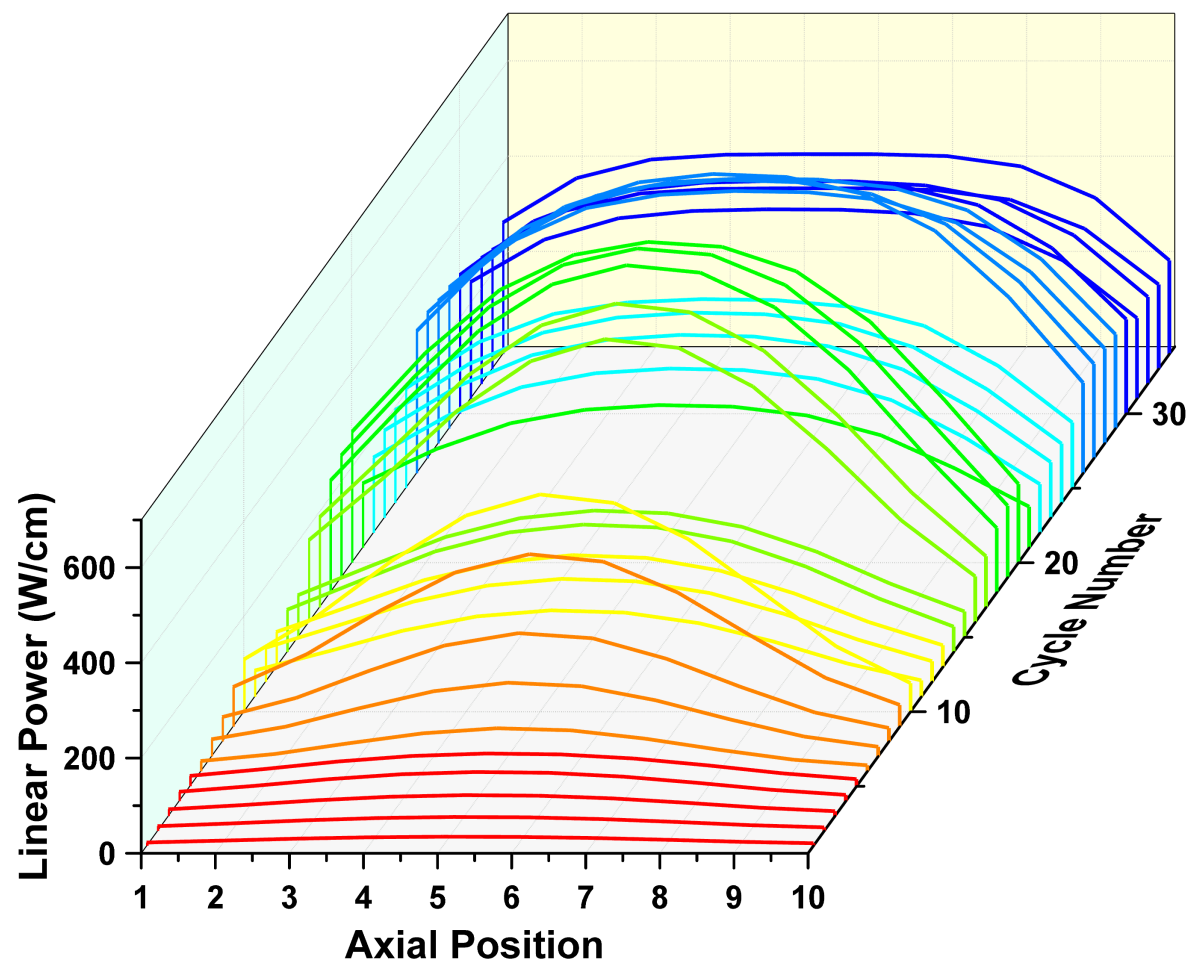

Figure 2.3.1 Linear power profiles used in fuel performance simulations (Path A) 


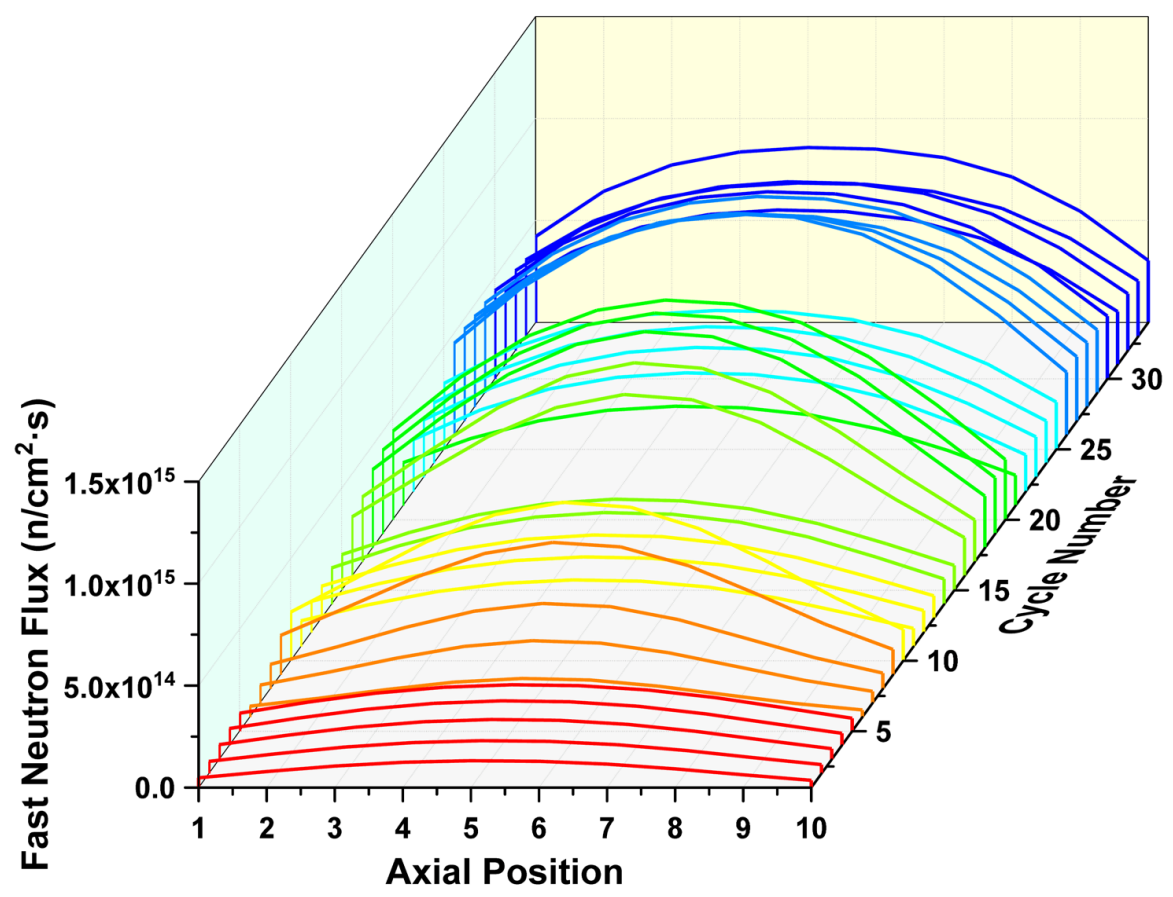

Figure 2.3.2 Fast neutron flux profiles used in fuel performance simulations (Path A)

It is prominent that the fuel power and fast neutron flux are quite limited in the first few cycles due to the scarce of fissile materials in the fresh depleted uranium fuel pin. With the increase of bred plutonium over the irradiation time, the fuel is able to generate more power. To ensure the smooth transition between cycles, a 2-day linear transition was added between cycles to facilitate the convergent solution of the BISON simulations.

On the other hand, the inlet coolant (liquid sodium) temperature is constantly $355^{\circ} \mathrm{C}$. The coolant flow flux of each fuel assembly region is well-designed as illustrated in Figure 2.3.3 in order to maintain a relatively constant fuel cladding temperature for all the fuel assemblies. 


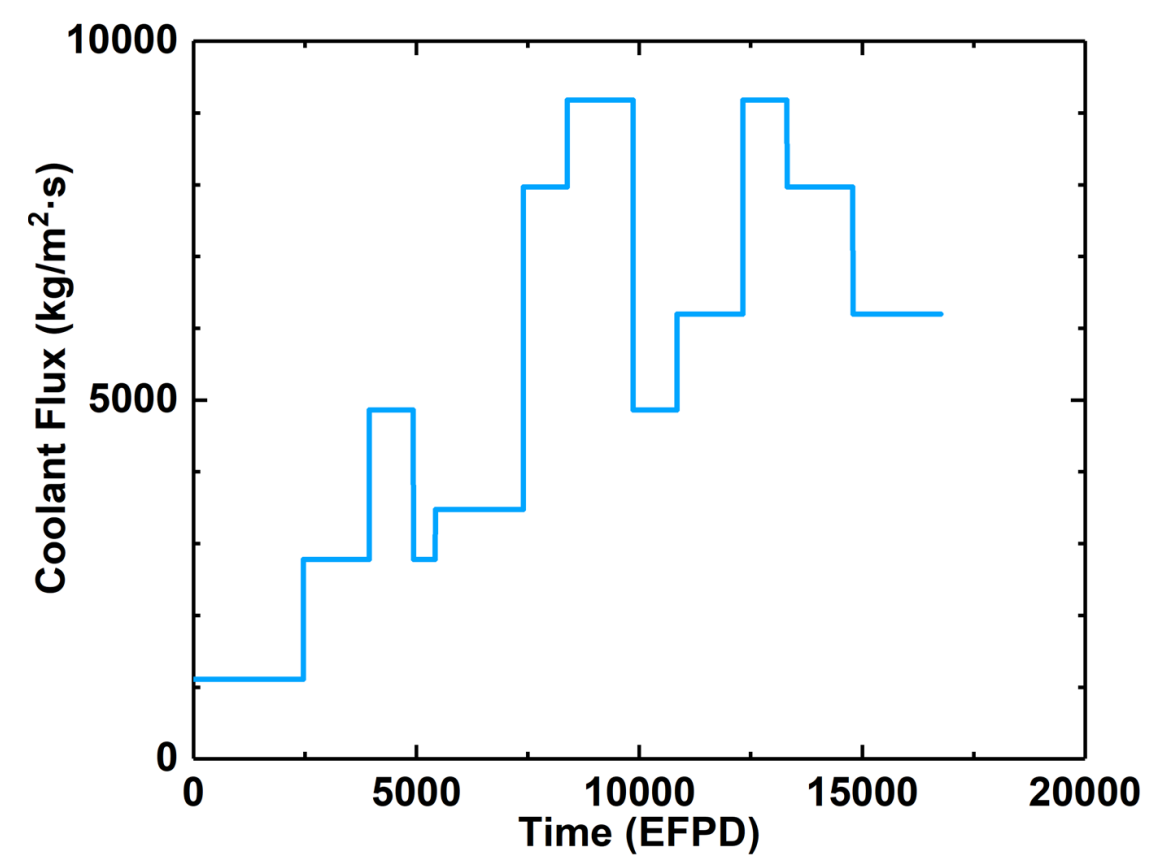

Figure 2.3.3 Coolant fluxes used in fuel performance simulations (Path A)

\subsection{Fuel Performance Simulations}

As shown in Figure 2.4.1, the entire 51 cycles of the SSFR fuel management (Path A) were simulated using BISON. The Path A irradiation gives a $28.4 \%$ FIMA average burnup and $\sim 37.0 \%$ FIMA peak burnup. For the annular fuel configuration, BISON simulations usually predict a premature fuel failure due to the cladding rupture (quantified by CDF), regardless which swelling and fission gas release model is used. The detailed failure mechanisms will be discussed in this section. On the other hand, those simulations of SSFR fuel pin with solid fuel configuration can last untill the end of the design fuel life, which will also be described in detail in this section.

During the SSFR design, time evolution of coolant outlet temperature was computed using a simplified thermos-hydraulics correlation available in the neutronics code. In the BISON code, given the coolant inlet temperature, coolant flow flux (Figure 2.3.3), fuel power (Figure 2.3.1) and fuel pin geometry parameters in the assembly, an implemented coolant model is used to predict the coolant temperature evolution. The time evolution of the coolant outlet temperature is shown in Figure 2.4.2. Compared to the coolant outlet temperature computed during design, the BISON predicted coolant outlet temperature is slightly higher. The difference is usually lower than $\sim 20^{\circ} \mathrm{C}$. This slight difference may originate from either the difference in thermo-hydraulics models or the linear interpolation of linear power profile. The peak cladding temperature and peak fuel temperature are also illustrated in the same figure for the solid fuel configuration. The peak cladding temperature is usually around $550^{\circ} \mathrm{C}$, which is relatively low for HT9 cladding, which was irradiated at $\sim 650^{\circ} \mathrm{C}$ peak cladding temperature in X447 experiment in EBR-II [Yacout 2017]. The peak fuel temperature is also below $900^{\circ} \mathrm{C}$, which is well below the melting temperature of the fuel. 


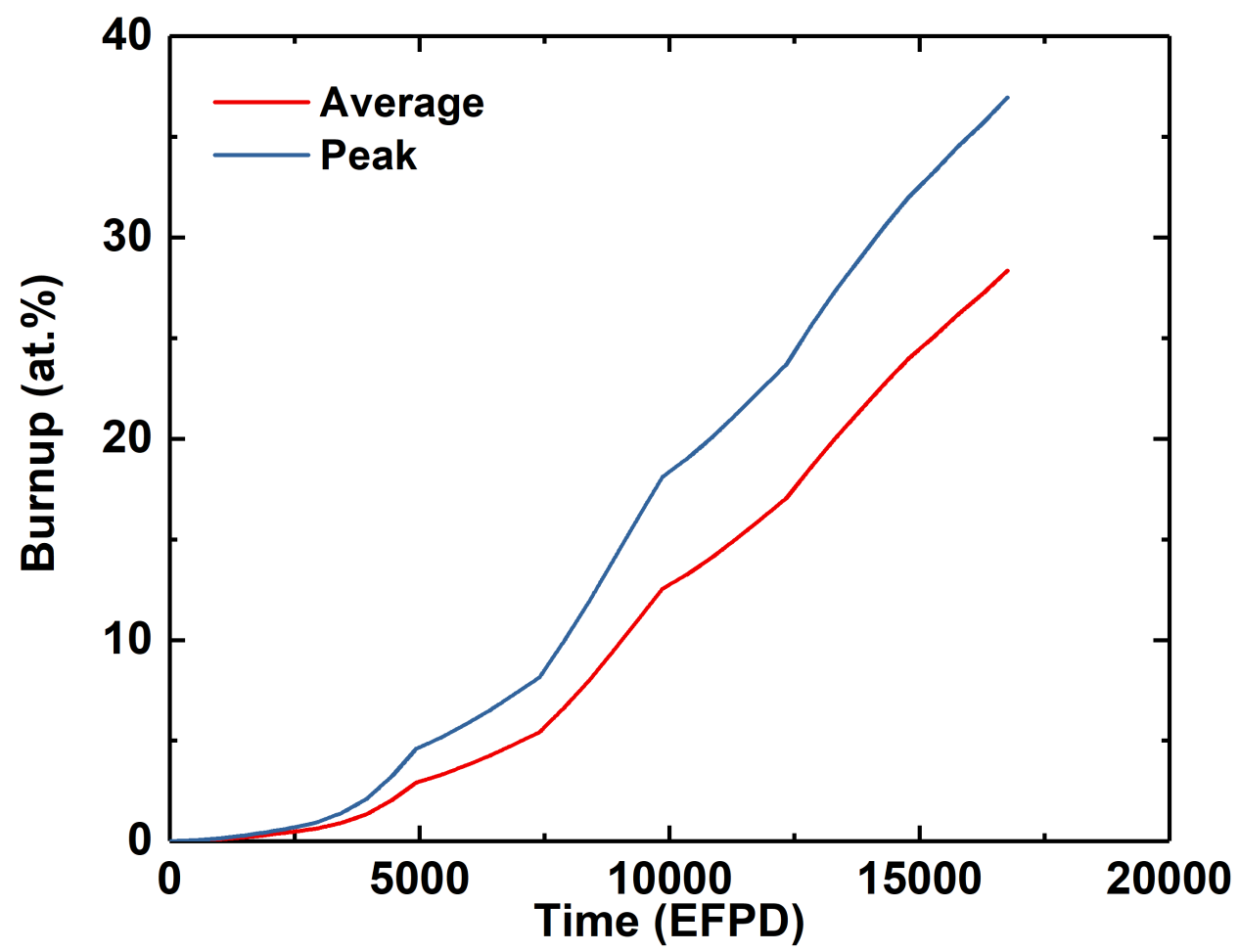

Figure 2.4.1 Time evolution of average and peak fuel burnup of SSFR fuel pin (Path A)

Meanwhile, the evolution of the FCCI wastage thickness for the solid fuel configuration is plotted versus pin-averaged burnup in Figure 2.4.3. A maximum of $\sim 100 \mu \mathrm{m}$ wastage is predicted to form after the 51-year irradiation. The wastage thickness is low for this long irradiation because of the relative low cladding temperature (thicker wastage was observed in X447 pins with only 10\%FIMA peak burnup [Billone 2017]). Still, a $100 \mu \mathrm{m}$ wastage is a significant fraction of the initial $560 \mu \mathrm{m}$ cladding thickness. At the maximum CDF location, as also shown in Figure 2.4.3, the FCCI wastage thickness is approximately $30 \mu \mathrm{m}$, which is more than $5 \%$ of the cladding thickness. Due to the limitation of the current BISON code, the CDF computation does not take FCCI into consideration. Therefore, the actually CDF is expected to be higher than the BISON computation value because the wastage layer cannot take as much load as HT9 steel with carbon. 


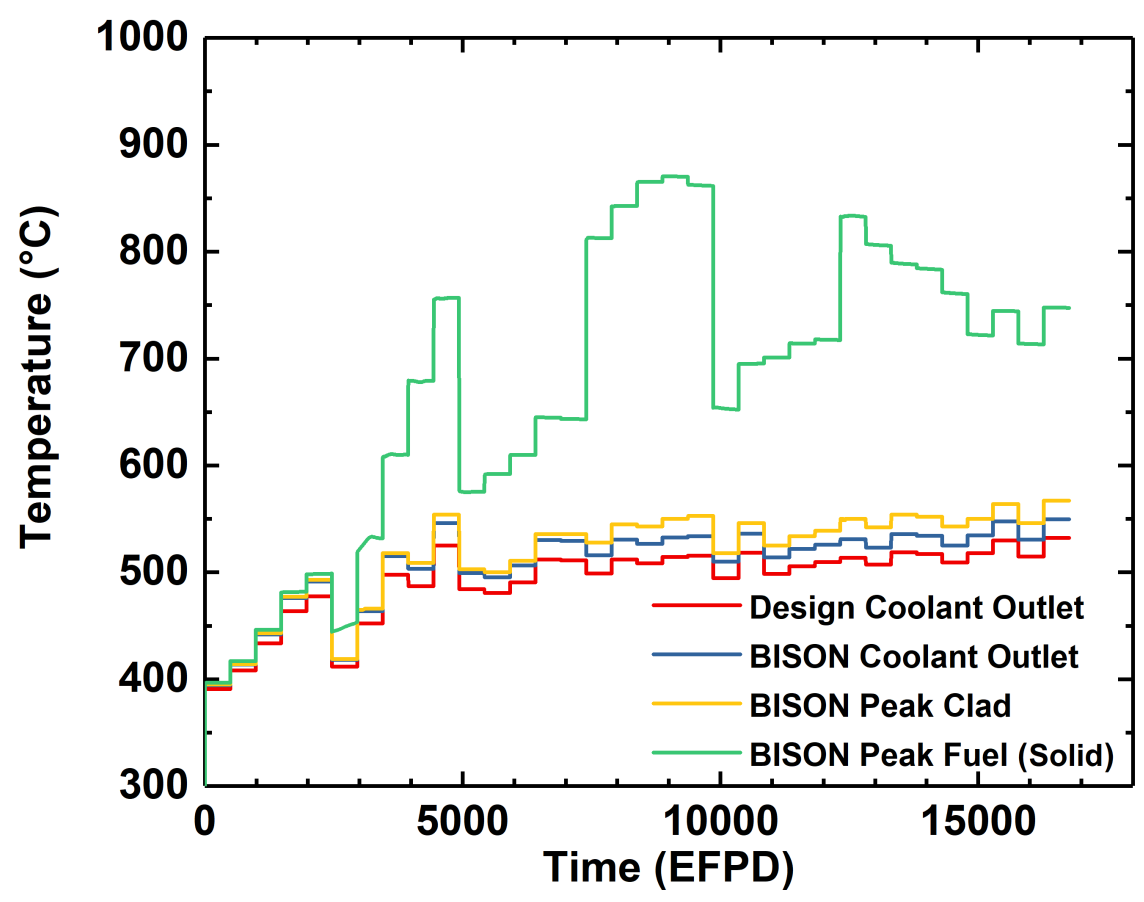

Figure 2.4.2 Coolant outlet, peak cladding, and peak fuel (solid fuel configuration) temperatures computed by BISON

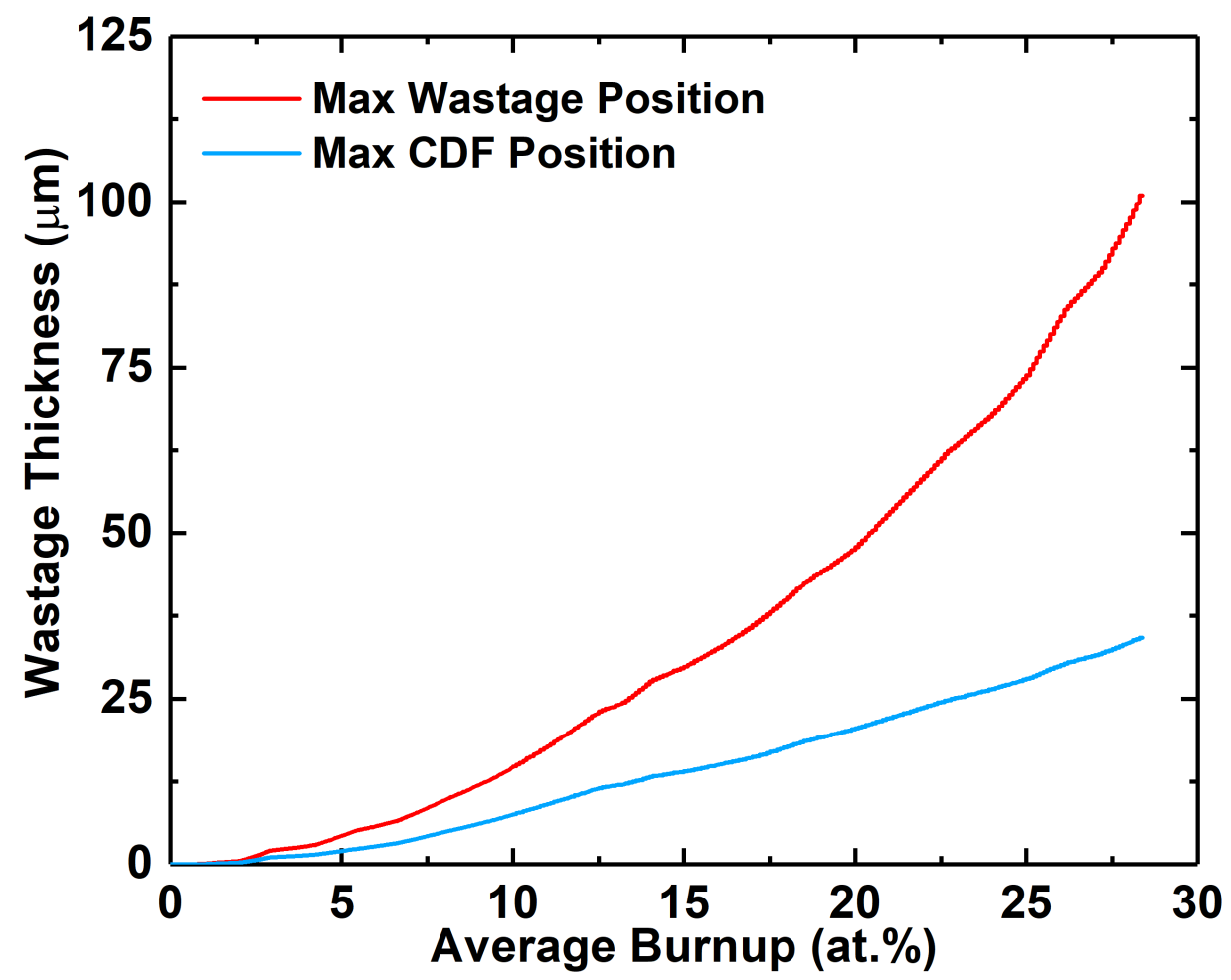

Figure 2.4.3 Time evolution of FCCI wastage thickness computed by BISON 


\subsubsection{Annular Fuel Performance}

As previously mentioned, using either the corrected Medvedev swelling and fission gas correlation or the LIFE-METAL correlation, the BISON code predicts premature cladding failure at a lower burnup ( 2\%FIMA) for the annular fuel configuration. In Figure 2.4.1.1, the evolution of the maximum CDF of the annular fuel system is illustrated versus burnup.

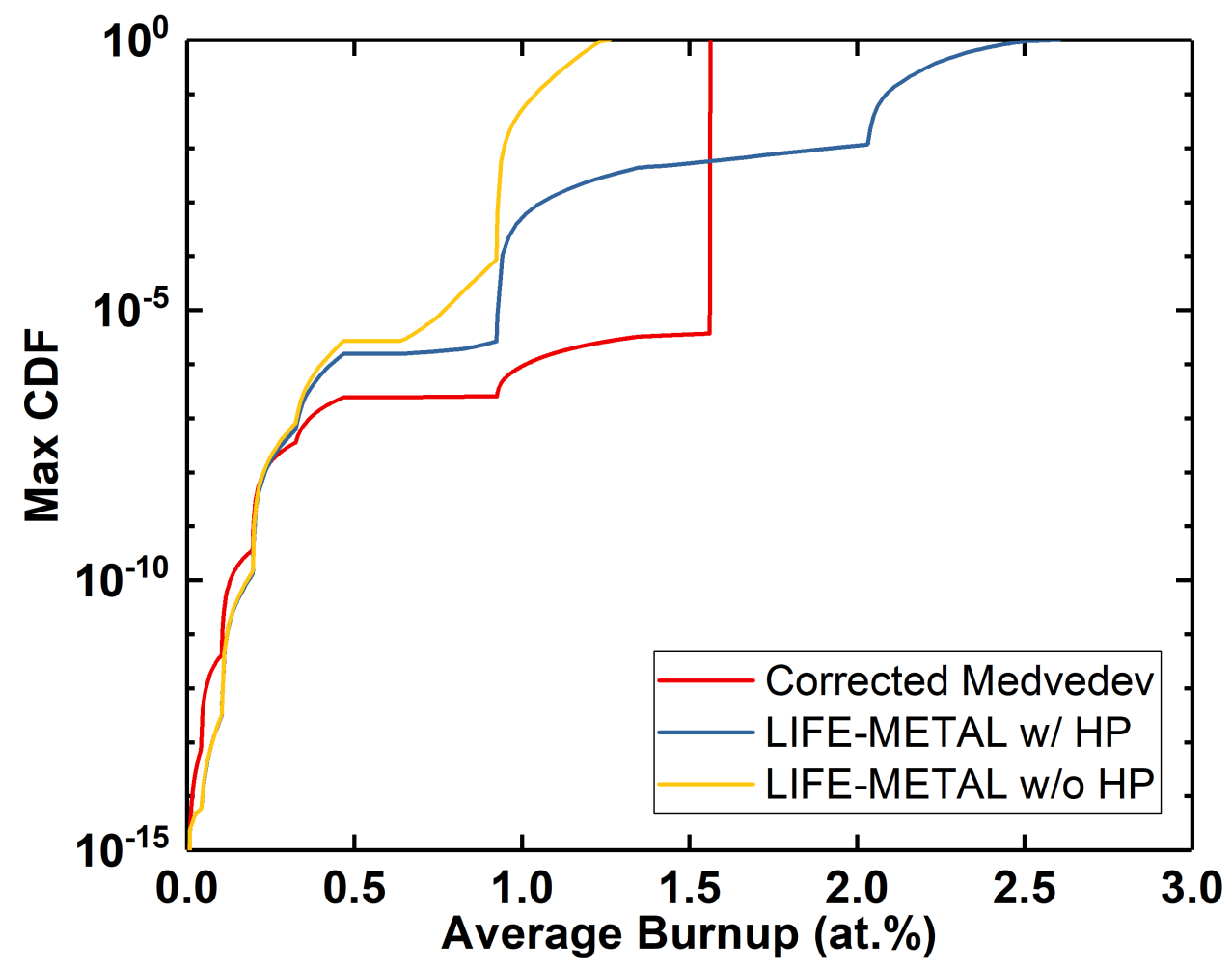

Figure 2.4.1.1 Evolution of maximum CDF for SSFR annular fuels using different BISON correlations

The corrected Medvedev correlation gives a cladding failure at $\sim 1.6 \%$ FIMA average burnup, while the LIFE-METAL correlation predicts that the failure occurs at $\sim 2.5 \%$ FIMA. In the LIFEMETAL correlation, hot pressing (HP) is controlled by both existing porosity and hydrostatic stress. In a conventional solid fuel configuration, based on which the correlation was developed and calibrated, hydrostatic stress becomes much higher than the plenum pressure only after the fuel-cladding gap closure. In that case, the fuel porosity is high enough for open porosity that enables hot pressing. On the contrary, in an annular fuel configuration, the hydrostatic stress could be high even when the porosity is low, which may induce this artifact in the simulation. Therefore, the hot pressing can be switched off as an option in the LIFE-METAL correlation. Both situations are shown in Figure 2.4.1.1. It is obviously that the fuel cladding fails earlier (at $\sim 1.2 \%$ burnup) without hot pressing helping relieve the swelling strain.

Another interesting phenomenon in Figure 2.4.1.1 is that the CDF rapidly increases from $\sim 0.00001$ to 1 using the corrected Medvedev correlation. On the contrary, the CDF slowly reaches to 1 using the LIFE-METAL correlation. This difference can be explained by looking 
into the evolution of volumetric swelling strain (Figure 2.4.1.2) and hoop stress (Figure 2.4.1.3). In the corrected Medvedev correlation, the hydrostatic stress has less effect on the swelling rate compared to the LIFE-METAL correlation. As a result, the swelling strain increases faster so that the porosity in the fuel facilitates the fuel creep by increasing effective stress (i.e. the fuel is softer). When the corrected Medvedev correlation is used, the central void is almost closed near the cladding failure point. However, due to the bonded cladding-fuel configuration, axial swelling is negligible in annular fuel. As a result, the central void needs to accommodate almost all the swollen fuel. In this case, a $25 \%$ central void (of a $75 \%$ SD fuel) is not enough to accommodate the $36 \%$ gaseous swelling plus solid swelling before gas release is fully initiated to slow down the swelling rate. Therefore, the cladding experiences an immediate failure once the central void is nearly closed. This phenomenon is comparable to the premature failure of solid fuel with a high SD (e.g. $>85 \%$ ). Lower SD was also simulated in this project to show improved fuel performance. However, in SSFR, it is challenging to design a core with enough reactivity considering the use of depleted uranium fuels. Hence, a lowered SD would cause significant difficulties in reactor design. As mentioned early in this study, a lower SD is usually considered for annular fuel, which could be a disadvantage of the annular fuel configuration for some specialized reactor designs such as the SSFR.

On the other hand, because the swelling strain in the LIFE-METAL correlation is very sensitive to hydrostatic stress, the fuel swelling rate is lower. This lower swelling strain also leads to lower creep rate, further limiting the inward swelling of the fuel. As a result, the hoop stress of the cladding is higher than the case using the corrected Medvedev correlation, leading to premature failure of the cladding. It is worth mentioning that in this SSFR fuel design, in order to have sufficient reactivity, aside from the high SD used, a much thicker fuel pin design is employed. To be specific, a $1.55 \mathrm{~cm}$ OD fuel pin is used compared to the ordinary $0.584 \mathrm{~cm}$ OD fuel pins and the "fat" $0.737 \mathrm{~cm}$ OD fuel pins used in EBR-II experiments. When a thick fuel pin design is adopted, the cladding thickness is not increased for reactivity and thermal efficiency consideration. Consequently, the cladding is required to constrain more swollen fuel volume compared to conventional design. This also explains the premature failure of the cladding in both models. If an annular fuel configuration is required (e.g. to eliminate in-cladding sodium), the design can be optimized by either lower the SD or lower the fuel/cladding ratio, although the reactivity may be affected accordingly. 


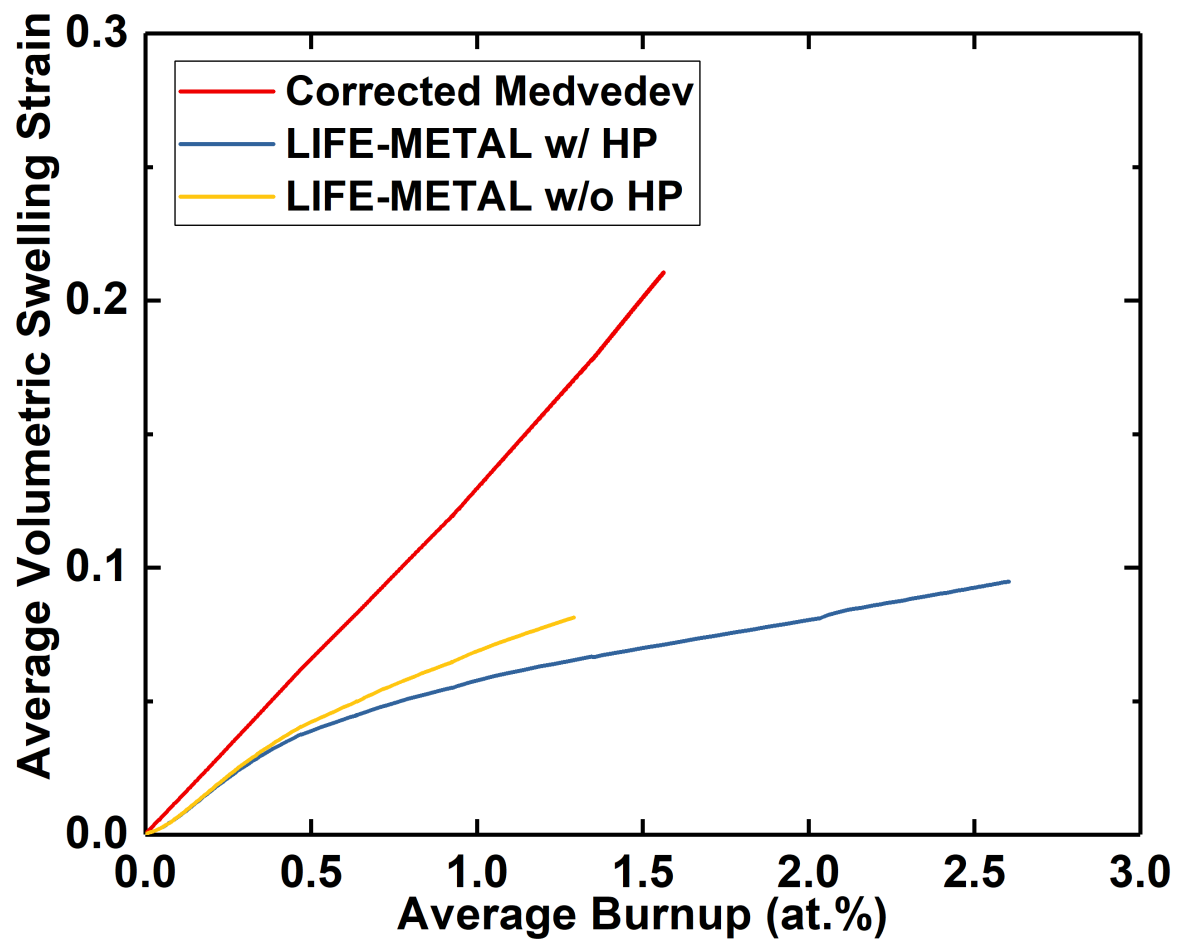

Figure 2.4.1.2 Average volumetric swelling strain evolution for the annular fuel configuration

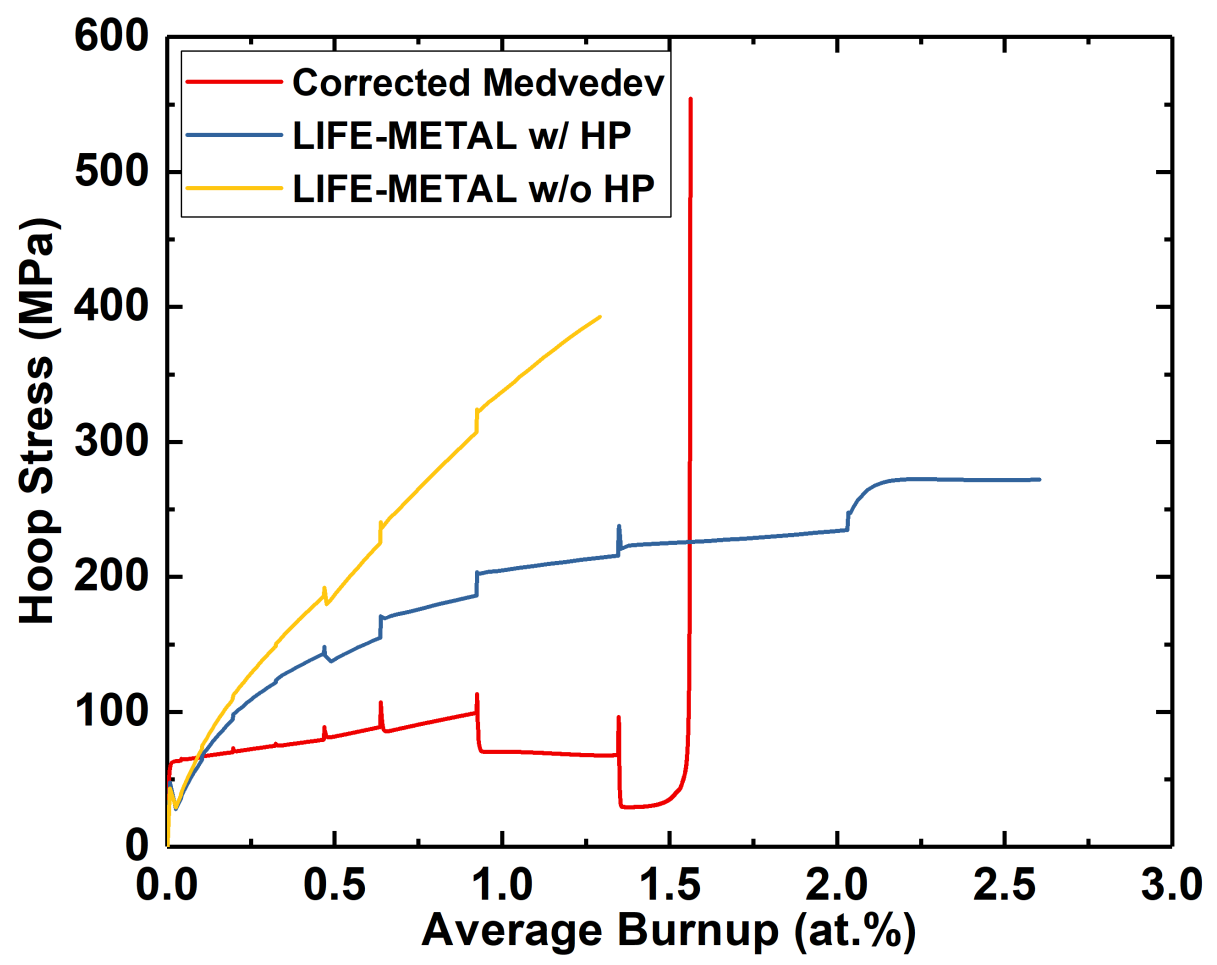

Figure 2.4.1.3 Time evolution of the hoop stress at the failure point 


\subsubsection{Solid Fuel Performance}

As premature failure is predicted by BISON simulations for the SSFR fuels, solid fuel configuration has to be considered as an alternative solution to potentially avert major re-design. The switch from annular fuel design to conventional solid fuel design is straightforward. The $75 \%$ SD is maintained but the annular fuel mechanically bonded to the cladding becomes a solid fuel slug bonded with cladding by liquid sodium. All the other operation conditions were kept the same.

For a solid fuel configuration, the swelling is usually anisotropic. Namely, the fuel swells more in the radial direction compared to the axial direction. With the increase in Pu content, this anisotropy becomes more and more prominent. In U-10Zr fuel, fuel swelling is approximately $8 \%$ in axial direction when the fuel-cladding gap starts to close. In the LIFE-METAL swelling correlation, the anisotropic swelling is originally achieved by controlling the axial elongation of the fuel using an empirical correlation developed based on in-pile irradiation PIE results (labelled as LIFE-METAL original in this report). Alternatively, the anisotropic swelling can be achieved by introducing an anisotropic swelling factor to manual allocate volumetric swelling strain to axial and radial direction (labelled as LIFE-METAL anisotropic). For comparison purpose, isotropic LIFE-METAL swelling model was also investigated in this study (labelled as LIFE-METAL isotropic). On the other hand, for the corrected Medvedev swelling and gas release correlation, a manual anisotropic factor can also be induced. In this study, only isotropic corrected Medvedev correlation was used because this correlation cannot simulate very high burnup solid fuel, which will be discussed later.

The time evolutions of maximum CDF of the solid fuel system in SSFR Path A using various swelling and fission gas release correlations are shown in Figure 2.4.2.1. The most obvious observation of this figure is the failure of cladding at low burnup when the corrected Medvedev correlation is adopted. The origin of this failure is related to the handling of hot pressing. In a solid metallic fuel slug, the accumulation of fission gas bubbles lead to rapid swelling at low burnup. Once the bubbles are interconnected, the gaseous swelling becomes "saturated" because fission gas can be released into the plenum through interconnected bubbles, which are open pores. Compared to the close pores, where the internal gas pressure could be high, the open pores have the same internal pressure as the plenum pressure and are therefore compressible. Once the hydrostatic stress in the fuel increases due to the FCMI, the open pores can easily be compressed to provide room to accommodate solid FPs, which is known as hot pressing. Due to the existence of hot pressing, the early stage of fuel cladding contact is "soft" as the fuel is compressible and therefore causes marginal damage in cladding. Once the open pores are consumed, the FCMI becomes serious and eventually leads to prominent cladding strain and failure. Therefore, the hot pressing mechanism needs to be well described by the swelling model so as to replicate the fuel behavior observed in experiments. In the corrected Medvedev correlation, the involvement of hot pressing is limited. The hot pressing is mainly used to accelerate the creep of fuel by enhancing the effective stress, which may help relieve the FCMI in frictionless contact model. As shown in Figure 2.4.2.2, the average volumetric strain of the fuel reaches $45 \%$ at merely $7 \%$. As the glue contact model is used, the hot pressing in Medvedev's swelling model cannot effectively relieve FCMI and thus causes early failure of the cladding. 


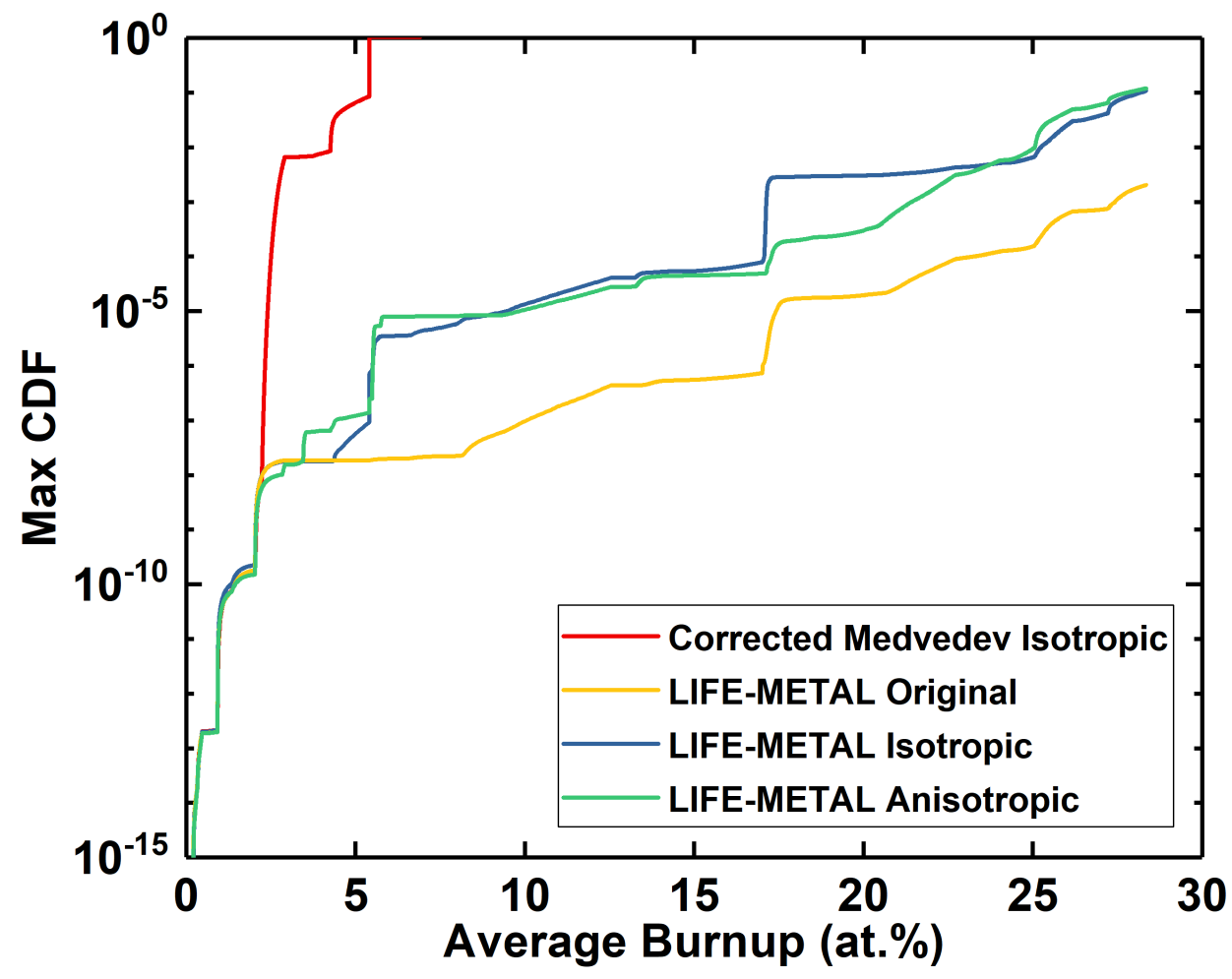

Figure 2.4.2.1 Time evolution of maximum CDF for SSFR solid fuels using different BISON correlations

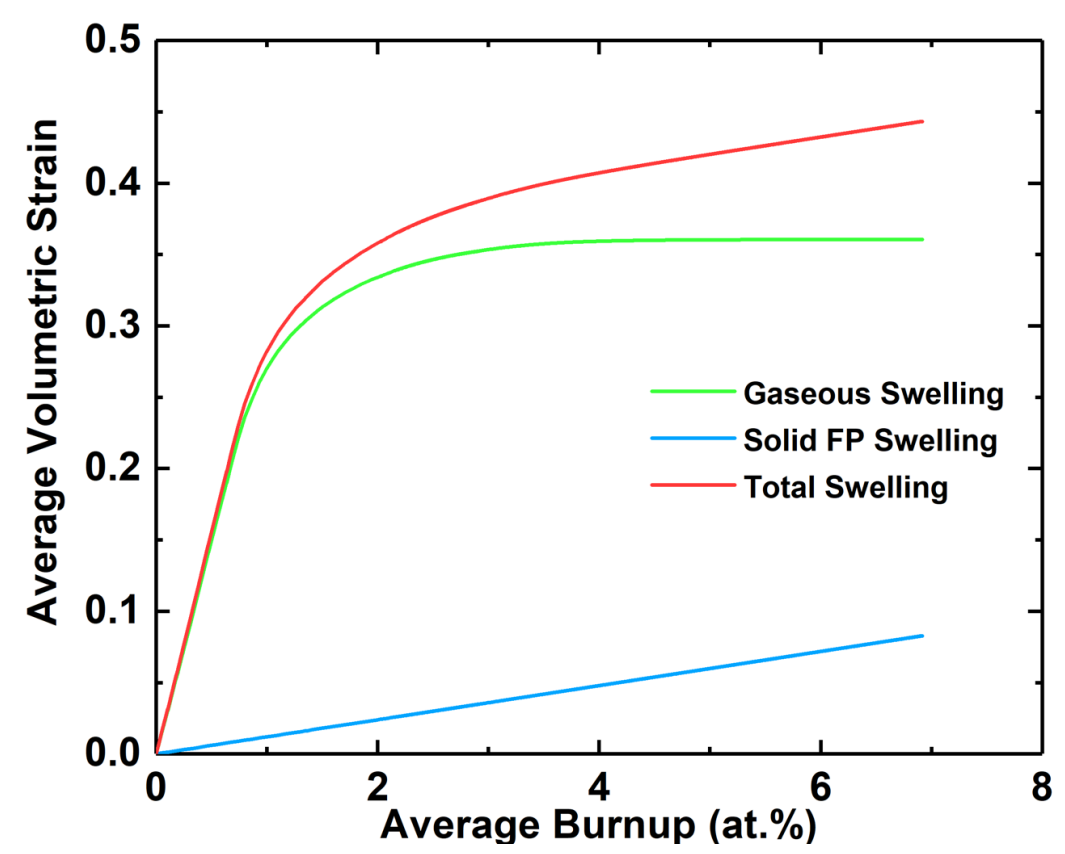

Figure 2.4.2.2 Time evolution of different components of volumetric swelling strain (Corrected Medvedev) 
On the other hand, when the LIFE-METAL swelling model is used, the maximum CDF are all lower than 1. In particular, the original LIFE-METAL correlation predicts a $\sim 0.05$ maximum CDF, which is way below the failure criteria $(0.1)$. The more realistic prediction of the CDF originates from the better description of the hot pressing behavior. In the LIFE-METAL correlation, hot pressing is described as a negative volumetric strain. As shown in Figure 2.4.2.3, hot pressing induces a negative volumetric strain that help compensate the extraneous solid fission product swelling strain at high burnup. This mechanism helps limit the average fuel swelling around $\sim 40 \%$ up to $\sim 20 \%$ FIMA average burnup. Beyond that point, the open pores are almost filled with solid fission products and the total volumetric swelling slowing reaches $\sim 45 \%$. Therefore, it is evident that the LIFE-METAL swelling correlation can successfully simulate the "soft" and "hard" contact stages of the FCMI and therefore provide a better assessment of fuel performance.

Another interesting phenomenon observed is the different approaches for anisotropic swelling of metallic fuel. In Figure 2.4.2.1, by using an anisotropic swelling factor to handle anisotropic swelling, BISON predict a maximum CDF that is $\sim 20$ times higher than the assessment by using a boundary condition, leading to a result that is close to the 0.1 failure criteria. This is a weird phenomenon because both approaches produce similar results when simulating the fuel behavior of EBR-II pins. The major difference between EBR-II simulation and SSFR simulation seems to be the irradiation time of the fuels. To look into this, the time evolution of axial fuel strain of different approaches is illustrated in Figure 2.4.2.4. For both cases using an anisotropic factor instead of a boundary condition, the axial strain continues to decrease after the initial increasing. The final axial strain is only $\sim 5 \%$. This predicted $5 \%$ axial strain differs significantly from the experimentally observed value, which should be comparable to the LIFE-METAL original prediction curve in Figure 2.4.2.4. As the irradiation lasts for 51 year, which is one order of magnitude higher than all existing experimental experience, the difference in predicted axial strain values is suspected to come from the creep of the fuel due to gravity. The gravity was artificially removed from the LIFE-METAL anisotropic case. The results are also shown in Figure 2.4.2.4. It seems without gravity; the axial strain is very similar to the LIFE-METAL original case. This can be further confirmed by looking into the creep strain components. 


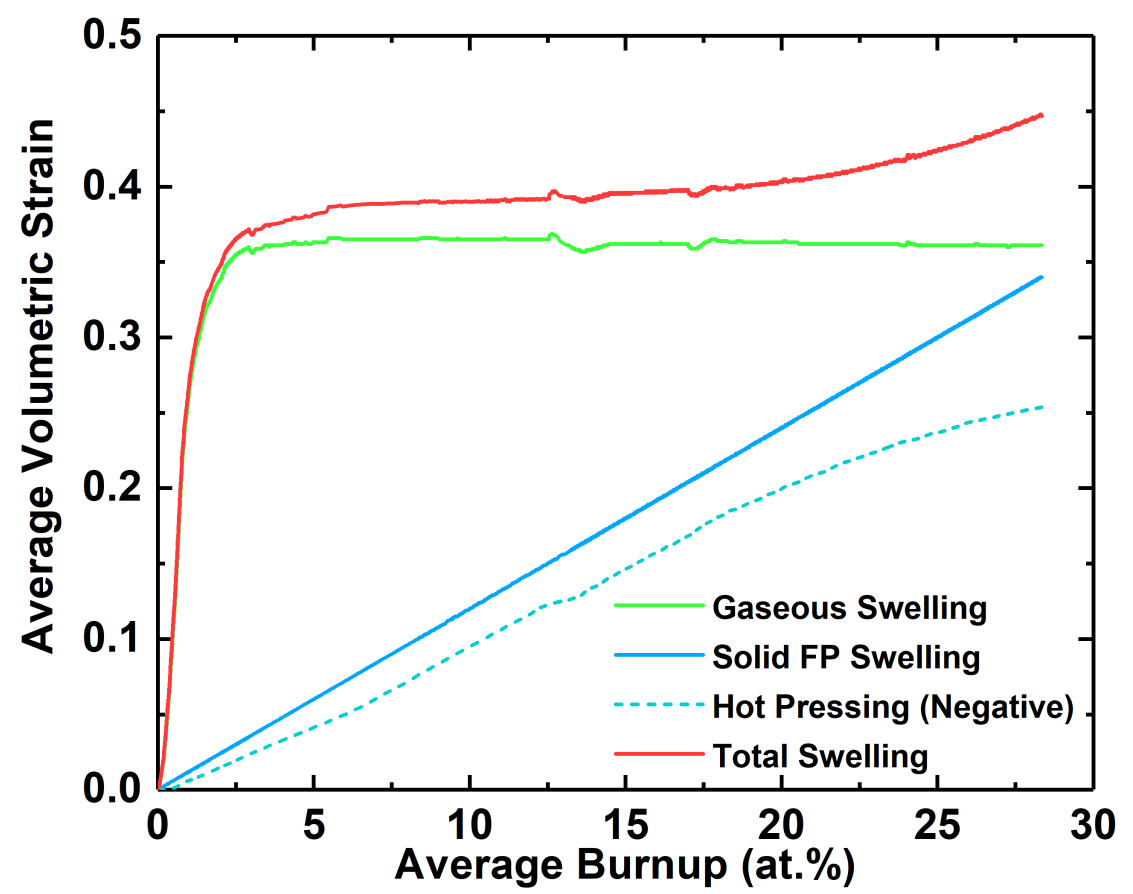

Figure 2.4.2.3 Time evolution of different components of volumetric swelling strain (LIFEMETAL)

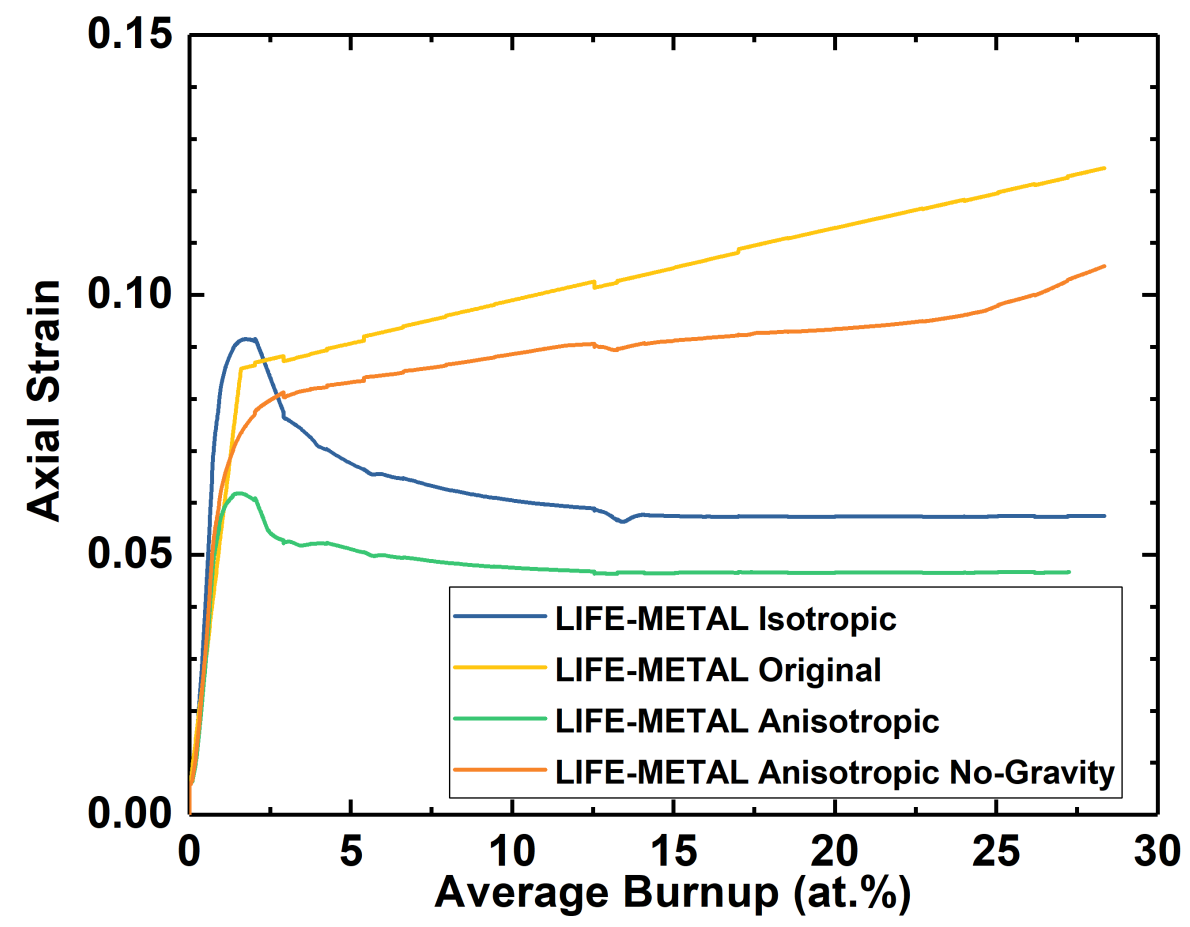

Figure 2.4.2.4 Time evolution of axial fuel elongation strain versus average burnup of the pin predicted by different approaches to handle anisotropic swelling. 
This finding reveals that in those once-through fuel cycle systems that last for decades, gravity creep of metallic fuel could be a potential issue. It has to be emphasized here that the thermal and irradiation creep model of metallic fuel used in BISON (and other codes such as LIFE-METAL) was developed by fitting the fuel behavior observed in those test reactor irradiation results. Those irradiations usually only last for months. Therefore, the prediction of gravity creep over the 51 years of irradiation is not expected to be accurate. However, considering the long irradiation time involved and the high temperature and irradiation dose, it is possible that the creep induced by gravity makes some contributions to the fuel deformation.

In summary, using the LIFE-METAL swelling and gas release correlation, BISON is capable of simulating the fuel performance of fuel pins in SSFR for the entire 34 cycles. Based on different approaches of anisotropic swelling, the final maximum CDF values are different but smaller than 1. Compared to the annular fuel configuration, solid fuel configuration provides improved fuel performance when the core design parameters are limited for these once-through fuel cycle systems such as SSFR. 


\section{Annular Metal Fuel Behavior in Transient Scenario}

Annular metallic fuel configuration has a central void region and it is bonded with the cladding. This configuration limits the axial fuel elongation hence the fuel radial swelling takes place preferentially inwards. Once the fuel is fully swollen at a given axial location the fuel behaves similarly to the solid cylindrical fuel at that location. Another feature of the annular fuel pins is that they do not contain in-pin sodium. Fuel melting during severe accidents can lead to in-pin molten fuel relocation inside the central hole of the pin prior to cladding failure. For modeling an annular fuel geometry, SAS4A's metallic fuel modeling routines have been upgraded. The pretransient characterization module SSCOMP-A, the transient fuel performance module DEFORM-5A and the pre-failure in-pin fuel relocation module PINACLE-M have been revised and improved to capture the differences in physical behavior between annular and solid cylindrical metallic fuels. The pre-failure in-pin molten fuel relocation in the pin hole is now modeled by the extended PINACLE-M module.

The new metallic fuel models of SAS4A [Tentner 2017] are included in the SSCOMP-A, DEFORM-5A, PINACLE-M and LEVITATE-M routines. SSCOMP-A [Tentner 2017, Karahan 2014] describes the metal fuel behavior during the pre-transient irradiation. The model captures essential physical phenomena taking place during normal operation. The main processes simulated are redistribution of fuel constituents, fuel swelling, porosity evolution, fission gas release, plenum pressurization, solid fission product swelling, radial and axial stresses, strains, and displacements for the fuel and cladding, formation of the fuel phases, lanthanide migration to the cladding and formation of brittle layer at the clad inner surface, iron migration to the fuel surface and formation of complex iron bearing layers, sodium infiltration into the fuel, burnupdependent formation of various nuclide groups and tracking of the corresponding reactivity feedback coefficients, and clad failure margin assessment. DEFORM-5A [Tentner 2017, Karahan 2014] simulates the metal fuel transient performance. The model is the extension of SSCOMP-A model, addressing transient-related issues such as eutectic formation between fuel and cladding, gas bubble behavior, creep of the soft fuel and cladding failure. PINACLE-M [Tentner 2017] is Eulerian, two-phase, transient hydrodynamic model describing the pre-failure in-pin relocation of the molten metal fuel. The LEVITATE-M model [Tentner 2017] describes the phenomena that occur in a metal fuel assembly after the occurrence of cladding failure and fuel ejection into the coolant channel. The LEVITATE-M module has not yet been extended to allow the modeling of annular fuel pins.

The report describes the simulation of the annular fuel pin behavior during severe accidents and shows example simulation results for postulated accidents in the ABTR plant using U-19Pu-10Zr annular fuel.

\subsection{Simulation of U-Pu-Zr annular fuel in ABTR reactor}

\subsubsection{Description of ABTR core}

Figure 3.1.1.1 shows the ABTR core layout, which is also described at Ref. [Chang 2006]. It is a homogeneous design with 199 assemblies - 54 driver assemblies, 78 reflector assemblies, 48 shield assemblies, 10 control rod assemblies, and 9 test assemblies. The rated reactor power is $250 \mathrm{MWt}$. Enrichment zoning strategy was chosen to flatten the power distribution, and two enrichment zones were used to simplify the refueling operation. The 54 driver assemblies are divided into two enrichment zones: the inner and outer cores composed of 24 and 30 driver 
assemblies, respectively. The fuel enrichments (i.e. TRU fractions) of inner and outer cores are $16.5 \mathrm{wt} \%$ and $20.7 \mathrm{wt} \%$, respectively.

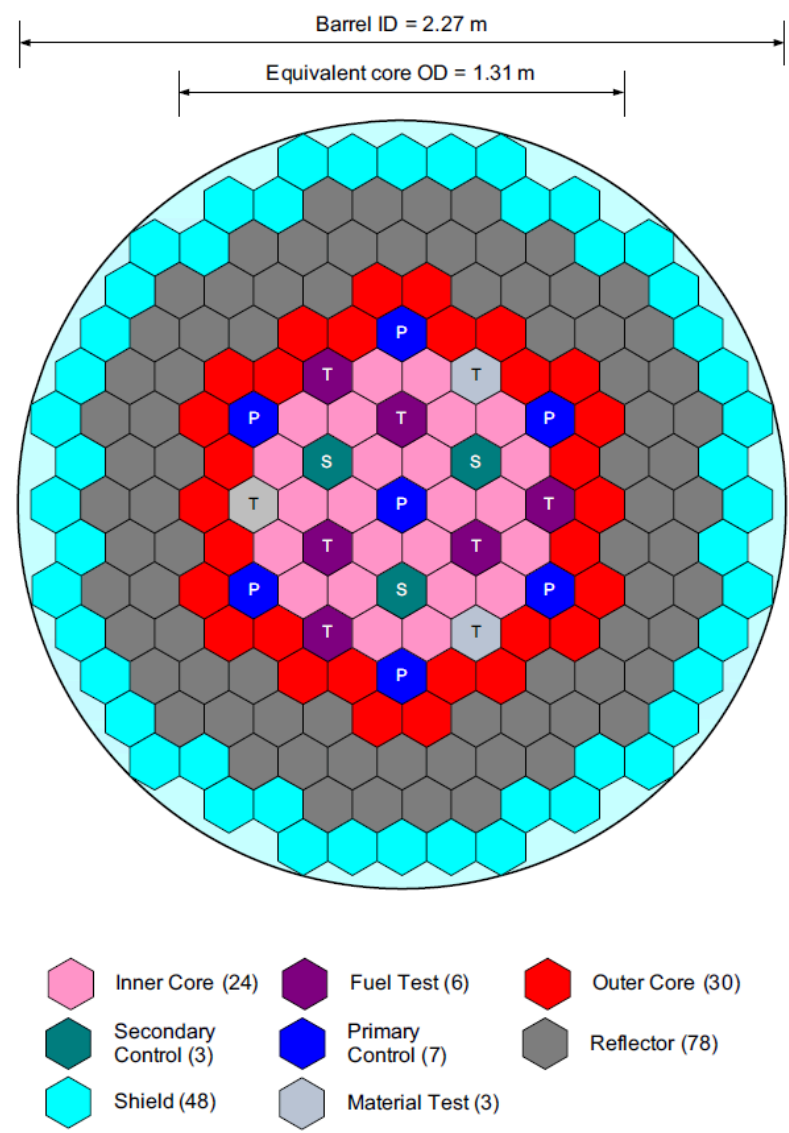

Figure 3.1.1.1 ABTR core layout

\subsubsection{ABTR fuel design}

The fuel assembly has an overall length of $328 \mathrm{~cm}$ and contains 217 fuel pins arranged in a triangular pitch array. The fuel pins are made of sealed cladding containing metallic fuel column of $80 \mathrm{~cm}$ length. Sodium is filled as the initial thermal bond between the fuel column and the cladding. The fuel pin diameter and cladding thickness are $8 \mathrm{~mm}$ and $0.52 \mathrm{~mm}$, respectively. The fuel smear density is $75 \%$. The fuel pin is helically wrapped with wire to maintain the pin spacing so that the coolant can flow freely through the pin bundle. The wire-wrap helical pitch is $20.32 \mathrm{~cm}$. A $120 \mathrm{~cm}$ long fission gas plenum is located above the fuel slug and sodium bond. The fuel assemblies are $14.198 \mathrm{~cm}$ across the outer hex flats and are position within the core at $14.598 \mathrm{~cm}$ triangular pitch spacing with $0.40 \mathrm{~cm}$ inter-assembly gap. The $80 \mathrm{~cm}$ high active core starts at $98 \mathrm{~cm}$ from the bottom of the assembly. Immediately below the core is a $60 \mathrm{~cm}$ shield region with the shield being an integral part of the fuel pin in the form of an extended fuel-pin bottom end cap. 


\subsubsection{Pre-transient Simulation}

Table 3.1.3.1 shows the operating conditions of the hot channel of ABTR core. Three annular fuel pins with low burnups were simulated using the SAS4A metal fuel models, including the new SSCOMP-A module which describes the metal fuel component radial relocation during irradiation. The burnup values studied were 0.15 atom $\%, 0.25$ atom $\%$, and 0.50 atom $\%$. The distribution of the fuel component mass fractions at the end of the irradiation for these three burnups is shown in Figures 3.1.3.1 through 3.1.3.3, respectively.

Table 3.1.3.1 Hot Channel Operating Conditions

\begin{tabular}{|l|l|}
\hline Parameter & Value \\
\hline Peak Linear Heat Rate $(\mathrm{kW} / \mathrm{m})$ & 35.2 \\
\hline Coolant Inlet Temperature $\left({ }^{\circ} \mathrm{C}\right)$ & 355 \\
\hline Coolant Exit Temperature $\left({ }^{\circ} \mathrm{C}\right)$ & 539 \\
\hline
\end{tabular}

\section{Fuel Mass Fractions for ABTR Fuel at 21 days, $B U=0.15 \%$}
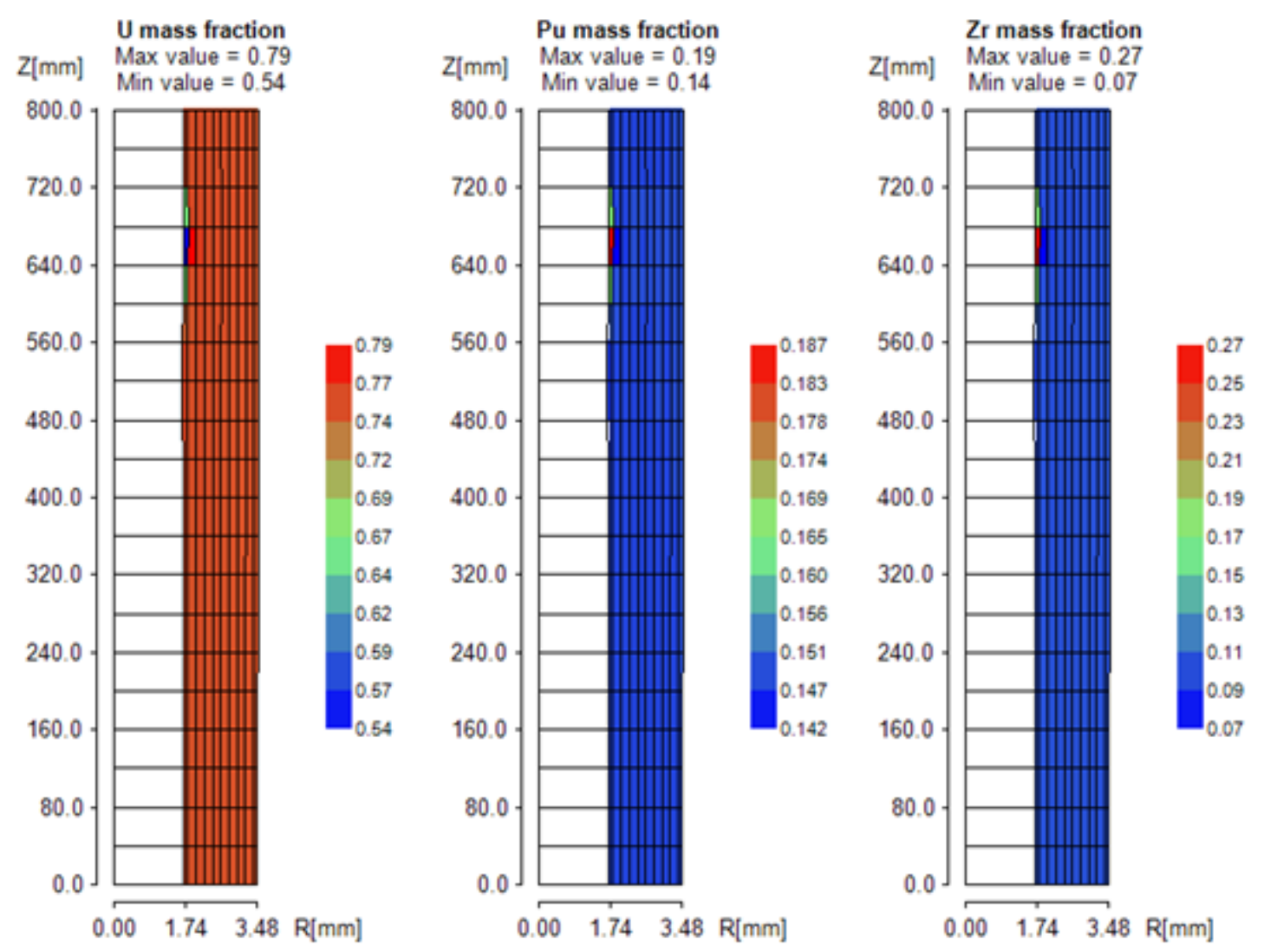

Figure 3.1.3.1 Fuel component distribution after 21 days of irradiation, burnup $\sim 0.15 \%$ 
Fuel Mass Fractions for ABTR Fuel at 35 days, $B U=0.25 \%$
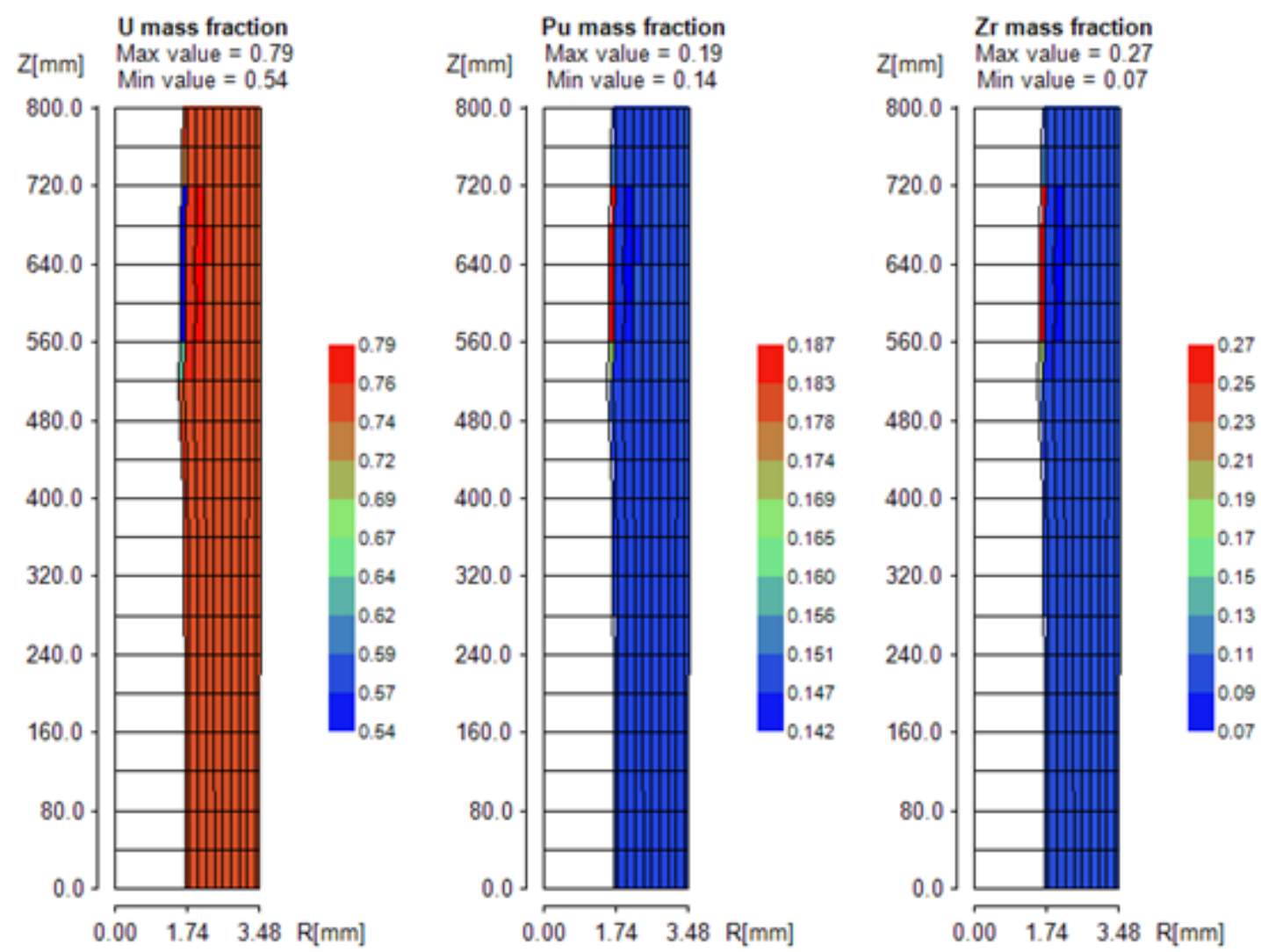

Figure 3.1.3.2 Fuel component distribution after 35 days of irradiation, burnup $\sim 0.25 \%$ 
Fuel Mass Fractions for ABTR Fuel at 69 days, $B U=0.50 \%$
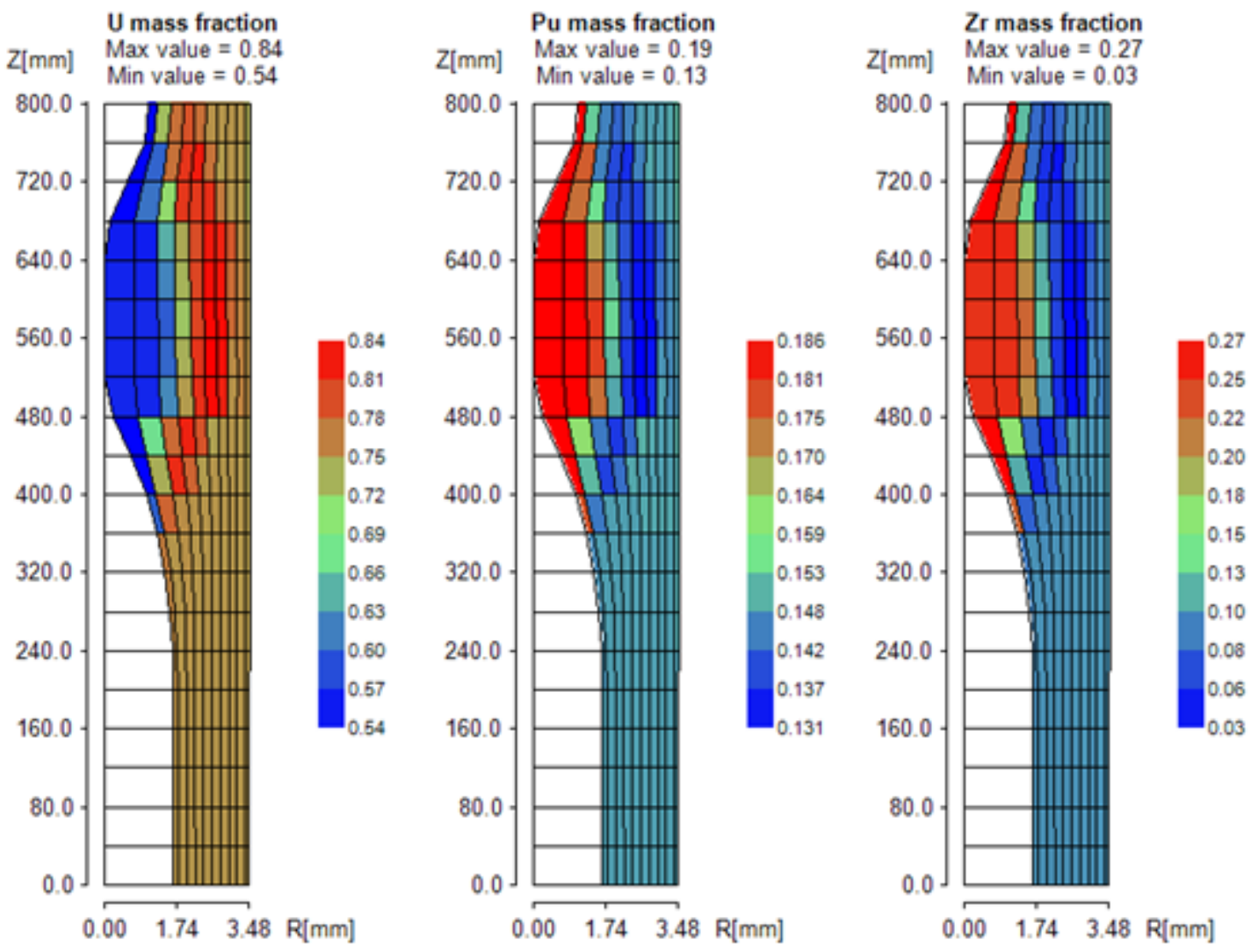

Figure 3.1.3.3 Fuel component distribution after 69 days of irradiation, burnup $\sim 0.50 \%$

For the lower burnup values $0.15 \%$ and $0.25 \%$ there is limited pin swelling and radial component migration as shown in Figures 3.1.3.1 and 3.1.3.2. At $0.50 \%$ burnup significant inward pin swelling is predicted as well as significant radial migration of the fuel components, illustrated in Figure 3.1.3.3. The inner pin hole is completely closed between $520-640 \mathrm{~mm}$ from the fuel pin bottom and an annular Zr-depleted region has formed, with a corresponding Zr-rich region formed at the inner boundary of the fuel pin.

The corresponding fuel temperatures at the end of the irradiation are shown in Figures 3.1.3.4 through 3.1.3.6. The distribution of the fuel melting temperature remains fairly uniform for the fuel pins with burnup $0.15 \%$ (Figure 3.1.3.4) and $0.25 \%$ (Figure 3.1.3.5) due to limited fuel component radial migration at these low irradiation levels. The migration of $\mathrm{Zr}$ towards the fuel inner boundary leads to a small region of fuel with a higher melting temperature for the $0.16 \%$ BU fuel pin (Figure 3.1.3.4), which increases axially but remains limited to a narrow radial layer near the fuel inner boundary for the $0.25 \%$ fuel pin (Figure 3.1.3.5). The fuel pin with $0.50 \%$ BU however exhibits a pronounced change in the distribution of the fuel melting temperature (Figure 3.1.3.6) corresponding to the significant radial migration of the fuel components shown in Figure 3.1.3.3. The lowest melting temperatures are located in the annular region with lower 
$\mathrm{Zr}$ content, while the higher fuel melting temperatures are located near the inner boundary of the annular fuel pin in the region with increased $\mathrm{Zr}$ content. The range of the calculated fuel melting temperatures is over $300 \mathrm{~K}$. The fuel margin-to-melting distribution is also shown in Figure 3.1.3.6. It shows a pattern similar to that observed in the fuel melting temperature distribution, indicating that the fuel melting during a postulated accident is likely to occur first in the annular fuel region with lower $\mathrm{Zr}$ content. The fuel melting temperature and margin-to-melt distribution determines the fuel melting and subsequent relocation patterns during postulated accidents as described in the following sections.

Fuel Temperatures for ABTR Fuel at 21 days, BU $=0.15 \%$
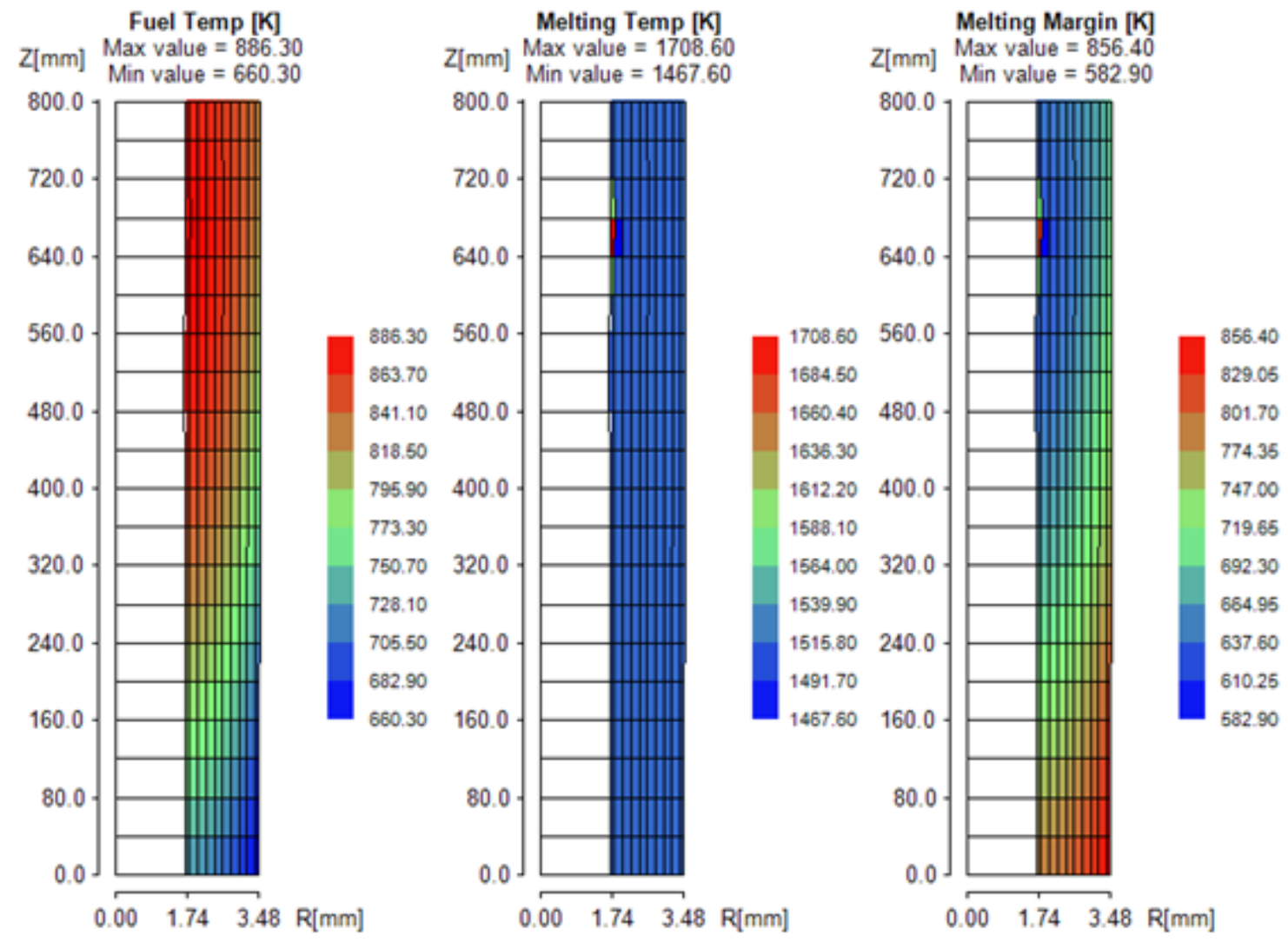

Figure 3.1.3.4 Fuel temperatures for ABTR fuel after 21 days of irradiation, burnup 0.15\% 
Fuel Temperatures for ABTR Fuel at 35 days, $B U=0.25 \%$
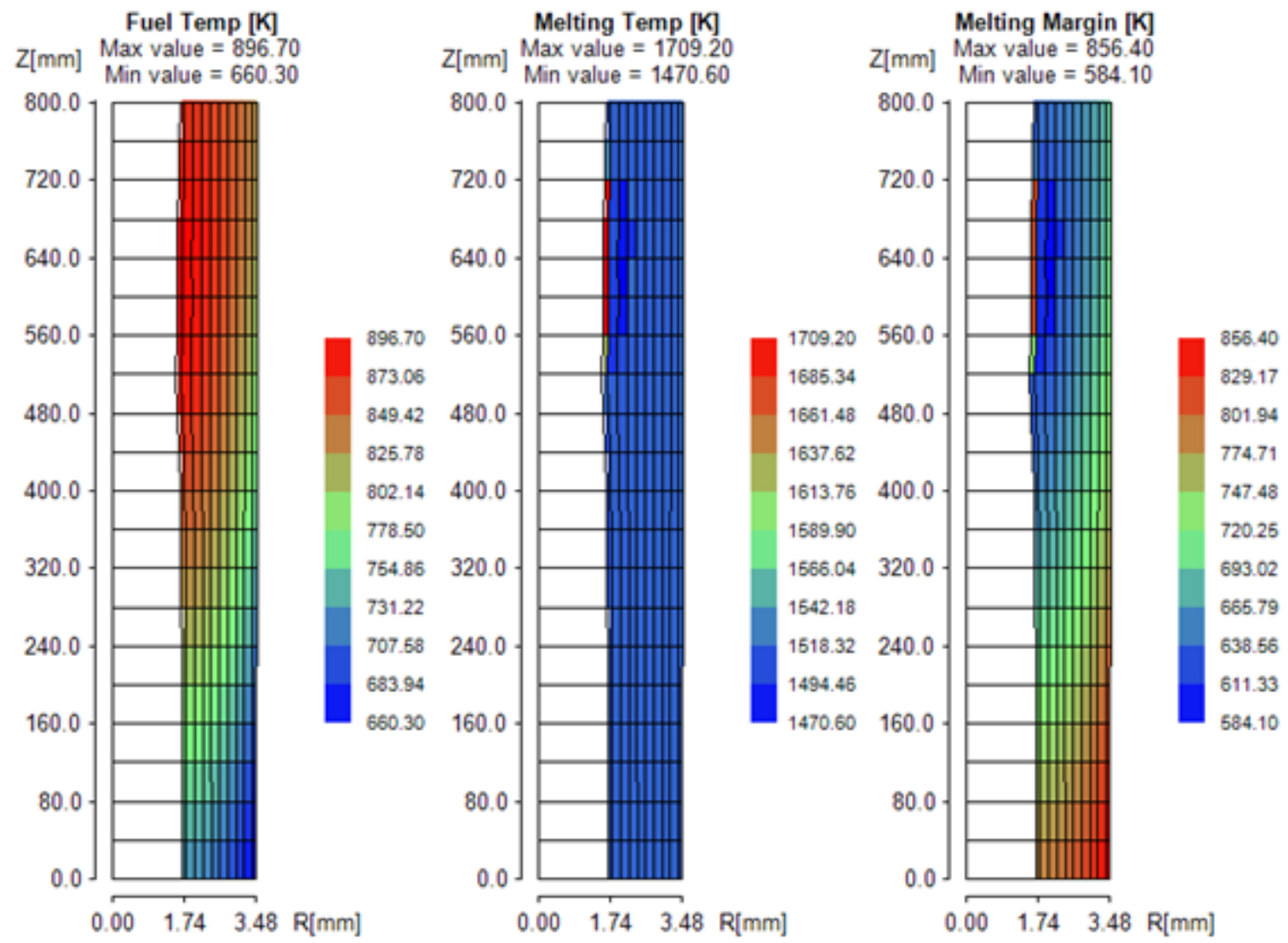

Figure 3.1.3.5 - Fuel temperatures for ABTR fuel after 35 days of irradiation, burnup $0.25 \%$ 
Fuel Temperatures for ABTR Fuel at 69 days, BU $=0.50 \%$
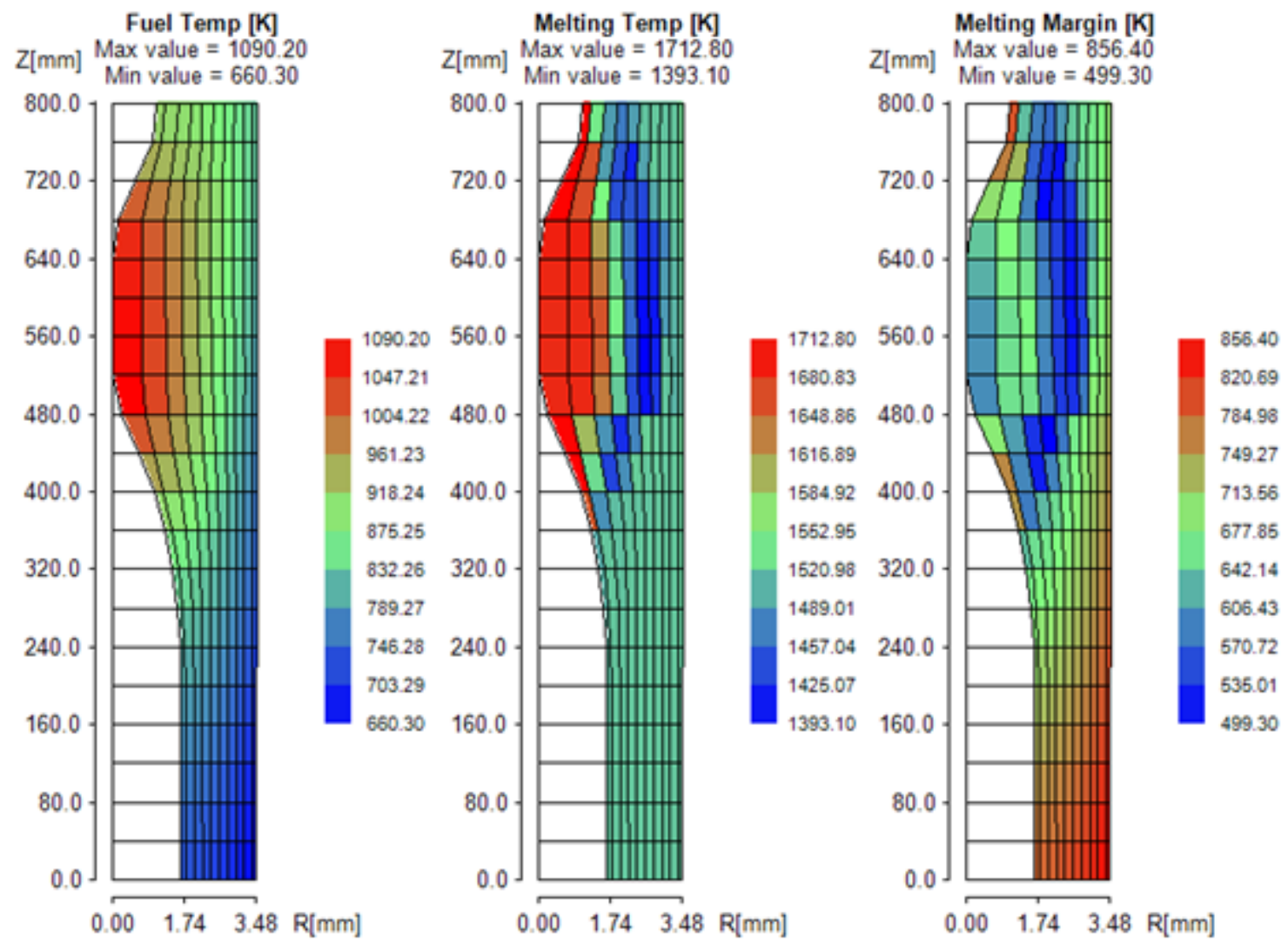

Figure 3.1.3.6 Fuel temperatures for ABTR fuel after 69 days of irradiation, burnup $0.50 \%$

\subsubsection{Predicted Molten Fuel Cavity Patterns for postulated unprotected LOF and LOF- TOP Accidents}

To evaluate the annular fuel melting patterns an Unprotected Loss of Flow (ULOF) transient scenario with degraded coolant pump torque was simulated with SAS4A. During the transient the coolant flow rate decreases to 0.5 of the nominal value after $1.38 \mathrm{~s}$ and to 0.1 of the nominal value after $6.3 \mathrm{~s}$. The rapid coolant flow rate coast-down leads to coolant boiling, dryout, rapid heat up of the fuel pin, extensive fuel melting and clad failure. A combined ULOF-TOP accident was also simulated. In this case, the ULOF conditions described above were combined with a reactivity ramp of $2 \mathrm{c} / \mathrm{s}$ leading to a maximum reactivity insertion of $60 \mathrm{c}$. In these simulations the relocation of the molten fuel in the central pin hole was not considered. Figures 3.1.4.1 and 3.1.4.2 illustrate the fuel conditions at the time of cladding failure for the ULOF and ULOF-TOP cases respectively when the fuel burnup is 0.15 at $\%$. In both cases the molten fuel region has reached the inner boundary of the annular fuel pin at the time of the predicted cladding failure, indicating that relocation of the molten fuel in the central pin hole would occur prior to cladding failure. 
SAS4A ABTR LOF BU $=0.15$ at $\%$ at $10.52 \mathrm{~s}$

Channel 5 Plenum Pressure $=3.55$ bar

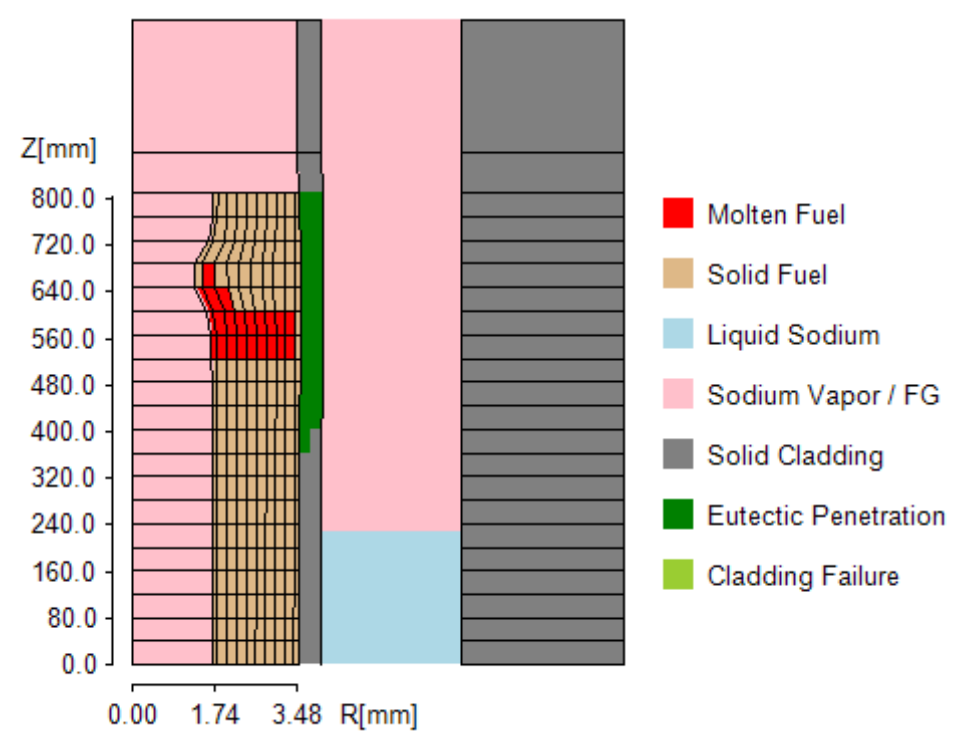

Figure 3.1.4.1 Fuel and Coolant Status in Channel $5(\mathrm{BU}=0.15 \%)$ at the time of cladding failure for the postulated ULOF accident 
SAS4A ABTR LOF BU $=0.15$ at $\%$ at $9.17 \mathrm{~s}$

Channel 5 Plenum Pressure $=3.50$ bar

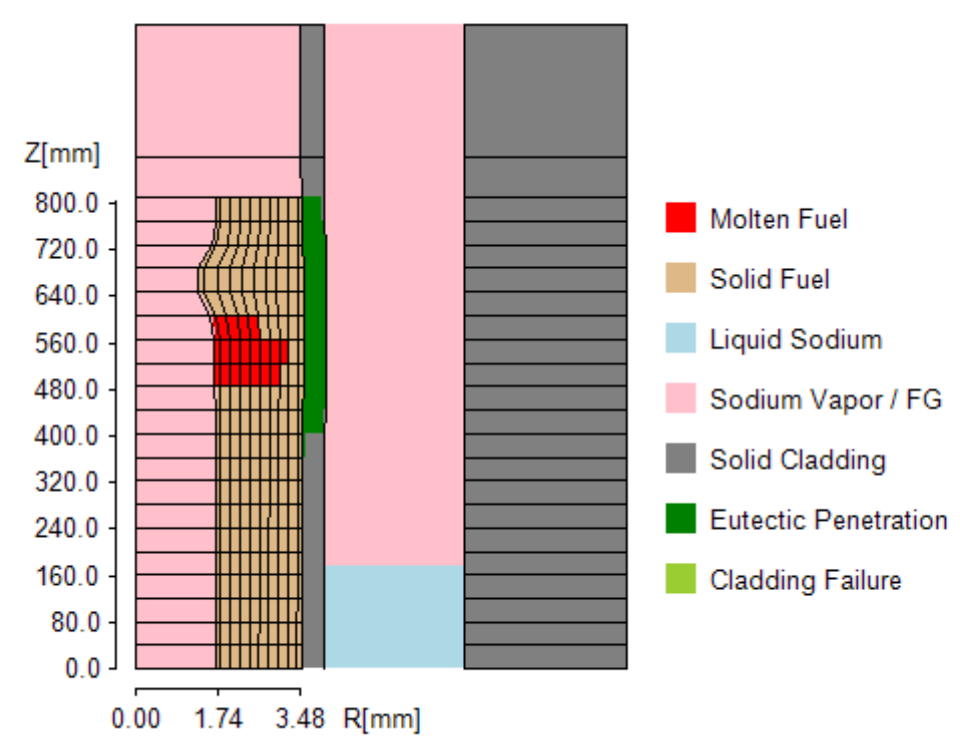

Figure 3.1.4.2 Fuel and Coolant Status in Channel $5(\mathrm{BU}=0.15 \%)$ at the time of cladding failure for the postulated ULOF-TOP accident with $2 \mathrm{c} / \mathrm{s}$ ramp

Figures 3.1.4.3 and 3.1.4.4 illustrate the fuel conditions at the time of cladding failure for the ULOF and ULOF-TOP cases respectively when the fuel burnup is $0.25 \mathrm{at} \%$. In both cases the molten fuel region has not reached the inner boundary of the annular fuel pin at the time of the predicted cladding failure, but is quite close this boundary. The relocation of the molten fuel in the central pin hole could still occur prior to cladding failure if a rupture of the thin remaining solid fuel is caused by the over-pressure of the molten fuel in the pin molten cavity. This type of failure of the inner fuel wall was not considered in the simulations presented in the next section but will be examined in future work. The difference in the molten fuel cavity location which has moved away from the inner fuel boundary for the 0.25 at $\%$ burnup fuel compared to the 0.15 at $\%$ burnup fuel is attributed to the continued radial migration of the metal fuel components. The radial migration of $\mathrm{Zr}$ towards the inner fuel boundary where the temperatures are higher leads to higher fuel melting temperatures near the inner fuel boundary and delays the melting of the inner fuel layer as seen in Figures 3.1.4.3 and 3.1.4.4. 
SAS4A ABTR LOF BU $=0.25$ at $\%$ at $10.54 \mathrm{~s}$

Channel 5 Plenum Pressure $=3.56$ bar

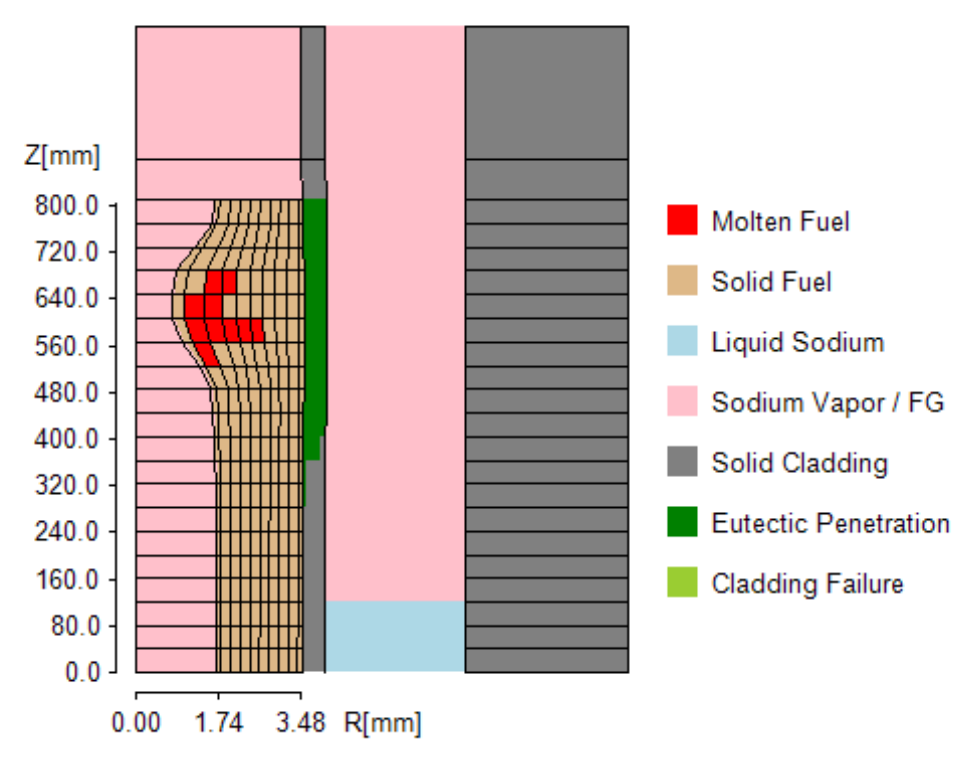

Figure 3.1.4.3 Fuel and Coolant Status in Channel 5 (BU 0.25\%) at the time of cladding failure for the postulated ULOF accident 
SAS4A ABTR LOF BU $=0.25$ at $\%$ at $9.19 \mathrm{~s}$

Channel 5 Plenum Pressure $=3.51$ bar

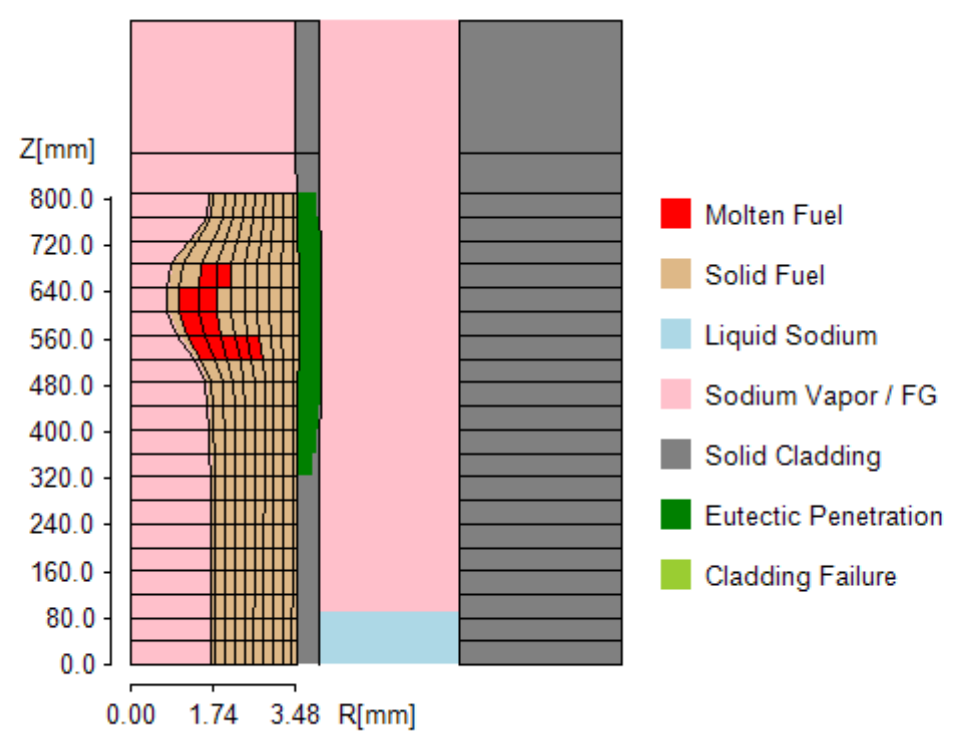

Figure 3.1.4.4 Fuel and Coolant Status in Channel 5 (BU 0.25\%) at the time of cladding failure for the postulated ULOF-TOP accident with $2 \mathrm{c} / \mathrm{s}$ ramp

Figures 3.1.4.5 and 3.1.4.6 illustrate the fuel conditions at the time of cladding failure for the ULOF and ULOF-TOP cases respectively when the fuel burnup is $0.50 \mathrm{at} \%$. In both cases the molten fuel region has moved decisively away from the inner boundary of the annular fuel pin at the time of the predicted cladding failure at higher elevations where higher fuel temperatures are present, but is approaching the inner fuel boundary towards the lower end of the molten cavity. For the ULOF-TOP case I particular the bottom end of the molten cavity is quite close to the inner fuel boundary. The ejection of the molten fuel in the pin cavity and relocation of the molten fuel in the central pin hole could still occur prior to cladding failure if a rupture of the thin remaining solid fuel at the lower end of the molten cavity is caused by the over-pressure of the molten fuel in the pin molten cavity. The difference in the molten fuel cavity location which has moved further away from the inner fuel boundary for the $0.50 \mathrm{at} \%$ burnup fuel compared to the $0.25 \mathrm{at} \%$ burnup fuel is attributed to the continued radial migration of the metal fuel components which is more pronounced in the axial fuel regions with higher temperatures.

The evaluation of the molten fuel cavity patterns presented in this section indicates that the inpin molten fuel relocation is most likely to occur in the case of very low burnup fuel, when the radial migration of the fuel components is limited and the molten fuel cavity tends to occur adjacent to the inner boundary of the annular fuel. Therefore we selected the 0.15 at $\%$ burnup annular fuel for the initial in-pin fuel relocation simulations presented in the next section. 
SAS4A ABTR LOF BU $=0.50$ at $\%$ at $10.63 \mathrm{~s}$

Channel 5 Plenum Pressure $=4.02$ bar

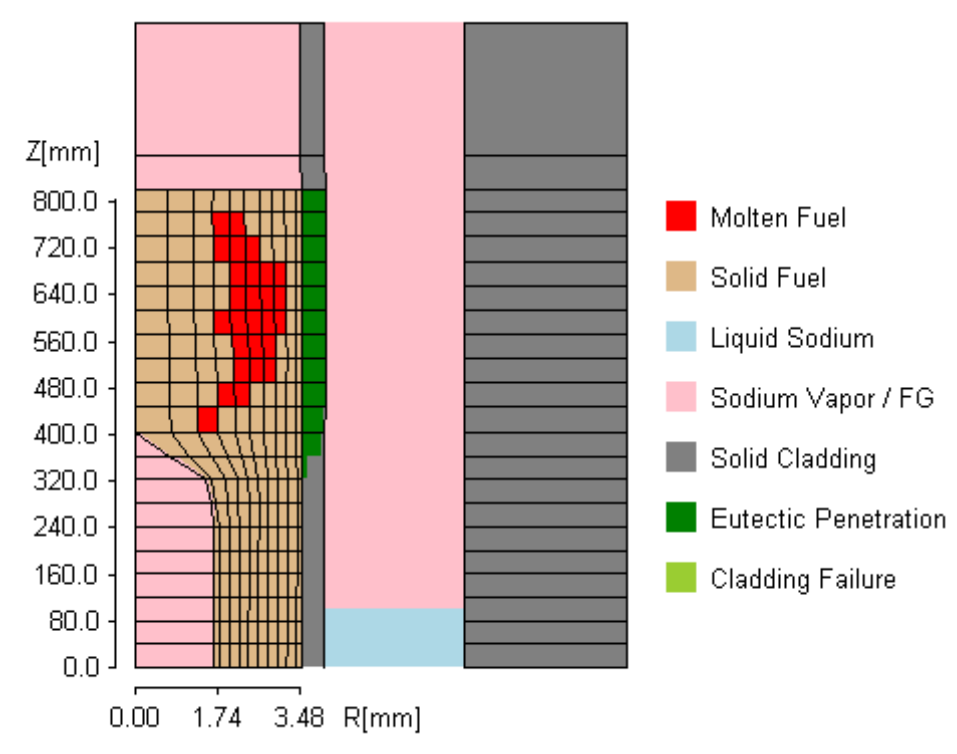

Figure 3.1.4.5 Fuel and Coolant Status in Channel $5(\mathrm{BU}=0.50 \%)$ at the time of cladding failure for the postulated ULOF accident 
SAS4A ABTR LOF BU $=0.50$ at $\%$ at $9.24 \mathrm{~s}$

Channel 5 Plenum Pressure $=3.96$ bar

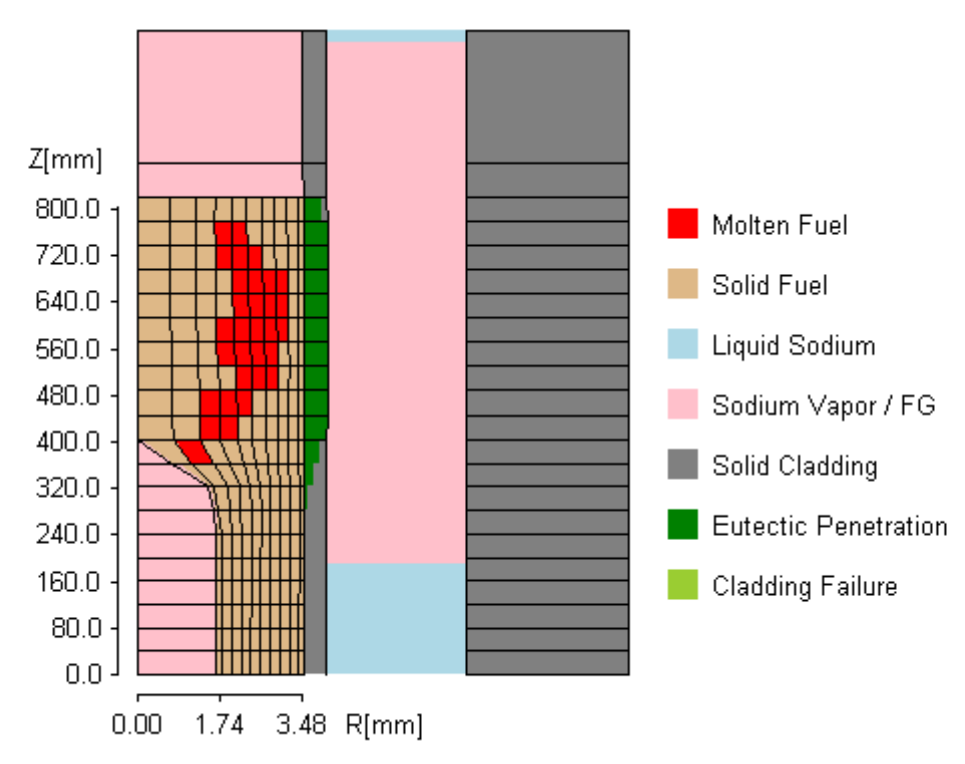

Figure 3.1.4.6 Fuel and Coolant Status in Channel $5(\mathrm{BU}=0.50 \%)$ at the time of cladding failure for the postulated ULOF-TOP accident with $2 \mathrm{c} / \mathrm{s}$ ramp

\subsubsection{Initial Simulations of In-Pin Molten Fuel Relocation for low burnup annular fuel pins}

Exploratory simulations of the fuel relocation in the pin hole were performed using the extended PINACLE-M models. A simulation of the ABTR LOF-TOP 0.15 at $\%$ BU case was run to 275 $\mathrm{ms}$ after the initiation of PINACLE-M. The initiation of LEVITATE-M due to cladding failure which occurs at $\sim 40 \mathrm{~ms}$ after the initiation PINACLE-M was suppressed in this case, in order to allow a longer time for the simulation of in-pin fuel relocation and evaluate the performance of the new annular-pin molten fuel relocation models. Mild fuel dispersal is observed initially ( $\sim 30$ $\mathrm{ms}$ ) due to the higher pressure in the molten fuel region of the pin hole compared to the pressure in the adjacent pin hole region that contain fission gas only. The conditions of the fuel pin at 43 $\mathrm{ms}$ after the initiation of PINACLE-M are illustrated in Figure 3.1.4.7.

The molten fuel region in the annular fuel pin extends axially from 486 to $608 \mathrm{~mm}$ from the fuel pin bottom. The inner wall rupture was determined at the initiation of the PINACLE-M to extend over the same length. As shown in Figure 3.1.4.7 a significant amount of molten fuel has been ejected into the pin hole after $43 \mathrm{~ms}$ and molten fuel can be seen both above and below the wall rupture region. The molten fuel in the pin hole is shown adjacent to the fission gas space in the figure in order to allow a better evaluation of the fuel volume fraction in the pin hole. However, in the current version of PINACLE-M the fission only a bubbly fuel flow regime is available, which assumes a mixture of molten fuel and fission gas bubbles. As the pin-hole diameter is relatively large and the volume fraction of the ejected molten fuel decreases due to fuel dispersal 
there is a need to implement in future work an annular fuel flow regime in order to more accurately describe the in-pin molten fuel relocation.

\section{SAS4A ABTR LOF BU $=0.15$ at $\%$ at $9.20 \mathrm{~s}$ (time_pnc $=0.043 \mathrm{~s}$ ) \\ Channel 5 Plenum Pressure $=\mathbf{3 . 5 0}$ bar}

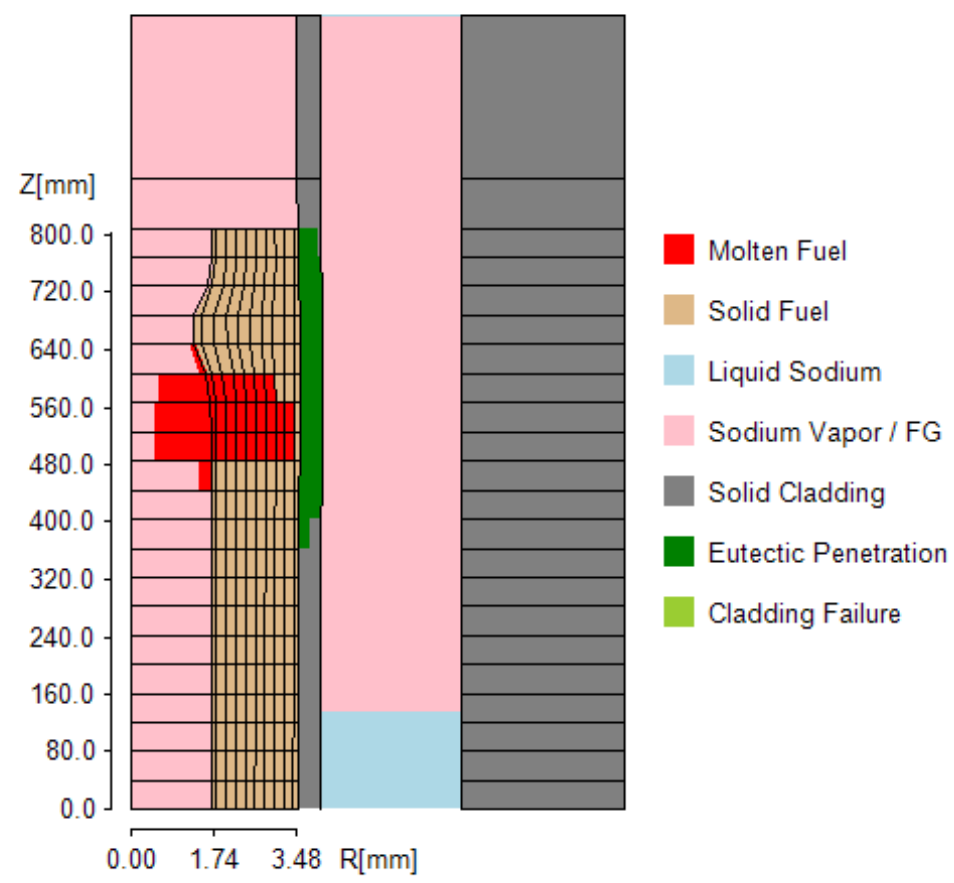

Figure 3.1.4.7 Fuel and Coolant Status in Channel $5(\mathrm{BU}=0.15 \%)$ at $43 \mathrm{~ms}$ after the initiation of PINACLE-M for the postulated ULOF-TOP accident with $2 \mathrm{c} / \mathrm{s}$ ramp

The pressures in the molten fuel region of the pin hole and rest of the pin hole equilibrate quickly and the molten fuel in the pin hole is draining downwards due to gravity with average velocities between $0.005-0.01 \mathrm{~m} / \mathrm{s}$. Fuel freezing on the inner fuel surface is not yet considered in these calculations. As shown in Figure 3.1.4.8 at $153 \mathrm{~ms}$ after the initiation of PINACLE-M the molten fuel in the pin-hole that was above the inner wall rupture at $43 \mathrm{~ms}$ has now disappeared and the amount of molten fuel in the cell below the inner wall rupture has increased due fuel downward relocation. The axial extent of the molten fuel cavity in the fuel pin has also increased. It is noted that the axial extension of the inner wall rupture is not yet implemented and thus is not considered in this initial calculation. 
SAS4A ABTR LOF BU $=0.15$ at $\%$ at $9.31 \mathrm{~s}$ (time_pnc $=0.153 \mathrm{~s}$ )

Channel 5 Plenum Pressure $=3.51$ bar

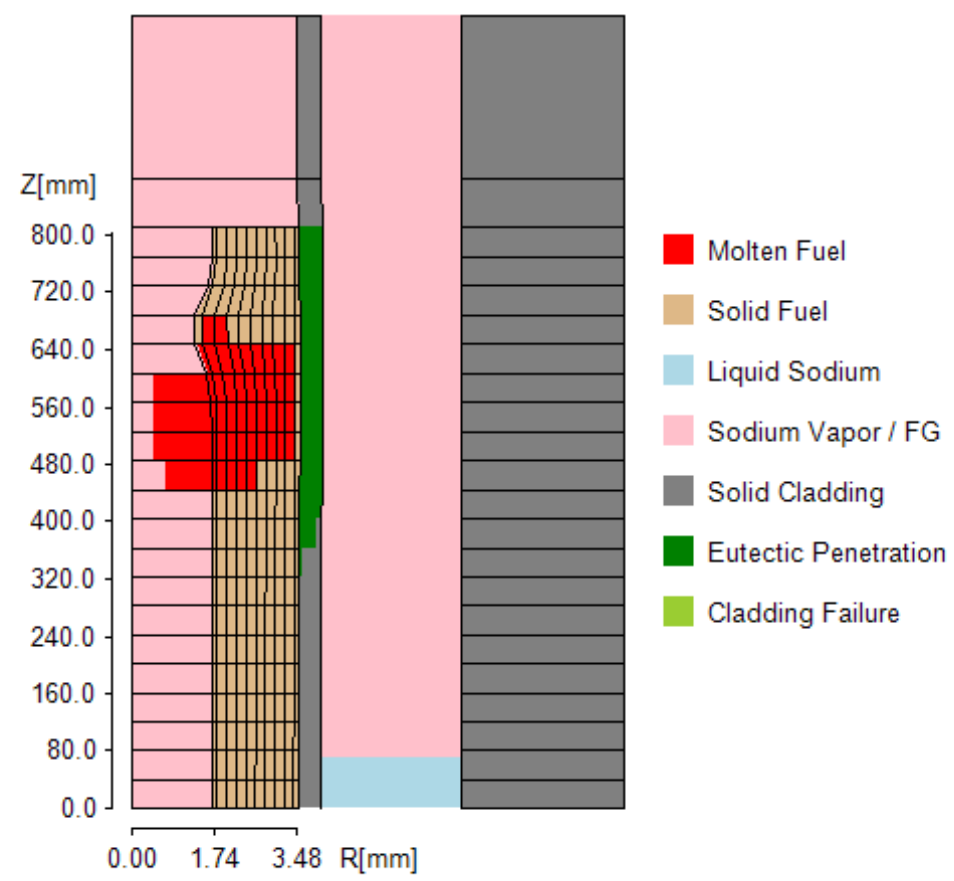

Figure 3.1.4.8 Fuel and Coolant Status in Channel $5(\mathrm{BU}=0.15 \%)$ at $153 \mathrm{~ms}$ after the initiation of PINACLE-M for the postulated ULOF-TOP accident with $2 \mathrm{c} / \mathrm{s} \mathrm{ramp}$

The conditions of the fuel pin at $203 \mathrm{~ms}$ after PINACLE-M initiation are shown in Figure 3.1.4.9. The molten fuel in the pin-hole has moved further downward and the extent of the molten fuel region inside the annular fuel pin has also increased both axially and radially.

The conditions of the fuel pin at $273 \mathrm{~ms}$ after PINACLE-M initiation are shown in Figure 3.1.4.10. The molten fuel in the pin-hole has moved even further downward the core centerline at $404 \mathrm{~mm}$. The velocity of the molten fuel in the lowest pin-hole cell, just above the core centerline, is $-0.34 \mathrm{~m} / \mathrm{s}$. Because the molten fuel region is located above the core centerline and molten fuel in the pin hole is moving downward in this simulation the initial reactivity effect would be to add a limited amount of positive reactivity. The reactivity addition due to the in-pin fuel relocation would begin to decrease and turn negative as the molten fuel moves below the core centerline if the downward fuel relocation continues. It is noted that the coupling of the inpin fuel relocation with the reactivity feedback calculation has not yet been implemented and is planned for future work. The extent of the molten fuel region inside the annular fuel pin has also increased both axially and radially compared to Figure 3.1.4.9. 
SAS4A ABTR LOF BU $=0.15$ at $\%$ at $9.36 \mathrm{~s}$ (time_pnc $=0.203 \mathrm{~s}$ )

Channel 5 Plenum Pressure $=3.51$ bar

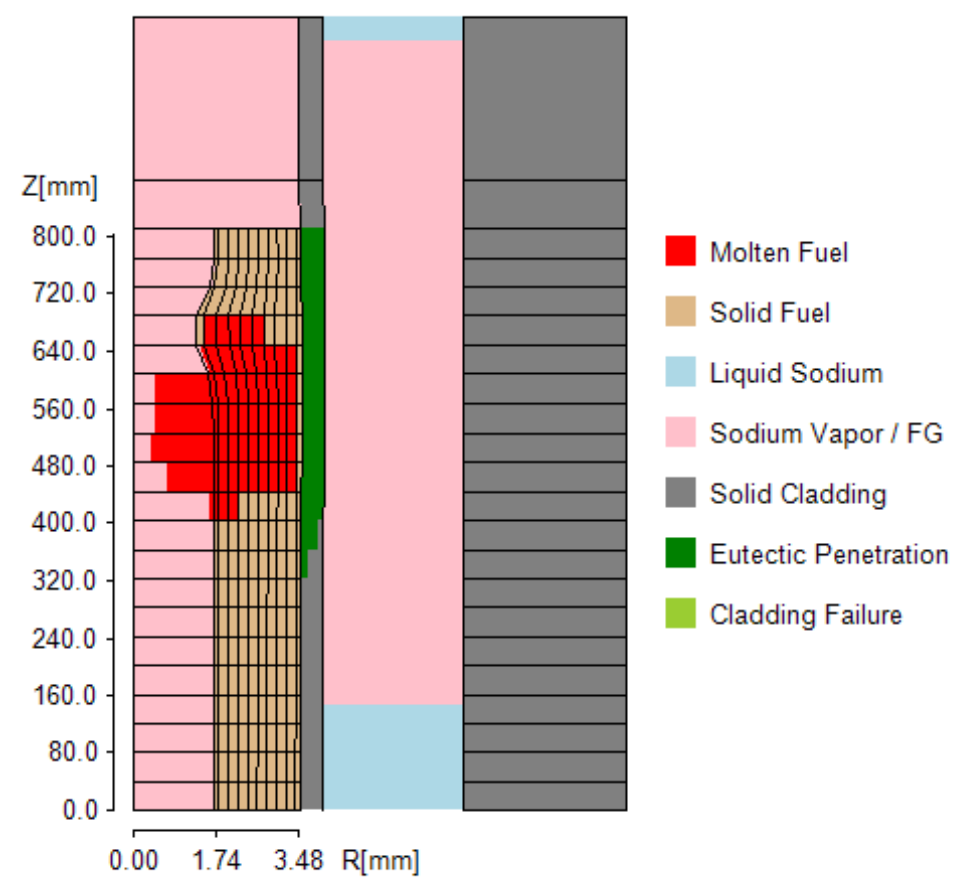

Figure 3.1.4.9 Fuel and Coolant Status in Channel $5(\mathrm{BU}=\mathbf{0 . 1 5 \%})$ at $203 \mathrm{~ms}$ after the initiation of PINACLE-M for the postulated ULOF-TOP accident with $2 \mathrm{c} / \mathrm{s}$ ramp 
SAS4A ABTR LOF BU $=0.15$ at $\%$ at $9.43 \mathrm{~s}$ (time_pnc $=0.273 \mathrm{~s}$ )

Channel 5 Plenum Pressure $=\mathbf{3} .52$ bar

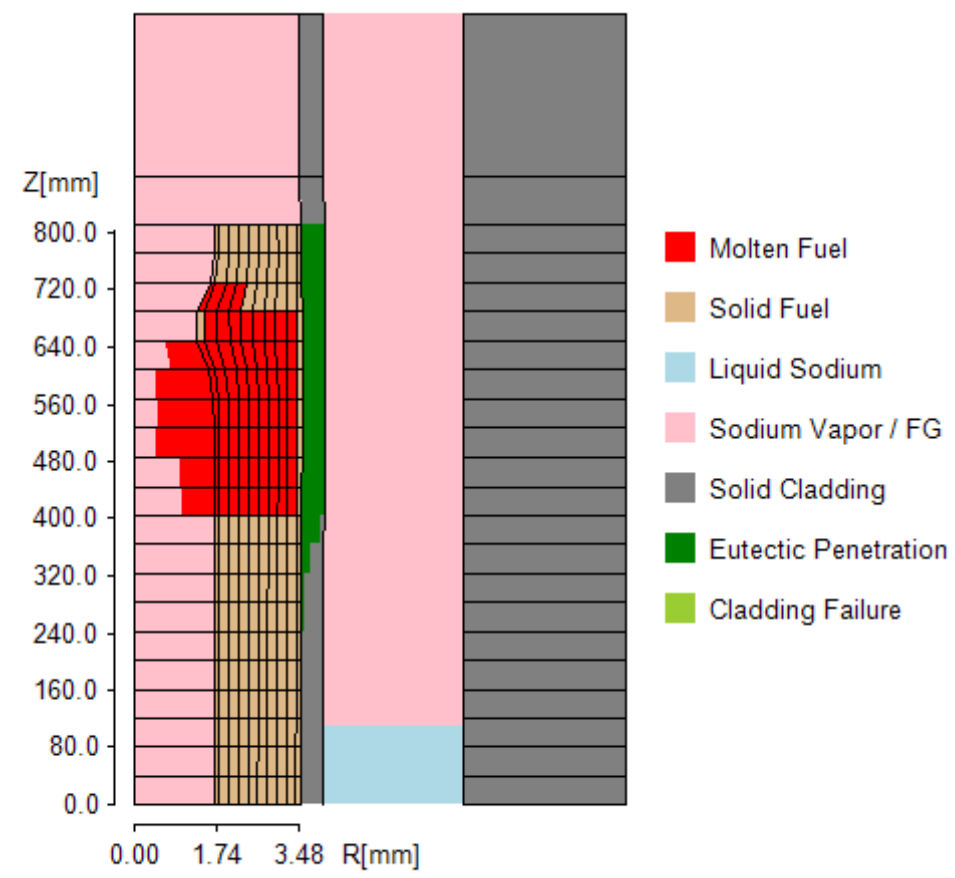

Figure 3.1.4.10 Fuel and Coolant Status in Channel $5(\mathrm{BU}=0.15 \%)$ at $273 \mathrm{~ms}$ after the initiation of PINACLE-M for the postulated ULOF-TOP accident with $2 \mathrm{c} / \mathrm{s} \mathrm{ramp}$ 


\section{Feasibility of Closed Fuel Cycle using Melt-Refining}

For recovering actinides from a used metallic fuel, melt-refining is an economically attractive with simple process, but as a trade-off, it loses a relatively large fraction (5-10\%) of actinides per process and cannot separate fission products completely from actinides. Thus, the objective of this work is to test the feasibility of a sustainable closed fuel cycle in a fast reactor utilizing the melt refining process and to obtain technical information (in particular, mass flow data). For this purpose, the melt-refining process was briefly reviewed and a wide-range of fast reactor core design study was performed to achieve a closed fuel cycle by recycling the materials recovered from the metal refining.

\subsection{Melt-refining process}

The melt-refining technology was developed to implement an economic recycling of used nuclear fuels in fast reactors [Stevenson 1987], and its recycling concept was demonstrated in the Experimental Breeder Reactor II (EBR-II) and Fuel Cycle Facility. EBR-II was a $62.5 \mathrm{MWt}$ sodium-cooled fast reactor and Fuel Cycle Facility was a plant for reprocessing the fuels discharged from the reactor. Figure 4.1.1 shows the schematic diagram of the fuel cycle demonstrated, which includes disassembling and de-cladding of the discharged fuels, decontaminating and mixing with fresh fuel if needed, re-fabrication, reassembling, and irradiation in the EBR-II.

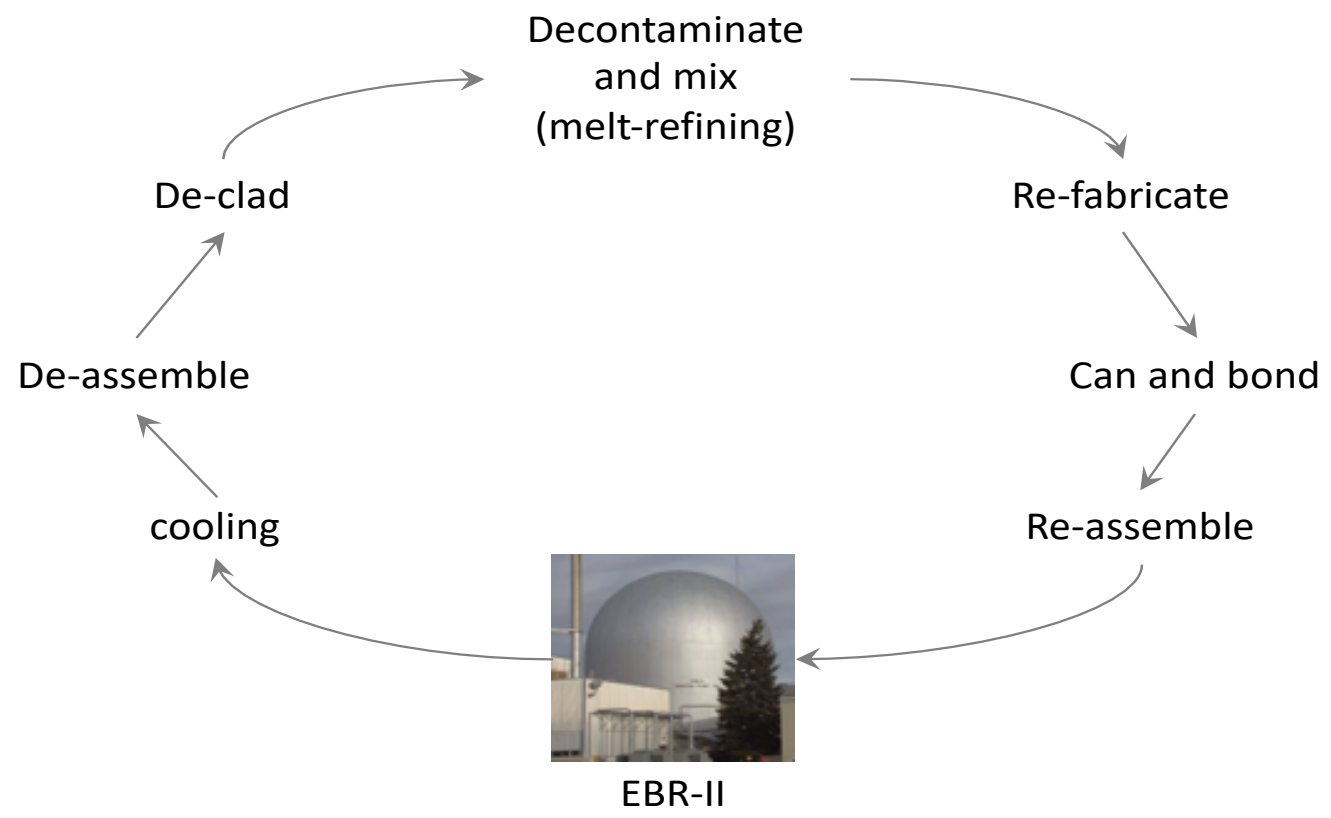

Figure 4.1.1 Schematic Diagram of EBR-II Fuel Cycle based on Melt-Refining

Melt refining is a recycle process where the metallic fuel is melted in a furnace. The meltrefining furnace consists of crucible, fume trap, mold and mold holder, and heating device. In the melt-refining process, the de-cladded metallic fuels are charged into the crucible and liquated at high temperature $\left(1300-1400{ }^{\circ} \mathrm{C}\right)$. Depending on the behaviors during the fuel melt, fission products are divided into three groups: volatile and gaseous elements $(\mathrm{Br}, \mathrm{Kr}, \mathrm{Rb}, \mathrm{Cd}, \mathrm{I}, \mathrm{Xe}$, and 
$\mathrm{Cs})$, reactive elements ( $\mathrm{Sr}, \mathrm{Y}, \mathrm{Te}, \mathrm{Ba}$, and $\mathrm{RE})$ and noble metal elements $(\mathrm{Zr}$., $\mathrm{Nb}, \mathrm{Mo}, \mathrm{Tc}, \mathrm{Ru}$, et al.). The volatile and gaseous elements are removed by volatilization during fuel melting process, and the reactive elements remain at the crucible surface by oxidation with zirconia, while noble elements are not separated from the melted fuel.

Figure 4.1.2 shows the distribution of elements during the melt-refining process. It is noted that about $5-10 \%$ of noble fission products and melted actinides remain as skull in the crucible. As a result, the product ingot contains about $90-95 \%$ actinides and noble fission products, and those are refabricated and reloaded into the reactor. The skull materials are removed through a separate skull oxidation process: i.e., after oxidation in a separate oxidation furnace, the skull oxide can be poured from the crucible into a suitable container for storage. In order to minimize the material loss, additional process of skull has been proposed, which would greatly reduce the losses but increase the cost of the system. This $90-95 \%$ pour recovery was for low burnup fuel (1-2\%FIMA). Higher burnup fuel (6\%FIMA) was shown to have lower pour recovery and the high burnup fuel (10\%FIMA) was not studied. It was assumed that through design or other controls that losses of high burnup fuels could be achieved for an improved melt refine process.

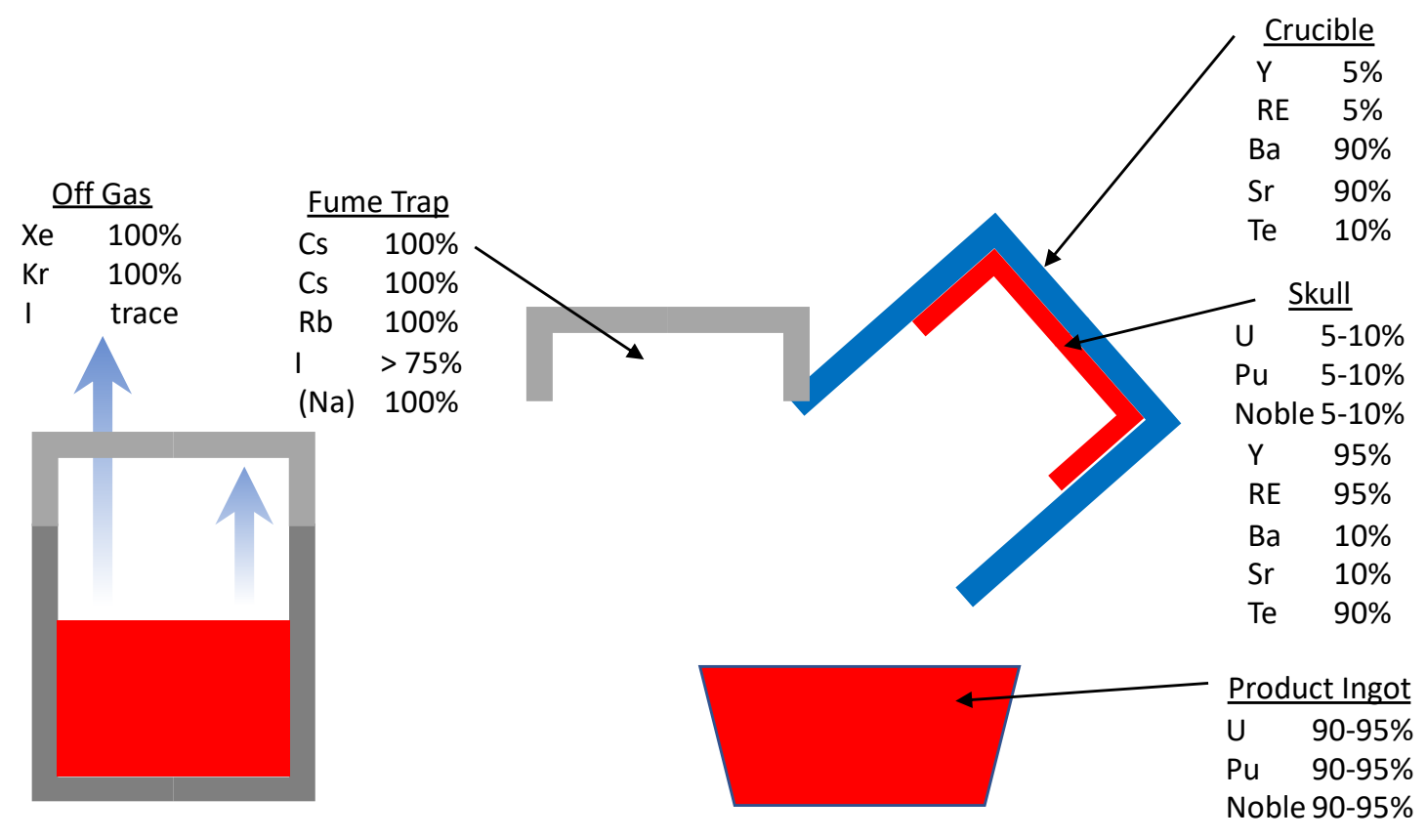

Figure 4.1.2. Distribution of elements in the melt-refining process

\subsection{Closed Fuel Cycle Concept with Melt-Refining}

Figure 4.2.1 shows a material flow diagram of used nuclear fuel recycling concept utilizing the melt-refining process. For comparison, a material flow diagram of a close fuel cycle utilizing a high performing reprocessing technology (for instance, electrochemical pyro-processing or PUREX) is provided in Figure 4.2.2. The major differences between two fuel cycle concepts are the recovered material quality and actinide loss rate per process. Recovered material from the metal refining process is a mixture of $U$, TRU, and noble fission products and about $5-10 \%$ of actinides are not recovered per process. Thus, in order to make a sustainable fuel cycle using the recovered materials from the melt-refining process, fast reactor has to breed extra fissile 
materials to compensate parasitic neutron absorptions by fission products and actinides loss per process.

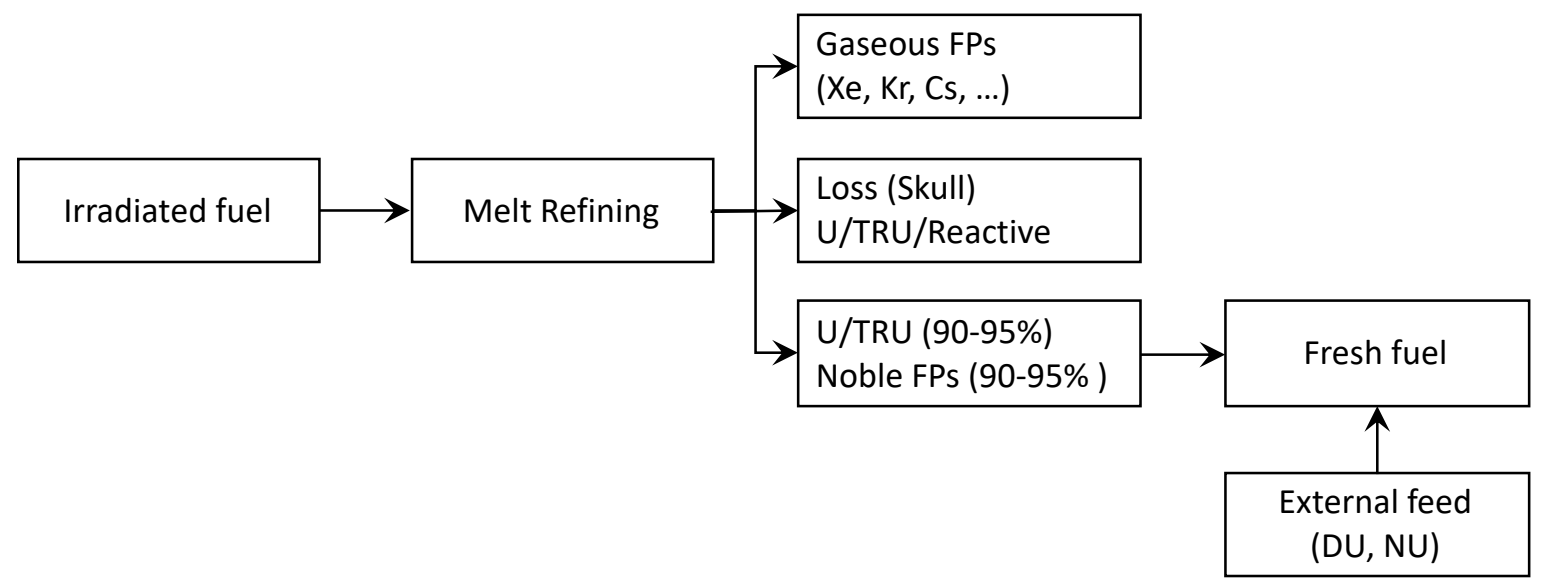

Figure 4.2.1 Mass flow of used fuel recycling concept based on melt-refining process

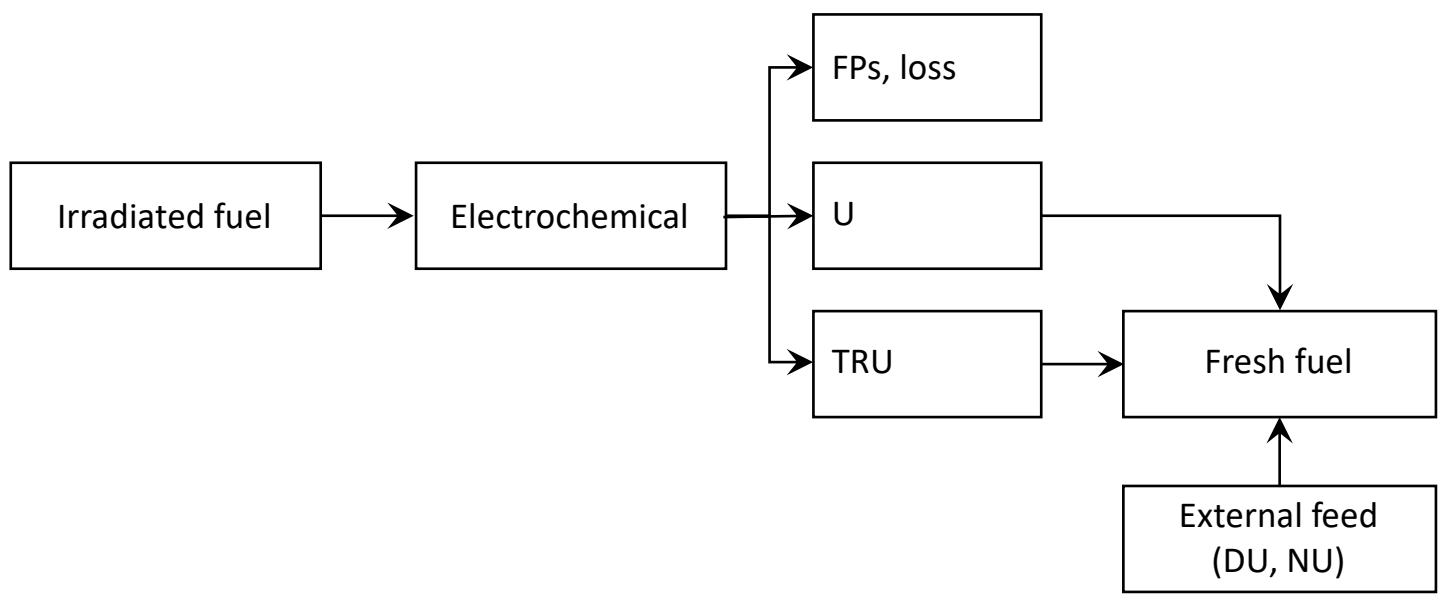

Figure 4.2.2 Mass flow of used fuel recycling concept based on high-performing reprocessing technology

In this work, the feasibility of the sustainable fuel cycle utilizing the melt refining process was tested using the breeder reactor concept developed in the International Nuclear Fuel Cycle Evaluation (INFCE) study [Till 1980]. Figure 4.2.3 shows the core configuration, which is $2750 \mathrm{MWth} / 1000 \mathrm{MWe}$ core with 264 driver fuels and 204 radial blankets. The driver fuel pin consists of lower axial blanket, active fuel, and upper axial blanket from the bottom. Thanks to the radial and axial blankets, the core has a high breeding ratio ( $>1.4)$. The cycle length was 274 effective full power days, and the driver fuels reside in the core for 2 cycles based on two-batch fuel management scheme, while blankets reside core for 5 cycles to breed Pu sufficiently. The detailed design parameters are provided in Ref. [Till 1980]. 


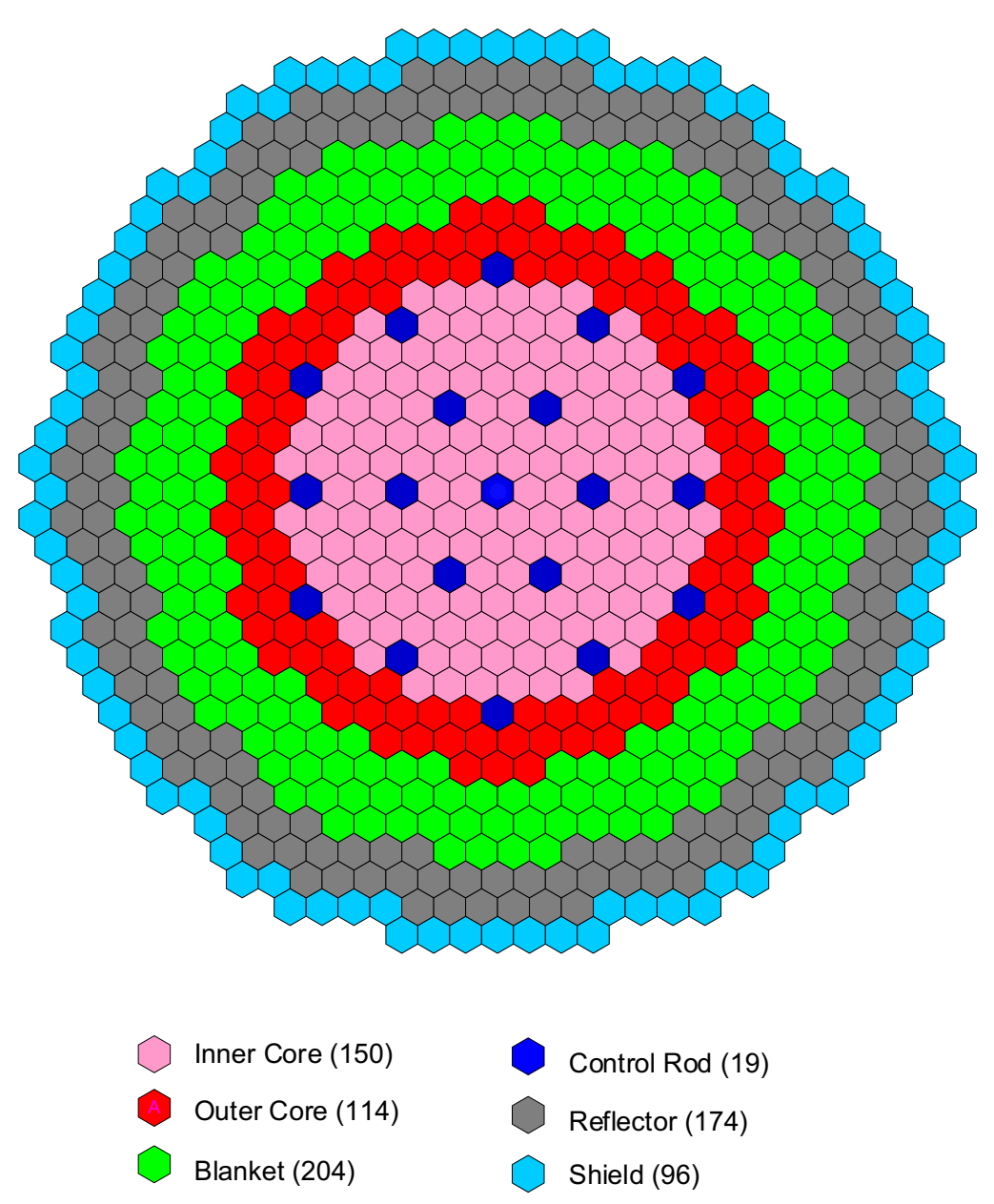

Figure 4.2.3 Breeder core configuration

Table 4.2.1 shows the primary core performance data that made a closed fuel cycle with the melt-refining and high-performing reprocessing technologies. In Table 4.2.1, the reference fuel cycle indicates the closed fuel cycle concept utilizing a high-performing reprocessing technology, which was assumed that $100 \%$ of actinides are recovered and $100 \%$ FPs are not separated from the actinides. However, in the fuel cycle concepts utilizing the melt-refining process, the recovery fractions of actinides and fission products were varied. In the INFCE study, two batch fuel management scheme (i.e., half driver fuels were replaced by fresh fuels per cycle) was adopted, but four batch fuel management scheme was preferred in this work for consistent comparison with targeting discharge burnup of $\sim 100 \mathrm{GWd} / \mathrm{t}$.

For the closed fuel cycle concept utilizing a high performing reprocessing technology, the achieved plutonium breeding ratio is 1.40 with $10.6 \%$ Pu content driver fuel. For the fuel cycle concepts utilizing the melt-refining, the breeding ratio is dependent on the recovery fractions of and actinides. For complete removal of fission products (which is unrealistic in the melt-refining 
process), the required $\mathrm{Pu}$ content and achieved breeding ratio are comparable to the reference fuel cycle even though 5\% of actinides are not recovered. However, for the case of 55\% fraction of fission products is recycled along with actinides, the achieved breeding ratio decreases to 1.24 and $\mathrm{Pu}$ content in driver fuel increases to $13.2 \%$. If the fraction of fission products increases to $65 \%$ (highlighted in yellow in Table 4.2.1), the core cannot make a sustainable fuel cycle because of high neutron absorption penalty by fission products. Similarly, if the actinides loss rate increases to $10 \%$, the core cannot make a sustainable fuel cycle because of insufficient fissile materials in the core.

Table 4.2.1 Comparison of fuel cycle performance utilizing melt-refining and highperforming reprocessing

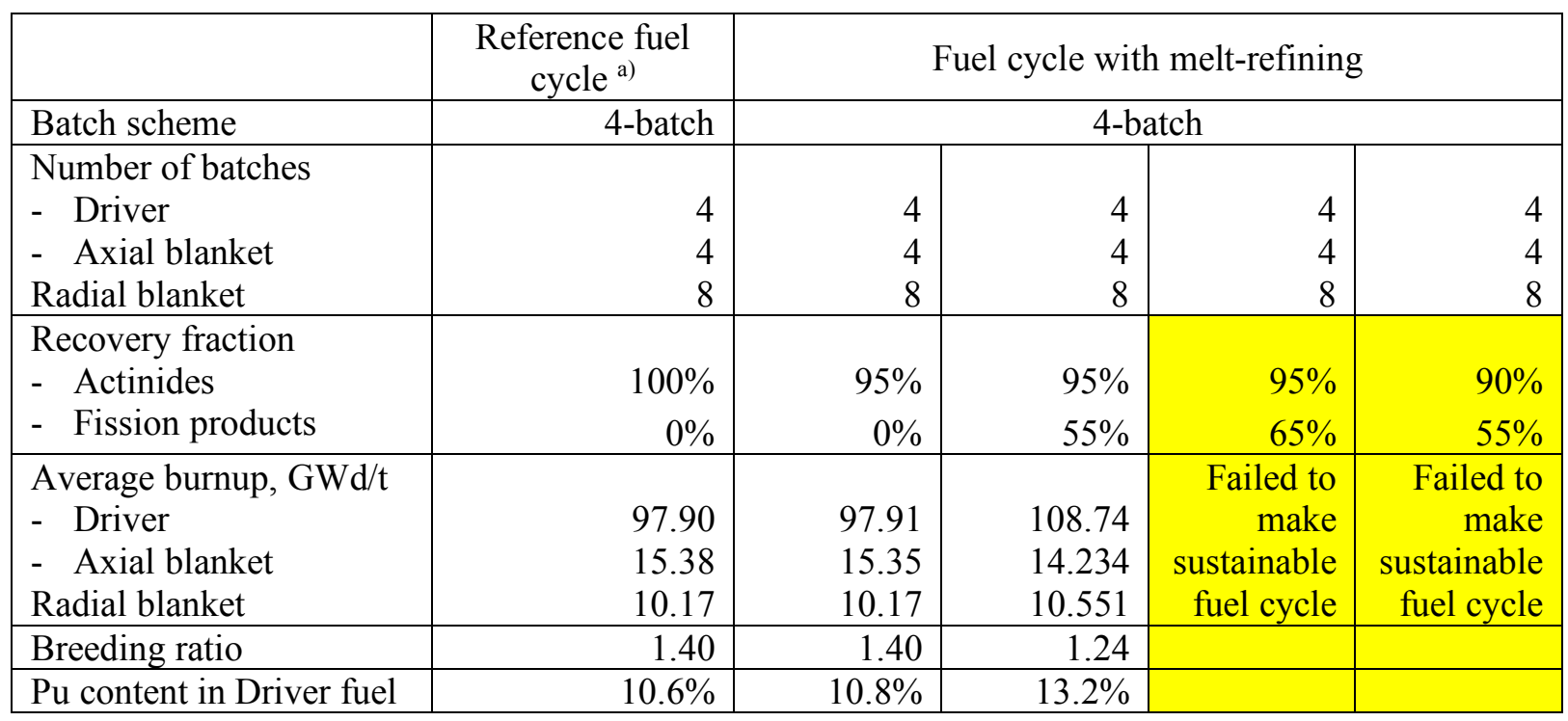

a) Reference fuel cycle informs that the used nuclear fuel is reprocessed by high-performing reprocessing technologies.

The sensitivity study informs that the fission products fraction in the recovered materials and the actinides loss rate are critical factors to achieve a sustainable closed fuel cycle utilizing the meltrefining process. The fission products fraction in the recovered materials and actinides loss rate are dependent on various factors that are adopted in the melt-refining process, and determination of the correct values is out of this work scope. However, through additional sensitivity analyses, the required values on fission products fraction in the recovered materials and actinides loss rate are determined: i.e., in order to achieve a sustainable closed fuel cycle, the fission products fraction in the recovered materials and actinides loss rate should be less than $60 \%$ and $7 \%$, respectively.

Additional penalties of the closed fuel cycle utilizing the melt-refining process are expected in fuel fabrication with fission products and nuclear waste management with large high-level waste (HLW) production. Since the U, Pu (or TUR), and fission products are recovered separately from a high-performing reprocessing technology, a sustainable closed fuel cycle is possible with a break-even fast reactor (i.e., TRU breeding and burning ratios are comparable). However, a breeder reactor is required to achieve a sustainable closed fuel cycle utilizing the melt-refining process, which produces additional high-level wastes. 
Table 4.2.2 shows the annual mass flow data per unit electricity generation (i.e., gram/year/MWe). The mass data for a closed fuel cycle based on break-even core and highperforming reprocessing were obtained from a $250 \mathrm{MWe}$ break-even core concept developed under the GNEP program [Kim 2009], and the mass data for a closed fuel cycle based on meltrefining were obtained from the 4-batch core with $95 \%$ actinide and 55\% FP recycling case in Table 4.2.1.

Table 4.2.2 Mass flow data comparison for closed fuel cycles concepts based on highperforming reprocessing and melt-refining process

\begin{tabular}{|c|c|c|c|c|c|c|}
\hline & \multicolumn{3}{|c|}{$\begin{array}{l}\text { Closed fuel cycle based on break-even } \\
\text { core and high-performing reprocessing }\end{array}$} & \multicolumn{3}{|c|}{$\begin{array}{l}\text { Closed fuel cycle based on breeder core } \\
\text { and melt-refining process }\end{array}$} \\
\hline & $\mathrm{U}$ & TRU & FP & $\mathrm{U}$ & TRU & FP \\
\hline Charge & 16803.8 & 2374.8 & 0.0 & 15019.0 & 1083.0 & 793.6 \\
\hline Discharge & 15365.2 & 2466.1 & 1341.0 & 13822.8 & 1354.8 & 1714.6 \\
\hline Recovered & 15365.2 & a) 2374.8 & 0.0 & 11051.1 & a) 1083.0 & 793.6 \\
\hline Loss $^{\text {b) }}$ & 0.0 & 0.0 & 1341.0 & 691.1 & 67.8 & 771.6 \\
\hline Not used $^{\mathrm{c})}$ & 0.0 & 91.3 & 0.0 & 2080.6 & 204.0 & 149.4 \\
\hline External feed & 1442.5 & 0.0 & 0.0 & 3967.9 & - & - \\
\hline $\mathrm{HLW}^{\mathrm{d})}$ & 0.0 & 91.3 & 1341.0 & 2771.7 & 271.8 & 921.0 \\
\hline
\end{tabular}

a) Recover TRU as much as the required mass for charge fuel

b) Actinide loss rate: $0 \%$ for high-performing reprocessing, 5\% for melt-refining; FP loss rate: 100\% for high-performing reprocessing, $45 \%$ for melt-refining.

c) Not used mass $=$ discharge mass - recovered mass - loss mas

d) $\mathrm{HLW}=$ loss mass + not used mass

In the closed fuel cycle based on break-even core and high-performing reprocessing, only fission products are released from the fuel cycle and treated as high-level wastes, which is about $1.34 \mathrm{~kg} / \mathrm{year} / \mathrm{MWe}$. In a realistic scenario, additional HLW would be expected from material losses during fabrication and reprocessing, but those are small and were ignored here.

Compared to the high-performing reprocessing, the melt-refining produces less fission products as HLW because a fractional FP is recycled in the core. However, the closed fuel cycle based on melt-refining process produces additional HLW, which are not recovered (i.e., loss) and not-used actinides. Since the reactor was designed to be breeder to compensate the penalties from the fission products in the fresh fuel and actinides loss per process. Thus, the TRU amount at discharge is larger than that of the charge, and some amount of discharged fuel is not used for fresh fuel fabrication. In Table 4.2.2, only $80 \%$ of actinides are needed for next cycle, and the remaining $20 \%$ was not used and considered as HLW. Table 4.2.2 indicates that the meltrefining process produces about a factor of 2.7 larger HWL compared to high-performing reprocessing technologies in a closed fuel cycle. 


\section{Conclusions}

Three activities have been performed in FY 2019 to support the Advanced Fuel Cycle Campaign, which include application of annular metallic fuel concept to ultra-high burnup sodium-cooled reactor (SFR), modeling of the annular fuels during a transient condition, and evaluation of fuel cycle performance for a simple reprocessing technology, and this report documents the results on three activities.

The motivation of the first activity is to assess annular fuel behavior in a long-life SFR because the annular fuel is under development by the Advanced Fuel Campaign as a high burnup fuel. For this purpose, the annular fuel behavior in a $3000 \mathrm{MWt}$ Sustainable Sodium-cooled Fast Reactor (SSFR) was simulated by BISON fuel performance code. The SSFR is a once-through long-life core based on 34-batch fuel management scheme with 1.5-year cycle length. Thus, a fuel resides in a core for 51 years and the discharged burnup is about $30 \%$.

Annular metallic fuel has potential to accommodate ultra-high burnup fuel without major fuelcladding mechanical interaction (FCMI). This feature is achieved by using a low smeared density (SD 55\%). In the SSFR design, however, a 75\% smeared density and a thick fuel pin were preferred to maintain criticality for 51 years. Due to the high SD and thick fuel pin, the annular fuel configuration was predicted to suffer premature cladding failure at relatively low burnup. The current fuel creep model predicts a prominent creep strain due to gravity over the halfcentury irradiation, which may significantly affect the evolution of CDF. Thus, in order to use the annular fuel in an ultra-high burnup core such as SSFR, a low SD and thin annular fuel is strongly recommended

The motivation of the second activity is to understand molten fuel behavior during a severe transient condition. Modeling of the annular fuel pins during normal operation and the transients including the in-pin molten fuel motion prior to clad failure has been accomplished in this work. Exploratory simulations of in-pin fuel relocation for an Unprotected Loss of Flow and Transient Over Power (ULOF-TOP) accident in the Advanced Burner Test Reactor (ABTR) have been performed using the new metallic fuel models of SAS4A. During this simulations, molten fuel flow through the central fuel hole was observed when the central hole is not fully closed: i.e., the fuel melting occurs near the top of the fuel and the molten fuel flows downward, which adds a limited amount of positive reactivity to the reactor.

A feasibility of a sustainable closed fuel cycle utilizing melt-refining process was tested in this work. Major differences of the melt-refining compared to a high-performing reprocessing technology (such as electrochemical or PUREX) are a bad recovered material quality and higher actinide loss rate per process. In the melt-refining, noble fission products are recycled along with actinides and about $5-10 \%$ of actinides are not recovered per process. Thus, in order to compensate the reactivity penalties from parasitic absorption by fission products and actinides loss, a closed fuel cycle utilizing the melt-refining process is only possible in a breeder reactor, while a break-even core is sufficient to achieve the closed fuel cycle utilizing the highperforming reprocessing technology. Thus, compared to the high-performing reprocessing technology, the melt-refining process makes fast reactor design space narrow (i.e., only allowed in a high breeding ratio domain) to achieve a closed fuel cycle and produces more high-level waste. 


\section{References}

[Billone 2017]

[Blacker 1994]

[Chang 2006]

[Gaston 2009]

[Gilleland 2010]

[Hales 2016]

[Harp 2018]

[Hesson 1963]

[Hofman 1994]

[Hofman 2019]

[Karahan 2014]

[Kim 2009]

[Kim 2010]

[Matthews 2015]

[Medvedev 2013]
M.C. Billone, "X447/X447A HT9/U-10Zr Data and Correction for FuelCladding Chemical Interaction", Intra-laboratory Memo, Argonne National Laboratory, (2017).

T.D. Blacker, W.J. Bohnhoff, and T.L. Edwards. CUBIT mesh generation environment. Volume 1: Users manual. No. SAND--94-1100. Sandia National Labs., Albuquerque, NM (United States), 1994.

Y. I. Chang, P. J. Fink, C. Grandy, "Advanced Burner Test Reactor Preconceptual Design Report,” Report \#ANL-ABR-1, (2006).

D. Gaston, C. Newman, G. Hansen, and D. Lebrun-Grandie. "MOOSE: A parallel computational framework for coupled systems of nonlinear equations." Nuclear Engineering and Design 239, no. 10 (2009): 1768-1778.

J. Gilleland, "The history of TerraPower and travelling wave reactor development, 2006 to present", Proceedings of the INES-3, Tokyo, Japan 31 (2010).

J.D. Hales, R.L. Williamson, S.R. Novascone, G. Pastore, B.W. Spencer, D.S. Stafford, K.A. Gamble, D.M. Perez, and W. Liu. BISON Theory Manual The Equations Behind Nuclear Fuel Analysis. No. INL/EXT-13-29930. Idaho National Laboratory (INL), Idaho Falls, ID (United States), 2016.

J.M. Harp, H.J.M. Chichester, L. Capriotti. "Postirradiation examination results of several metallic fuel alloys and forms from low burnup AFC irradiations", Journal of Nuclear Materials, 509 (2018) 377-391.

J. C. Hesson, M. J. Feldman, and L. Buriis, "Description and Proposed Operation of the Fuel Cycle Facility for the Second Experimental Breeder Reactor (EBR-II),” ANL-6605, Argonne National Laboratory (1963).

G.L. Hofman and L.C. Walters. "Metallic Fast Reactor Fuels," Materials Science and Technology (1994).

G.L. Hofman, M.C. Billone, J.F. Koenig, J.M. Kramer, J.D.B. Lambert, L. Leibowitz, Y. Orechwa, D.R. Pedersen, D.L. Porter, H. Tsai, A.E. Wright, "Metallic Fuels Handbook." ANL-NSE-3 (2019) (Compiled in 1989)

A. Karahan, "Development of Advanced In-Pin Metallic Fuel Performance Models for SAS4A," Transactions of American Nuclear Society, Vol. 110, pp. 912-915, June, (2014).

T. K. Kim et al, "Core Design Studies for a 1000 MWth Advanced Burner Reactor," Annals of Nuclear Energy 36 (2009)

T. K. Kim and T.A. Taiwo, "Fuel Cycle Analysis of Once-Through Nuclear Systems", Argonne National Laboratory, ANL-FCRD-308, August 10, (2010).

C Matthews and C Unal. Unpublished work. 2015.

P.G. Medvedev, "Summary report on the fuel performance modeling of the 
AFC-2A, 2B irradiation experiments." INL/EXT-13-30006. (2013).

[Miao 2019] Y. Miao, N. Stauff, A. Oaks, A.M. Yacout, T.K. Kim, "Fuel performance evaluation of annular metallic fuels for an advanced fast reactor concept." Nuclear Engineering and Design, 352 (2019) 110157.

[Novascone 2018] S.R. Novascone, A. Casagranda, P.G. Medvedev, C. Matthews, A.X. Zabriskie, "Summary and Assessment of Metallic Fuel Capabilities in BISON." INL/EXT-18-51399 (2018)

[Ogata 1999] T. Ogata and T. Yokoo, "Devlopment and Validation of ALFUS: An Irradiation Behavior Analysis Code for Metallic Fast Reactor Fuels." Journal of Nuclear Technology, 128 (1999) 113-123.

[Ogata 2012] T. Ogata, Y.S. Kim, A.M. Yacout, "Metal Fuel Performance Modeling and Simulation." In: Konings R.J.M., (ed.) Comprehensive Nuclear Materials, volume 3, pp. 713-753 Amsterdam: Elsevier.

[Savage 2006] H. Savage. The heat content and specific heat of some metallic fast-reacdtor fuels containing plutonium. Journal of Nuclear Materials, 25 (2006) 583-594.

[Tak 2013] T. Tak, D. Lee, T.K. Kim. "Design of Ultralong-Cycle Fast Reactor Employing Breed-and-Burn Strategy", Nuclear Technology, 183 (2013) 427-435.

[Tentner 2017] A. M. Tentner, S.H. Kang, A. Karahan, "Advances in the Development of the SAS4A Code Metallic Fuel Models for the Analysis of PGSFR Postulated Severe Accidents", International Conference on Fast Reactors and Related Fuel Cycles, Yekaterinburg, Russian Federation, June, (2017)

[Williamson 2016] R.L. Williamson, K.A. Gamble, D.M. Perez, S.R. Novascone, G. Pastore, R.J. Gardner, J.D. Hales, W. Liu, A. Mai. "Validating the BISON fuel performance code to integral LWR experiments." Nuclear Engineering and Design, 301 (2016) 232-244.

[Yacout 2013] A.M. Yacout and M. C. Billone. "Current Status of the LIFE Fast Reactors Fuel Performance Codes." (2013).

[Yacout 2017] A.M. Yacout, A. Oaks, W. Mohamed, K. Mo, "FIPD: EBR-II Fuels Irradiation \& Physics Database.” ANL-ART-124. 